Aus der Abteilung Neurodegeneration und Neurorestaurationsforschung

(Prof. Dr. med. J. B. Schulz)

im Zentrum Neurologische Medizin

der Medizinischen Fakultät der Universität Göttingen

\title{
Einfluss des GDNF-Rezeptors Ret auf die Erholung des nigrostriatalen Systems im MPTP-Mausmodell der Parkinsonerkrankung
}

\section{INAUGURAL-DISSERTATION}

\author{
zur Erlangung des Doktorgrades \\ der Medizinischen Fakultät \\ der Georg-August-Universität zu Göttingen
}

vorgelegt von

Charlotte Pöppelmeyer

aus

Burgwedel 
Dekan: Prof. Dr. med. C. Frömmel

I. Berichterstatter: Prof. Dr. med. J. B. Schulz

II. Berichterstatter/in: Priv.-Doz. Dr. med. D. Liebetanz

III. Berichterstatter/in: Prof. Dr. med. J. Staiger

Tag der mündlichen Prüfung: 02.05.2011 


\section{Inhaltsverzeichnis}

\section{Abkürzungsverzeichnis}

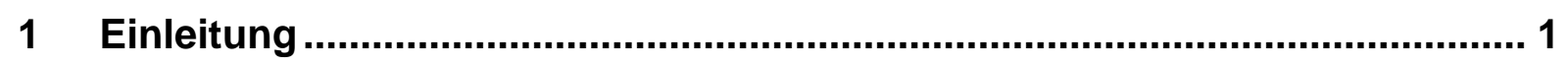

1.1 Das idiopathische Parkinsonsyndrom ......................................... 1

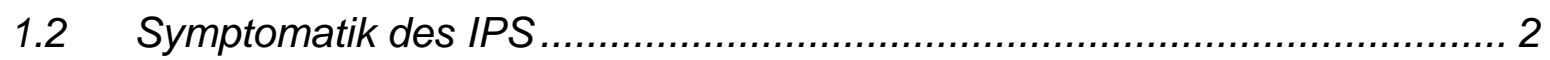

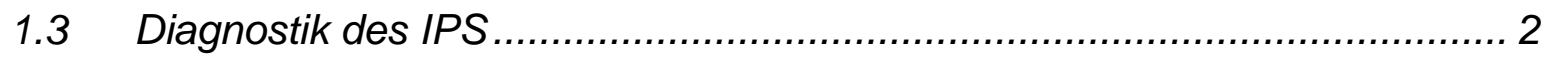

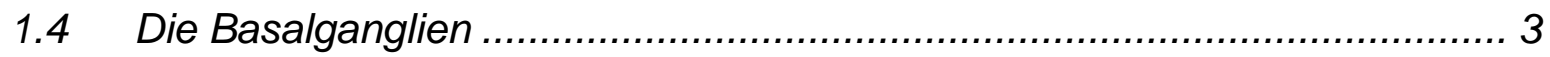

1.4.1 Neurochemische und funktionale Organisation der Basalganglien....... 3

1.4.2 Pathophysiologie der Basalganglien im Rahmen des IPS .................. 5

1.5 Neuropathologische und neurochemische Veränderungen beim IPS ......... 6

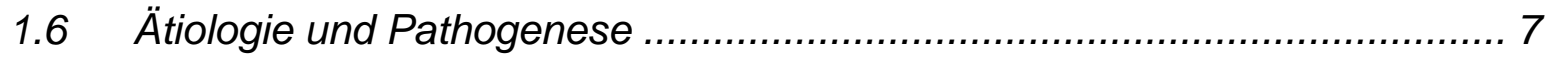

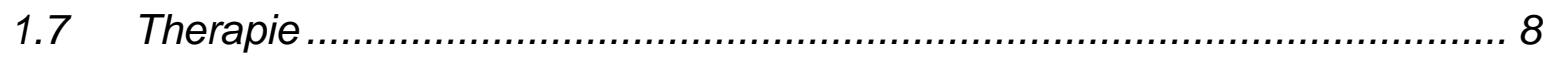

1.7.1 Physiologie einer dopaminergen nigrostriatalen Synapse ................... 9

1.7.2 Derzeitige Therapiestrategien.............................................. 9

1.7.3 Zukünftige Therapieoptionen .............................................. 11

1.8 Experimentelle Parkinsonmodelle ................................................ 11

1.8.1 MPTP: Ein Neurotoxin als experimentelles Modell des IPS ............... 11

1.8.2 MPTP: Selektive Wirkung auf dopaminerge Neurone ....................... 12

1.8.3 Die Wirkung von $\mathrm{MPP}^{+}$auf die Atmungskette und oxidativer Stress ... 13

1.8.4 Speziesunterschiede in der Empfindlichkeit gegenüber MPTP .......... 14

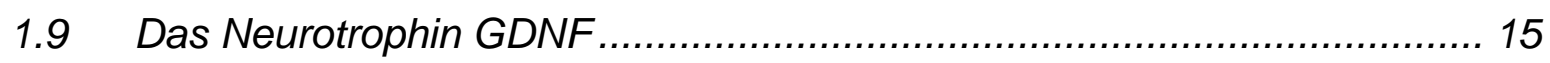

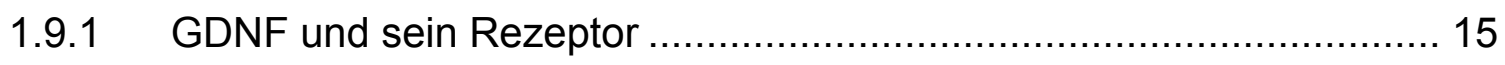

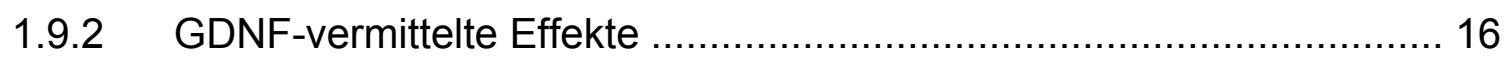

1.10 Fragestellung und Zielsetzung der Arbeit.................................... 19

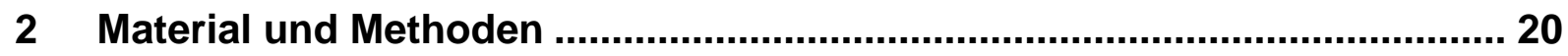

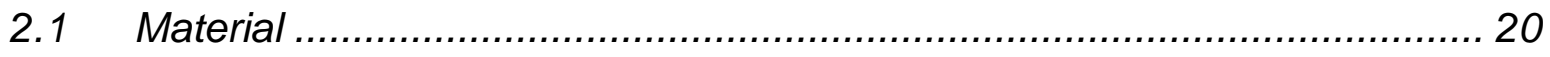

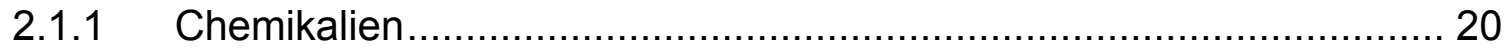

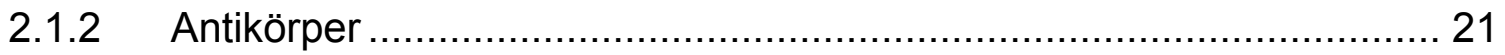

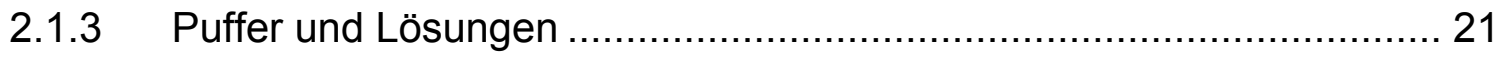




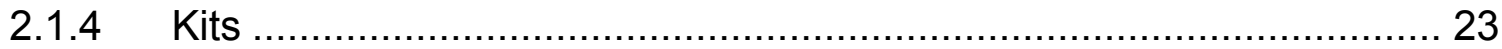

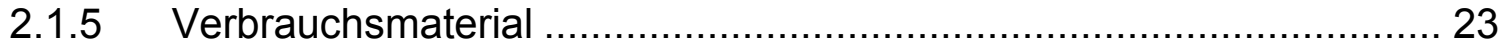

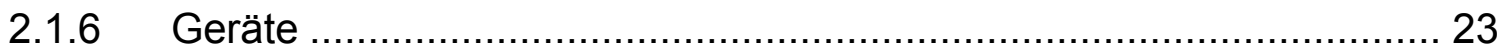

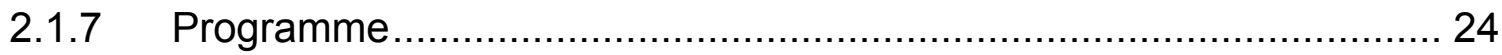

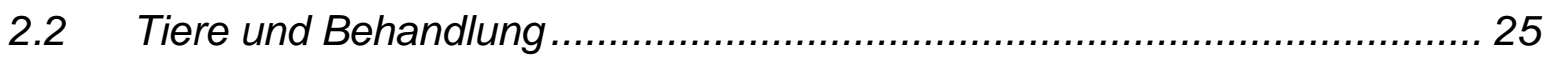

2.2.1 Tierzüchtung und Versuchsgruppen ............................................ 25

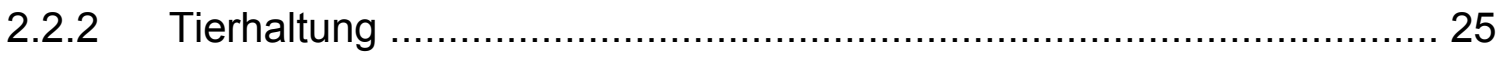

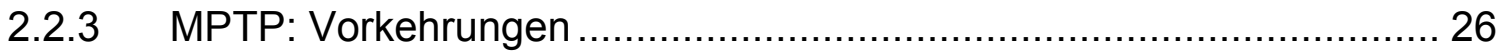

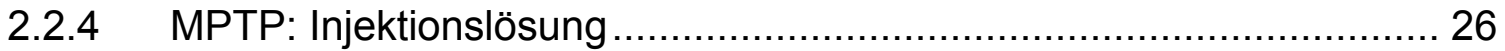

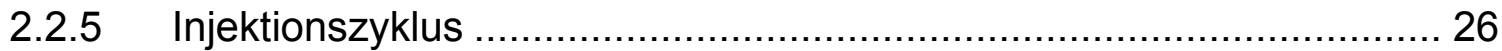

2.3 Gewebeaufarbeitung und Vorbereitung.............................................. 27

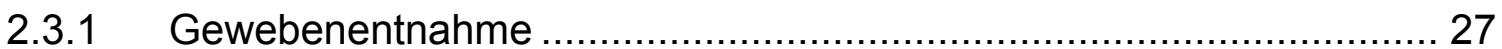

2.3.2 Gewebefixierung und Kryoprotektion............................................ 28

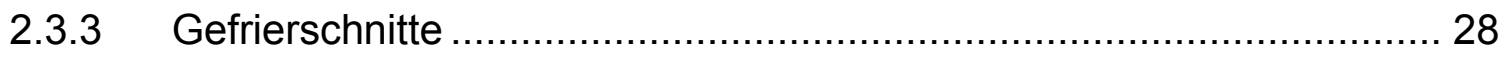

2.3.4 Gelatinisierte Objektträger ....................................................... 29

2.4 Immunohistochemie und Auswertung ................................................... 29

2.4.1 Immunohistochemische TH-Färbung zur Quantifizierung dopaminerger Neurone im Mittelhirn ............................................................... 29

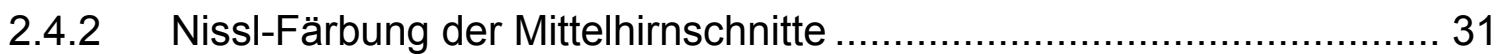

2.4.3 Stereologische Auswertung dopaminerger Neurone in der SNpc........ 33

2.4.4 Immunhistochemische TH-Färbung des Striatums zur Messung der

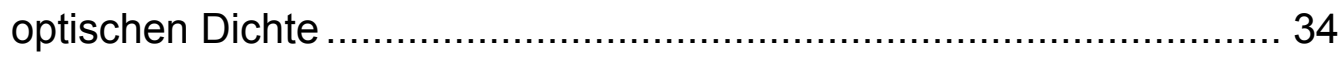

2.4.5 Entwässerung des rechten Striatums ........................................ 35

2.4.6 Bestimmung der optischen Dichte des Striatums ............................. 36

2.4.7 Fluoreszenzfärbung und Quantifizierung des Striatums für die Bestimmung der striatalen Faserdichte

2.4.8 Messung der nigrostriatalen Faserdichte nahe dem Ursprung rostral der SNpc.

2.5 Bestimmung der Katecholaminkonzentrationen im Striatum und Auswertung mittels HPLC 38

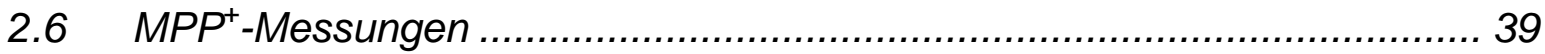

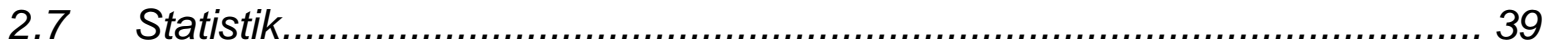




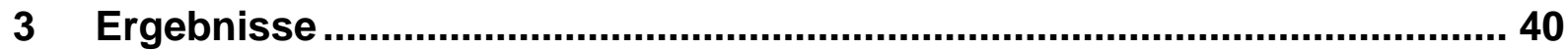

3.1 Die Effekte von MPTP auf die Zahl dopaminerger Neurone der SNpc...... 40

3.1.1 Die Effekte von MPTP auf die TH-positiven Zellen der SNpc............. 40

3.1.2 Die Effekte von MPTP auf die Zahl Nissl-positiver Zellen in der SNpc 43

3.2 Die Effekte von MPTP auf synaptische Marker im Striatum .................... 44

3.2.1 Die Effekte von MPTP auf die optische Dichte der striatalen Fasern .. 44

3.2.2 Quantifizierung fluoreszenzgefärbter striataler Fasern ..................... 46

3.2.3 Der Effekt von MPTP auf die striatalen Konzentrationen von Dopamin, DOPAC und HVA

3.2.4 Die Effekte von MPTP auf die nigrostriatalen Fasern rostral der SNpc 49

3.3 MPTP-Metabolismus der 3 Genotypen 51

4 Diskussion 52

4.1 DAT-Ret ${ }^{\mid x / x}$-Mäuse zeigen kein primäres Defizit bzw. keine Entwicklungsstörung 52

4.2 Keine Neurogenese nach MPTP-Gabe. 53

4.3 GDNF und der zugehörige Rezeptor Ret vermitteln keine Protektion gegen MPTP 54

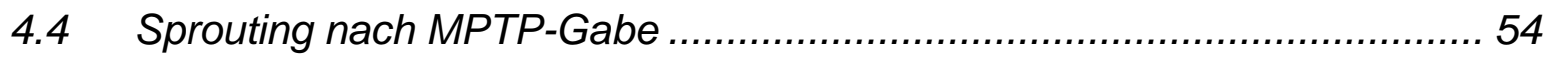

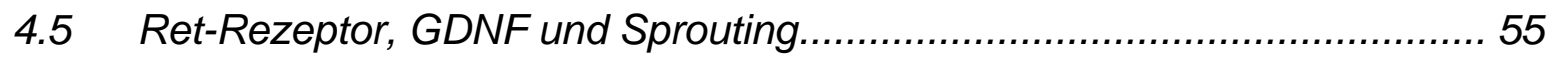

4.6 Die Wahl des Parkinsonmodells.................................................. 57

4.7 Tierexperimentelle Parkinsonmodelle - Parkinsonerkrankung................. 58

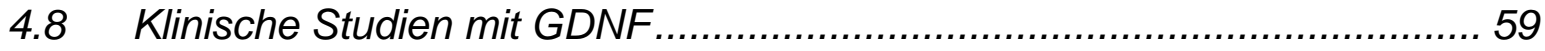

4.9 GDNF als zukünftiger Therapieansatz ......................................... 61

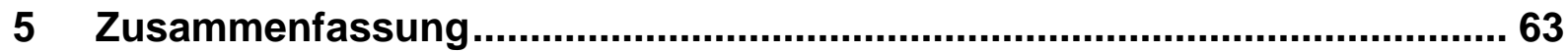

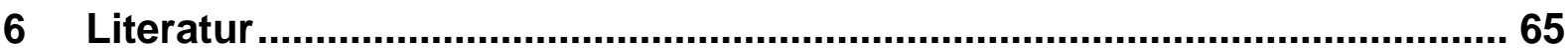

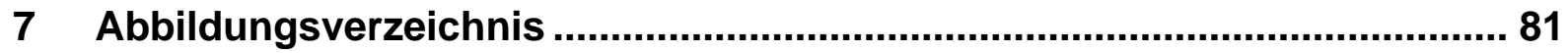

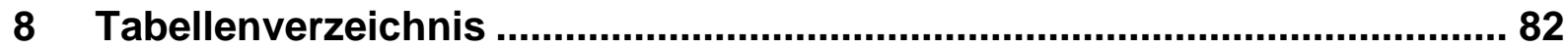




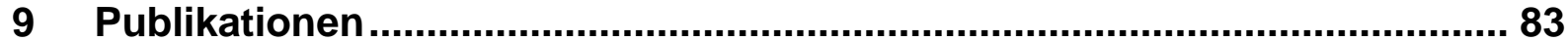




\section{Abkürzungsverzeichnis}

AADC

Abb.

ARTN

ATP

BDNF

COMT

d

DAB

DAT

DAT-mRNA

DOPAC

GABA

GDNF

GFLs

GFR

$\mathrm{GPe}$

GPi

GPI

$\mathrm{H}_{2} \mathrm{O}_{2}$

HPLC

HVA

i.p.

IPS

KG

L-DOPA

MAO B

$\min$

MPDP $^{+}$
Aromatische-L-Aminosäuren-Decarboxylase

Abbildung

Artemin

Adenosintriphosphat

Brain-derived neurotrophic factor

Catechol-O-Methyltransferase

day

3,3`'Diaminobenzidin

Dopamintransporter

Dopamine transporter-messenger ribonucleic acid

3,4-Dihydroxyphenylessigsäure

y-Aminobuttersäure

Glial cell line-derived neurotrophic factor

GDNF family ligands

GDNF family receptor

Globus pallidus externus

Globus pallidus internus

Glycosylphosphatidylinositol

Wasserstoffperoxid

High performance liquid chromatography

Homovanillinsäure

intraperitoneal

Idiopathisches Parkinsonsyndrom

Körpergewicht

L-3,4-Dihydroxyphenylalanin

Monoaminooxidase B

Minuten

1-Methyl-4-Phenyl-2,3-Dihydropyridinium 


\begin{tabular}{|c|c|}
\hline $\mathrm{MPP}^{+}$ & 1-Methyl-4-Phenylpyridinium \\
\hline MPPP & 1-Methyl-4-Phenyl-4-Propionoxy-Piperidin \\
\hline MPTP & 1-Methyl-4-Phenyl-1,2,3,6-Tetrahydropyridin \\
\hline MRT & Magnetresonanztomographie \\
\hline $\mathrm{NaCl}$ & Natriumchlorid \\
\hline $\mathrm{NADH}$ & Nikotinamidadenindinukleotid (reduziert) \\
\hline NGS & Normal Goat Serum \\
\hline NMDA & N-Methyl-D-Aspartat \\
\hline NRTN & Neurturin \\
\hline 6-OHDA & 6-Hydroxydopamin \\
\hline PB & Phosphatpuffer \\
\hline PBS & Phosphat gepufferte Salzlösung \\
\hline PET & Positronenemissionstomographie \\
\hline PFA & Paraformaldehyd \\
\hline PSPN & Persephin \\
\hline Ret & Rearranged during transfection \\
\hline ROS & reaktive Sauerstoffspezies \\
\hline Rpm & Runden pro Minute \\
\hline s & Sekunden \\
\hline SN & Substantia nigra \\
\hline SNpc & Substantia nigra pars compacta \\
\hline SNpr & Substantia nigra pars reticulata \\
\hline SPECT & Single Photon Emission Computed Tomography \\
\hline u.a. & unter anderem \\
\hline UPDRS & Unified Parkinson`s Disease Rating Scale \\
\hline Tab. & Tabelle \\
\hline TBS & Trisphosphatpuffer \\
\hline $\mathrm{TH}$ & Tyrosinhydroxylase \\
\hline VMAT & vesikulärer Monoamintransporter \\
\hline ZNS & Zentralnervensystem \\
\hline
\end{tabular}




\section{$1 \quad$ Einleitung}

\subsection{Das idiopathische Parkinsonsyndrom}

Das idiopathische Parkinsonsydrom (IPS) wurde erstmals im Jahre 1817 durch den aus London stammenden Arzt James Parkinson in seiner Monographie „An Essay on the shaking palsy“ („Eine Abhandlung über die Schüttellähmung“) dokumentiert.

Das IPS ist eine progrediente, hypokinetische neurodegenerative Erkrankung des extrapyramidalmotorischen Systems bzw. der Basalganglien und ist gekennzeichnet durch einen fortschreitenden selektiven Verlust von neuromelaninhaltigen dopaminergen Neuronen vor allem im ventrolateralen Teil der Substantia nigra pars compacta (SNpc) (Fearnley und Lees 1991).

Diese Erkrankung ist die zweithäufigste neurodegenerative Erkrankung nach der Alzheimer Krankheit (Cummings 1999) mit einem durchschnittlichen Erkrankungsalter zwischen 50 und 60 Jahren. In den USA liegt die Inzidenz des IPS bei 10,8 : 100.000 (Bower et al. 1999). Die Prävalenz des IPS liegt nach einer niederländischen Studie um 100-200 : 100.000 (de Rijk et al. 2000). Die Wahrscheinlichkeit zu erkranken steigt mit zunehmendem Alter. Mit $75 \%$ ist das IPS die am häufigsten auftretende Form unter den Parkinsonsyndromen.

Das IPS tritt meist sporadisch auf. In ca. 5-10\% der Fälle spielt ein erblicher Faktor bei der Entwicklung eines IPS eine wichtige Rolle. Als hierfür verantwortliche Gene wurden u.a. a-Synuklein (PARK1, PARK4), Parkin (PARK2), PINK1 (PARK6), DJ-1 (PARK7) und LRRK2 (PARK8) identifiziert (Gasser 2005; Thomas und Beal 2007).

Neben dem IPS werden unter dem Begriff Parkinsonsyndrom zwei weitere Formen zusammengefasst. Unter der sekundären, symptomatischen Form werden Krankheiten verstanden, die durch eine erkennbare Ursache bedingt sind wie z.B. vaskuläre Erkrankungen, Toxine oder Medikamente. Eine weitere Gruppe der Parkinsonsyndrome steht in Zusammenhang mit anderen neurodegenerativen Erkrankungen (atypische Parkinsonsyndrome) wie progressive supranukleäre Blickparese, Multisystematrophie, kortikobasale Degeneration und die Demenz vom Lewy-Körper-Typ. 


\subsection{Symptomatik des IPS}

Zu den charakteristischen klinischen Symptomen des IPS zählen eine verlangsamte Initiierung und Durchführung willkürlicher und unwillkürlicher Bewegungen (Bradykinese), die verminderte Bewegung (Hypokinese) bis hin zum Verlust von Bewegung (Akinese). Definitionsgemäß liegt ein IPS vor, wenn eine dieser Bewegungsstörungen zusammen mit einem der folgenden Symptome auftritt: Erhöhung des Muskeltonus (Rigor), Ruhetremor oder posturale Instabilität (Diener und Putzki 2008; Jackson-Lewis und Przedborski 2007; Sian et al. 1999). Dabei weist der Ruhetremor meist eine Frequenz von 4-6 $\mathrm{Hz}$ auf und bessert sich bei Bewegung (Deuschl et al. 2000). Als posturale Instabilität gelten Störungen, die nicht primär durch visuelle, vestibuläre, zerebelläre oder propriozeptive Störungen erklärbar sind (Diener und Putzki 2008).

Neben diesen charakteristischen klinischen Symptomen können weitere fakultative Symptome in unterschiedlicher Ausprägung auftreten. $\mathrm{Zu}$ diesen zählen u.a. autonome Dysregulationen mit Störungen von Blutdruck, Temperaturregulation und Harnblasenfunktion, psychische Verhaltensauffälligkeiten mit Depressionen (Brown und Marsden 1988; Tandberg et al. 1996) und kognitive Symptome im Rahmen einer Demenz (Hughes et al. 1993; Mayeux et al. 1992).

\subsection{Diagnostik des IPS}

Unterstützende Kriterien für die Diagnostik eines IPS und damit eine Abgrenzung zu den anderen Parkinsonsyndromen sind neben dem einseitigen Beginn, bzw. der persistierenden Asymmetrie im Krankheitsverlauf, auch das positive Ansprechen auf eine dopaminerge Stimulation (Ward und Gibb 1990). Diese Stimulation wird in der Regel mit L-DOPA (L-3,4-Dihydroxyphenylalanin) durchgeführt und fällt bei einer Über-30\%-Verbesserung der motorischen Untersuchung der Unified Parkinson`s Disease Rating Scale (UPDRS) positiv aus (Diener und Putzki 2008). Alternativ wird eine dopaminerge Stimulation durch die Gabe des Dopamin-D2-Rezeptoragonisten Apomorphin erreicht (Gasser et al. 1992).

Eine neurologische Untersuchung mit ausführlicher Anamnese und klinischer Untersuchung ist der Goldstandard zur Diagnose der Parkinsonerkrankung, da bis heute keine verlässlichen biologischen Marker existieren, um die Erkrankung zu 
Lebzeiten festzustellen (Lang und Lozano 1998b). Durch erweiterte apparative Diagnostik können eventuelle Anzeichen für ein sekundäres oder atypisches Parkinsonsyndrom festgestellt werden, wobei hierbei die bildgebenden Verfahren Magnetresonanztomographie (MRT), Single Photon Emission Computed Tomography (SPECT) oder Positronenemissionstomographie (PET) im Vordergrund stehen (Benamer et al. 2000; Brucke et al. 2000; Diener und Putzki 2008; Schrag et al. 2000; Schulz et al. 1994; Schulz et al. 1999; Schwarz et al. 1993; Varrone et al. 2001).

\subsection{Die Basalganglien}

\subsubsection{Neurochemische und funktionale Organisation der Basalganglien}

Beim IPS spielen die Regelkreise der Basalganglien eine wichtige Rolle (Alexander und Crutcher 1990). Diese sind für die Ausführung von motorischen, okulomotorischen, kognitiven und limbischen Funktionen verantwortlich. Reguliert werden diese Funktionen durch das Vermindern von ungewollten Handlungen und die automatische Abwicklung von gewünschten Bewegungen (Marsden 1990).

Als Eingangspunkt der Basalganglien wird das Striatum gesehen und erhält glutamaterge erregende Projektionen vom Kortex. Die dopaminergen Neurone der SNpc projizieren ebenfalls zum Striatum. Dopamin übt seine Wirkung im Striatum über postsynaptische D1- und D2-Rezeptoren aus (Kebabian und Calne 1979). Dabei bestehen unterschiedliche Effekte des Dopamins auf die Rezeptoren: Neurone mit D1-Rezeptoren werden erregt, Neurone mit D2-Rezeptoren wiederum inhibiert. D1-Rezeptoren dominieren auf Neuronen, die in die direkte Verschaltung der Basalganglien eingebunden sind, während D2-Rezeptoren in Verbindung mit dem indirekten Weg stehen (Abb. 1).

Der direkte Weg der Basalganglien führt vom Striatum über eine GABAerge ( $\gamma^{-}$ Aminobuttersäure) Hemmung unmittelbar zum Globus pallidus internus (GPi) und zur Substantia nigra pars reticulata (SNpr), den Ausgangskernen der Basalganglien.

Der indirekte Weg beinhaltet zwei GABAerge inhibitorische Verbindungen, die vom Striatum über den Globus pallidus externus (GPe) zum Nucleus subthalamicus führen. Dieser erregt wiederum mittels Glutamat den GPi und die SNpr (Abb. 1). 
Die gemeinsame Endstrecke besteht in einer GABAergen Hemmung des Thalamus durch die Ausgangskerne GPi und SNpr, die in einer glutamatergen Erregung des Kortex endet (Lang und Lozano 1998a) (Abb. 1).

Zusammenfassend betrachtet laufen beide Wege in der gemeinsamen Endstrecke zusammen, modulieren diese aber auf unterschiedliche Weise. Das direkte Projektionssystem verstärkt die Bahnung zweckmäßiger Bewegungsimpulse, während das indirekte Projektionssystem potentielle Störimpulse unterdrücken kann (Marsden und Obeso 1994) (Abb. 1).

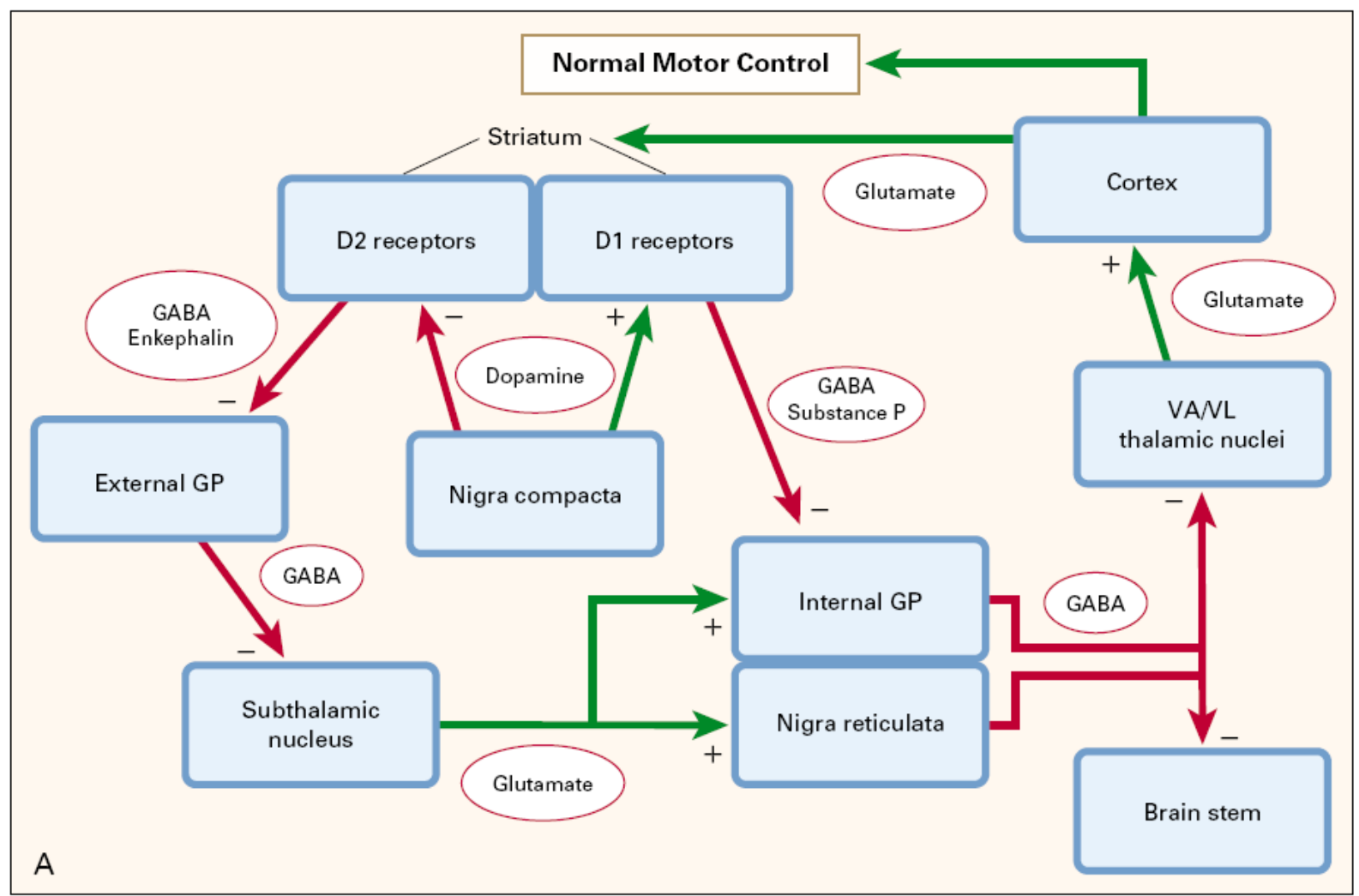

\section{Abb. 1 Schematische Darstellung der Basalganglien}

Funktion der Basalganglien von Personen mit normaler motorischer Funktion.

Umrandete Kästen zeigen die verschiedenen Gehirnregionen. Grüne Pfeile zeigen exzitatorische Wege und rote Pfeile zeigen inhibitorische Wege. Die umkreisten Substanzen sind Neurotransmitter. [entnommen aus Lang und Lozano (1998a),S.1132]. 


\subsubsection{Pathophysiologie der Basalganglien im Rahmen des IPS}

Der dopaminerge Mangel des IPS ist verbunden mit einer erhöhten Aktivität der inhibitorischen GABA im Striatum (indirekter Weg), des GPi und der SNpr (Abb. 2).

Die erhöhte inhibitorische Aktivität des GPi und der SNpr entsteht durch zwei Mechanismen. Zum einen durch eine reduzierte Inhibition der direkten GABAergen Verbindung vom Striatum und zum anderen durch eine erhöhte Erregung über den indirekten Weg mittels Glutamat (Abb. 2).

Die daraus resultierende verstärkte GABAerge Hemmung des Thalamus führt zur Reduktion erregender thalamo-kortikaler Projektionen mit einer Suppression des kortikalen motorischen Systems. Diese Suppression wird als Ursache für die Kardinalsymptome Akinese, Rigor und Tremor angenommen. Die vermehrte inhibitorische Projektion zum Hirnstamm wird als Ursache für die Veränderung des Gangbildes und der Haltung gesehen (Lang und Lozano 1998a) (Abb. 2).

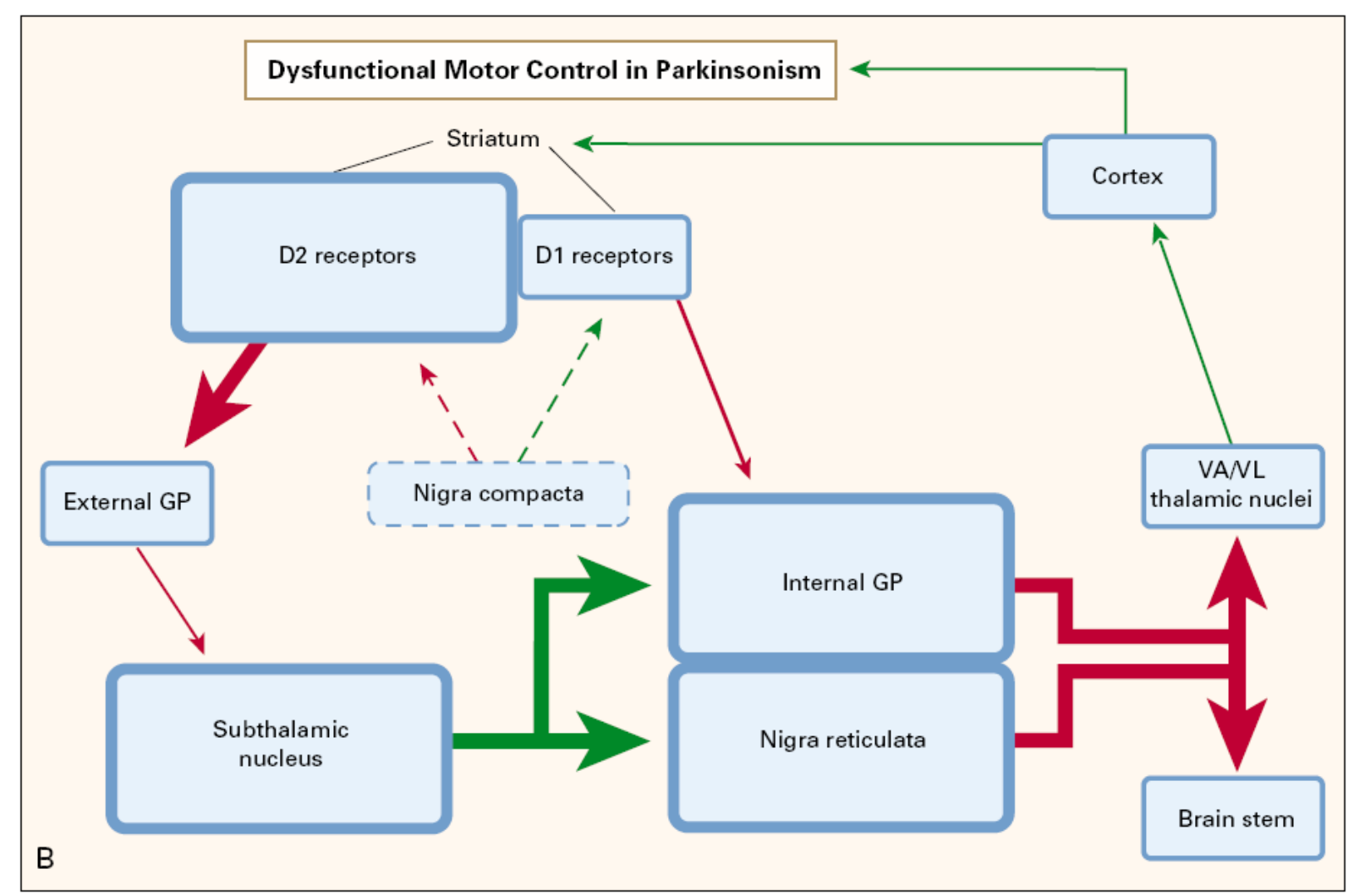

Abb. 2 Schematische Darstellung der Basalganglien bei einem Patienten mit IPS

Funktion der Basalganglien von Patienten mit IPS.

Umrandete Kästen zeigen die verschiedenen Gehirnregionen. Grüne Pfeile zeigen exzitatorische Wege und rote Pfeile zeigen inhibitorische Wege. Die Breite der Pfeile steht für das Ausmaß der funktionellen Veränderung in der Aktivität eines jeden Weges im Vergleich zur normalen Funktion 
(Abb.1). Die Größe und Umrandung eines jeden Kastens zeigt die Aktivität dieser Gehirnregion im Vergleich zur normalen Funktion (Abb.1). Gestrichelte Linien und Pfeile zeigen das gestörte nigrostriatale Dopaminsystem beim IPS. [entnommen aus Lang und Lozano (1998a), S.1132]

\subsection{Neuropathologische und neurochemische Veränderungen beim IPS}

Dopaminerger neuronaler Verlust vor allem im ventrolateralen Teil der SNpc (Fearnley und Lees 1991) in Verbindung mit der Präsenz von Lewy-Körpern in der Substantia nigra (SN) und anderen betroffenen Gehirnregionen (Gibb und Lees 1988; Spillantini et al. 1997) sind die charakteristischen neuropathologischen und biochemischen Merkmale des IPS.

Lewy-Körper sind sphärische zytoplasmatische Einschlüsse in verbliebenen dopaminergen Neuronen, die verschiedene Proteine wie $\alpha$-Synuklein, Parkin, Ubiquitin, Synphilin und Neurofilamente enthalten. Diese Strukturen sind jedoch nicht spezifisch für das IPS und kommen auch in der Demenz vom Lewy-Körper-Typ, der Alzheimer-Erkrankung und in gesunden älteren Menschen vor. Unter anderem können die charakteristischen Lewy-Körper neben der SNpc auch im Locus coeruleus, Nucleus basalis Meynert, dorsalen Vaguskern und im Kortex beobachtet werden (Gibb und Lees 1988). Die Ausbreitung dieser Lewy-Körper im Gehirn folgt einem bestimmten zeitlichen Muster mit frühem Beginn in der Medulla oblongata und im Bulbus olfactorius gefolgt von der SNpc (Braak et al. 2003).

In den striatalen Strukturen ist das IPS gekennzeichnet durch eine anhaltende Erniedrigung des Dopamingehalts (Bernheimer et al. 1973) und der Dopamine transporter-messenger ribonucleic acid (DAT-mRNA) (Joyce et al. 1997). Während sich die klinischen Symptome des IPS bei einem dopaminergen Neuronenverlust in der SNpc von etwa 50\% bemerkbar machen, zeigt sich der striatale Dopaminverlust klinisch erst ab einer Erniedrigung von 70-80\%. Dieser Dopaminverlust korreliert mit der Schwere der Erkrankung (Bernheimer et al. 1973). Der neuronale Verlust in der SNpc ist am ausgeprägtesten im ventrolateralen Teil, welcher zum Putamen des Striatums projiziert (Gibb und Lees 1991). Folglich hat das dorsolaterale Putamen einen weitaus höheren Dopaminverlust als der Nucleus caudatus (Bernheimer et al. 1973). 
Das Ausmaß des Verlustes von striatalen Terminalen erscheint ausgeprägter als das Ausmaß des dopaminergen Neuronenverlustes (Bernheimer et al. 1973). Diese Annahme läßt vermuten, dass die Nervenendigungen im Striatum als erstes degenerieren und ein neuronaler Untergang in der SNpc im Sinne eines „dying back“ daraus resultiert. Experimente mit 1-Methyl-4-Phenyl-1,2,3,6-Tetrahydropyridin (MPTP) von Herkenham et al. und $\mathrm{Wu}$ et al. unterstützen diese Annahme (Herkenham et al. 1991; Schulz und Falkenburger 2004; Wu et al. 2003).

Andere biologische Marker wie der Dopamin-Metabolit Homovanillinsäure (HVA) (Bernheimer und Hornykiewicz 1965), die Enzyme Tyrosinhydroxylase (TH) sowie LDOPA-Decarboxylase (Lloyd et al. 1975; Zhong et al. 1995) und die Dopamintransporter (DAT) (Pimoule et al. 1983; Wilson et al. 1996) sind ebenfalls erniedrigt.

Durch den dopaminergen Verlust sowohl im Striatum als auch in der SNpc werden zwei verschiedene Kompensationsmechanismen aktiviert. Die verbliebenen dopaminergen Neurone erhöhen ihren Dopamin-Metabolismus (Bernheimer und Hornykiewicz 1965) und die Anzahl der postsynaptischen D2-Rezeptoren im Striatum wird erhöht (Lee et al. 1978).

\section{6 Ätiologie und Pathogenese}

Die Ätiologie des IPS und des dafür verantwortlichen Untergangs nigrostriataler dopaminerger Neurone sind trotz großer wissenschaftlicher Bemühungen bis heute nicht ausreichend verstanden (Dauer und Przedborski 2003). Man nimmt an, dass ein Zusammenwirken von genetischer Prädisposition (Maher et al. 2002; Sveinbjornsdottir et al. 2000) und exogenen toxischen Umwelteinflüssen für die Entstehung des IPS verantwortlich sind. Hierbei sind sowohl Pestizide und Herbizide, als auch eine ländliche Umgebung mit einem erhöhten Risiko für ein IPS verbunden (Gorell et al. 1998; Tanner und Aston 2000). Die Entdeckung des IPS auslösenden Stoffes MPTP ist das führende Beispiel für ein exogen wirkendes Toxin, das alle klinischen und die meisten pathologischen Eigenschaften des IPS auslösen kann (Langston et al. 1983). Das Herbizid Paraquat ist strukturell ähnlich dem aktiven toxischen Metabolit 1-Methyl-4-Phenylpyridinium (MPP ${ }^{+}$) und das Insektizid Rotenon wirkt vergleichbar mit $\mathrm{MPP}^{+}$toxisch auf die mitochondriale Atmungskette. 
Zigaretten-, Alkohol- und Kaffeekonsum hingegen sind negativ mit dem Risiko für ein IPS assoziiert (Benedetti et al. 2000; Hernan et al. 2002; Tanner et al. 2002).

In 5-10\% der Fälle wird das IPS durch eine autosomal-dominante oder autosomalrezessive Mutation vererbt (Gasser 2005). Während Mutationen im Gen für $\alpha$ Synuklein (PARK1/PARK4) und LRRK2 (PARK8) zu dominanten spät auftretenden Parkinsonsyndromen führen (Singleton et al. 2003), verursachen Mutationen in den Genen Parkin (PARK2), PINK1 (PARK6) und DJ-1 (PARK7) rezessive früh auftretende Formen der Erkrankung (Thomas und Beal 2007).

Als weitere Möglichkeit für die Ursache für das IPS werden endogene Toxine gesehen. Eine Quelle dieser endogenen Toxine scheint der physiologische Metabolismus von Dopamin zu sein, der zu reaktiven Sauerstoffspezies (ROS) führt (Cohen 1984).

Als pathogenetische Faktoren werden sowohl die fehlerhafte Faltung und Aggregation von Proteinen als auch eine mitochondriale Dysfunktion mit oxidativem Stress angenommen (Dauer und Przedborski 2003). Auch werden die Pathomechanismen Exzitotoxizität, entzündliche Prozesse und Apoptose für die Entwicklung eines IPS verantwortlich gemacht (Hirsch et al. 1998; Schulz 2006; Teismann und Schulz 2004). Die Möglichkeit, dass mitochondriale Dysfunktion und oxidativer Stress ein Bestandteil für die Entwicklung des IPS darstellen, entwickelte sich nach der Entdeckung, dass MPTP durch Hemmung des Komplexes I die mitochondriale Atmungskette blockiert (Nicklas et al. 1987). Dies verleitet zu der Annahme, dass der neuronale Zelltod verstärkt mit der Entstehung freier Radikale und oxidativer Schädigung in Verbindung gebracht werden kann (Coyle und Puttfarcken 1993; Jenner und Olanow 1996).

\subsection{Therapie}

Es gibt bis jetzt keine medikamentöse Therapie, die den Verlust dopaminerger Neurone und die damit verbundene Progression der Erkrankung aufhalten könnte. Medikamente führen bisher nur initial zu einer symptomatischen Erleichterung. Das IPS ist eine sehr häufige Erkrankung und die Entwicklung von protektiven und regenerativen Therapiestrategien ist besonders in der heutigen Zeit durch das Altern der Bevölkerung ein wichtiges Ziel. 


\subsubsection{Physiologie einer dopaminergen nigrostriatalen Synapse}

Für die vielseitigen Therapieansätze sind die verschiedenen Mechanismen einer dopaminergen nigrostriatalen Synapse von großer Bedeutung.

Dopamin wird präsynaptisch aus der Aminosäure Phenylalanin hergestellt. Über die Stufe des Tyrosins wird es mittels TH zu L-DOPA und anschließend mit einer Decarboxylase für aromatische L-Aminosäuren (AADC) zu Dopamin umgewandelt. Über den vesikulären Monoamintransporter (VMAT-2) wird Dopamin in die Speichervesikel der dopaminergen Neurone aufgenommen (Riddle et al. 2005). Dopamin übt seine Wirkung über postsynaptisch gelegene D1- und D2-Rezeptoren aus (Kebabian und Calne 1979). Die Entfernung aus dem synaptischen Spalt erfolgt zum einen durch die Wiederaufnahme mittels des hochaffinen DAT in das präsynaptische Nervenende oder durch enzymatischen Abbau mittels Monoaminooxidase B (MAO B) oder Catechol-O-Methyltransferase (COMT) zu 3,4Dihydroxyphenylessigsäure (DOPAC) und HVA.

\subsubsection{Derzeitige Therapiestrategien}

Das Ziel der derzeitigen Therapien liegt in der Stimulation von Dopaminrezeptoren durch die Erhöhung der Dopaminspiegel oder das Einsetzen von Dopaminagonisten. Diese Strategien stellen jedoch keine kausalen Therapieoptionen dar.

Eine der weit verbreitetsten Therapieformen ist das Medikament L-DOPA. Als direkte Vorstufe des Dopamins muß L-DOPA stets in Kombination mit einem peripher wirksamen Decarboxylasehemmer (Benserazid oder Carpidopa) eingenommen werden, um eine periphere Decarboxylierung zu Dopamin und damit verbundene Nebenwirkungen zu vermeiden (Pahwa 2006). Die gewünschte Decarboxylierung zu Dopamin erfolgt somit erst nach der Aufnahme in das Zentralnervensystem (ZNS) durch die AADC und kann so dem entstandenen Dopaminmangel entgegenwirken (Playfer 1997).

Studien von Cotzias et al. und Fahn et al. belegen die Wirksamkeit von L-DOPA beim IPS (Cotzias et al. 1969; Fahn et al. 2004).

Anzumerken ist, dass sich die Wirkung von L-DOPA im Laufe einer Behandlung von etwa 5-7 Jahren abschwächt. Ein früher Einsatz dieses Medikaments resultiert in frühzeitigen motorischen Fluktuationen, Dyskinesien und L-DOPA induzierten 
Psychosen (Lang und Lozano 1998a), so dass IPS-Patienten bei Erkrankung vor dem 65.-70. Lebensjahr initial mit einem Dopaminagonisten behandelt werden sollten (Oertel et al. 2006; Rascol et al. 2000).

Bromocriptin zählt neben anderen Wirkstoffen zu den Dopaminagonisten. Vorteile bestehen zum einen in der direkten Wirkung des Dopaminagonisten, zum anderen in der Verminderung von Komplikationen (Rascol et al. 2000). Eine Kombination mit LDOPA erhöht dessen Wirkung und ermöglicht eine Reduzierung der Dosis von LDOPA (Calne et al.).

Eine weitere Gruppe der derzeitigen Medikamente umfasst die Inhibitoren des Dopaminmetabolismus. Hierzu zählen MAO-B-Hemmer und COMT-Inhibitoren.

Der MAO-B-Hemmer Selegilin blockiert irreversibel den oxidativen Abbau von Dopamin, so dass dieses vermehrt im synaptischen Spalt zur Verfügung steht (Gerlach et al. 1996). Durch die zusätzliche Gabe von Selegilin kann die L-DOPADosis bei $50 \%$ der Patienten um 10-15\% gesenkt werden, ohne dass es zu einer Verschlechterung der motorischen Symptome kommt (Heinonen und Rinne 1989).

Der COMT-Inhibitor Entacapon führt zu einer Wirkungsverlängerung von L-DOPA. Dadurch ist es möglich, eine Reduktion der L-DOPA-Dosis von ca. 20\% zu erreichen (Merello et al. 1994; Myllyla et al. 2001; Ruottinen und Rinne 1996). Hier scheint die Reduktion des inaktiven L-DOPA-Metaboliten 3-O-Methyldopa eine Rolle zu spielen, welcher mit L-DOPA um die Aufnahme in das ZNS konkurriert (Brannan et al. 1992). Weitere therapeutische Mittel sind der Glutamatrezeptorantagonist Amantadin und Anticholinergika wie Biperiden. Amantadin wirkt über die nicht-kompetitive Hemmung des NMDA-Rezeptors (N-Methyl-D-Aspartat) für Glutamat (Bormann 1989). Der Vorteil dieses Medikaments besteht in der Beeinflussung der motorischen Symptome Rigor, Tremor und besonders der Akinese (Sian et al. 1999). Anticholinergika (Biperiden) blockieren zentrale muskarinerge Rezeptoren, so dass der Tremor günstig beeinflusst wird (Koller 1986).

Tiefe-Hirnstimulation ist eine therapeutische Alternative für Patienten, die zwar auf LDOPA ansprechen, jedoch ausgeprägte und nicht anderweitig beherrschbare Wirkungsschwankungen zeigen (Limousin et al. 1998; Pahwa 2006). 


\subsubsection{Zukünftige Therapieoptionen}

Der neurotrophe Faktor GDNF (Glial cell line-derived neurotrophic factor) gilt als Wachstumsfaktor für dopaminerge Neurone des Mittelhirns (Lin et al. 1993) und steht im Mittelpunkt vieler wissenschaftlicher Projekte zur Entwicklung protektiver und neurorestaurativer Therapien für das IPS.

\subsection{Experimentelle Parkinsonmodelle}

Tiermodelle sind eine wichtige Methode, um sowohl pathologische Prozesse menschlicher Erkrankungen als auch therapeutische Strategien zu untersuchen.

In dieser Arbeit steht das MPTP-Mausmodell im Mittelpunkt, das mit der selektiven Zerstörung dopaminerger Zellen einen Beitrag zur Untersuchung des IPS leistet.

\subsubsection{MPTP: Ein Neurotoxin als experimentelles Modell des IPS}

1982 entwickelten Drogenabhängige nach der intravenösen Injektion eines selbst hergestellten Meperidin-Analogons 1-Methyl-4-Phenyl-4-Propionoxy-Piperidin (MPPP) ein schnell fortschreitendes Parkinsonsyndrom. Die Untersuchung dieses Substrats ergab eine Kontamination mit MPTP (Langston et al. 1983). Die systemische Exposition des Neurotoxins MPTP ruft bei Menschen, Affen und Nagern, biochemische und neuropathologische Defekte ähnlich denen des IPS hervor (Beal 2001; Heikkila et al. 1989; Kopin und Markey 1988; Langston et al. 1983; Langston und Irwin 1986). Diese Defekte beinhalten sowohl den selektiven fortschreitenden Verlust von TH-positiven Neuronen in der SNpc (Mori et al. 1988), als auch die Abnahme des striatalen Dopamingehalts und seiner Metaboliten (Heikkila et al. 1989; Kopin und Markey 1988) und führen in Primaten zu neuronalen Einschlüssen mit $\alpha$-Synuklein (Beal 2001). Die MPTP-Toxizität als Modell des IPS zeigt eine subakute bis akute Wirkung, während das IPS eine langsame progressive Erkrankung darstellt.

Das MPTP-Modell ist jedoch aufgrund der Imitierung der charakteristischen Defekte eines der weit verbreitetsten experimentellen Modelle für das IPS (Bloem et al. 1990; Przedborski und Vila 2003) und wird in dieser Arbeit im Mausmodell verwendet. 


\subsubsection{MPTP: Selektive Wirkung auf dopaminerge Neurone}

Seit der Entdeckung des MPTP-induzierten Parkinsonsyndroms im Jahre 1982 wurde der molekulare Wirkungsmechanismus dieses Stoffes mehrfach erforscht.

Nach systemischer Injektion von MPTP, welches ausgesprochen lipophil ist, überquert dieses die Blut-Hirn-Schranke innerhalb von Minuten (Markey et al. 1984) (Abb. 3).

Im Gehirn wird das Pro-Toxin MPTP durch das in glialen und serotoninergen Neuronen befindliche Enzym MAO-B zu 1-Methyl-4-Phenyl-2,3-Dihydroxypyridinium $\left(\mathrm{MPDP}^{+}\right)$oxidiert. Anzunehmen ist, dass $\mathrm{MPDP}^{+}$im Anschluss durch spontane Oxidation in $\mathrm{MPP}^{+}$umgewandelt wird (Chiba et al. 1985; Chiba et al. 1984). MPP ${ }^{+}$ist der aktive toxische Metabolit und wird durch einen unbekannten Mechanismus in den Extrazellularraum entlassen. Da es ein polares Molekül darstellt, hängt die Aufnahme in die Zelle von einem Plasma-Membran-Transporter ab. MPP ${ }^{+}$ist ein Substrat mit einer hohen Affinität zum DAT und gelangt auf diesem Wege in dopaminerge Neurone (Javitch et al. 1985; Mayer et al. 1986). Pharmakologische Inhibition oder genetische Deletion des DAT schützt vor MPTP-induzierten dopaminergen Schäden (Bezard et al. 1999; Javitch et al. 1985) (Abb. 3).

In dopaminergen Neuronen kann $\mathrm{MPP}^{+}$verschiedenen Wegen folgen. Zum einen können synaptosomale Vesikel $\mathrm{MPP}^{+}$mittels VMAT-2 aufnehmen. Dieser Mechanismus scheint vor MPTP-Toxizität zu schützen, da verschiedene Experimente mit einer erhöhten Dichte an VMAT-2 einen größeren Wiederstand gegen MPTP bewiesen (Liu et al. 1992) und heterozygote Mäuse mit einer VMAT-2Defizienz empfindlicher gegenüber MPTP-induzierter Neurodegeneration waren (Takahashi et al. 1997) (Abb. 4).

Zum anderen kann $\mathrm{MPP}^{+}$im Zytosol verbleiben und mit dortigen Enzymen reagieren (Klaidman et al. 1993) oder in Mitochondrien akkumulieren (Singer et al. 1987) (Abb. 4). 


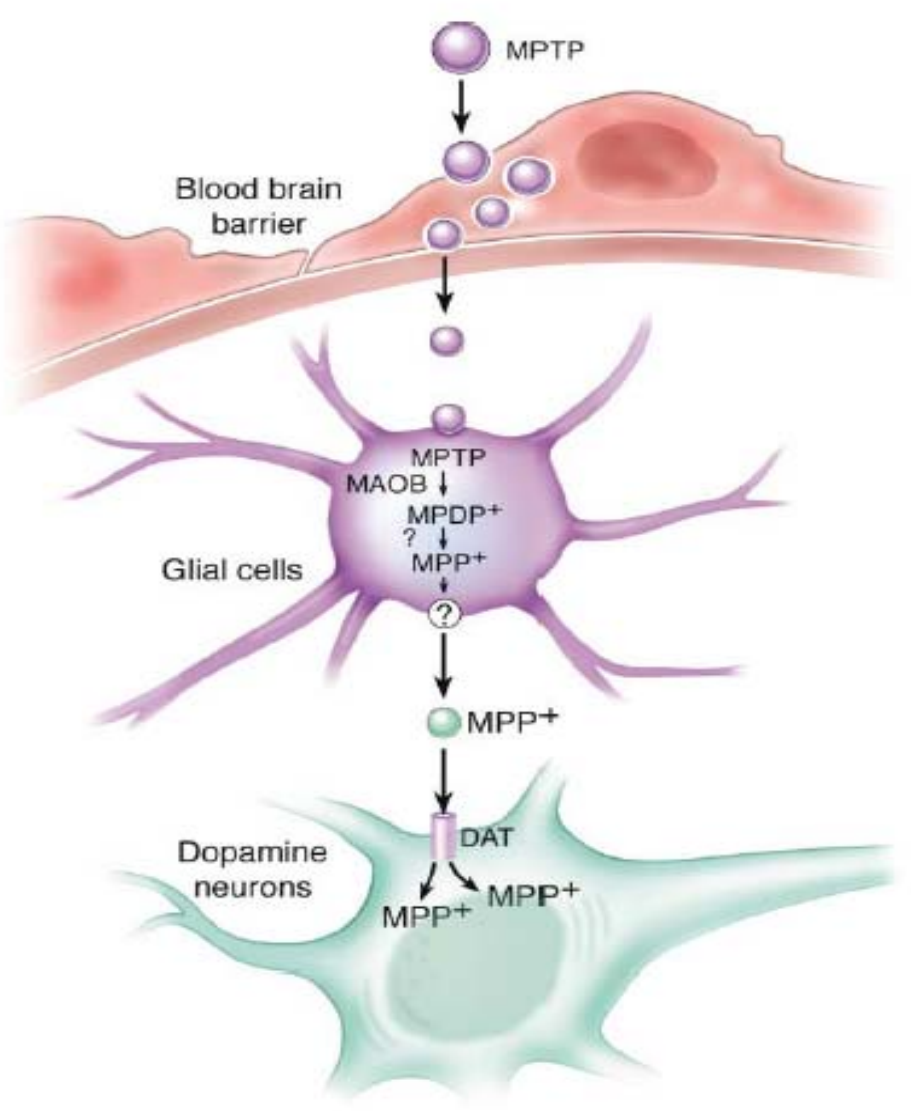

Abb. 3 Schematische Darstellung des MPTP-Metabolismus

Nach systemischer Applikation überquert MPTP die Blut-Hirn-Schranke. In der Gliazelle wird MPTP durch die MAO-B zu MPP ${ }^{+}$umgewandelt und von diesen Zellen in den Extrazellularraum entlassen. Dopaminerge Neurone nehmen MPP ${ }^{+}$über den DAT auf. [entnommen aus Dauer und Przedborski (2003), S.897]

\subsubsection{Die Wirkung von $\mathrm{MPP}^{+}$auf die Atmungskette und oxidativer Stress}

Der eigentliche toxische Metabolit $\mathrm{MPP}^{+}$wird nach Aufnahme in dopaminerge Neurone in Abhängigkeit vom elektrischen Membrangradienten in die Mitochondrien aufgenommen (Ramsay und Singer 1986) (Abb. 4). Dort inhibiert $\mathrm{MPP}^{+}$den Multienzymkomplex I (NADH-Dehydrogenase) der mitochondrialen Atmungskette (Nicklas et al. 1985) und resultiert in einer verminderten Synthese von Adenosintriphosphat (ATP), vor allem in den Regionen des Striatums und des ventralen Mittelhirns (Chan et al. 1991; Fabre et al. 1999). Diese Inhibition ist mit 
einer Erhöhung von ROS verbunden (Hasegawa et al. 1997; Hasegawa et al. 1990; Przedborski und Jackson-Lewis 1998). Adams et al. und Sriram et al. zeigten die Beteiligung von ROS bei der toxischen Wirkung von MPTP (Adams et al. 1993; Sriram et al. 1997). Diese freien Radikale und der oxidative Stress werden in Verbindung mit dem durch MPTP induzierten neuronalen Zelluntergang gebracht (Dawson et al. 2002).

Aufgrund der Auswirkungen des Neurotoxins MPTP sollten im Umgang mit diesem Stoff stets die Sicherheitsbedingungen eingehalten werden (Przedborski et al. 2001).

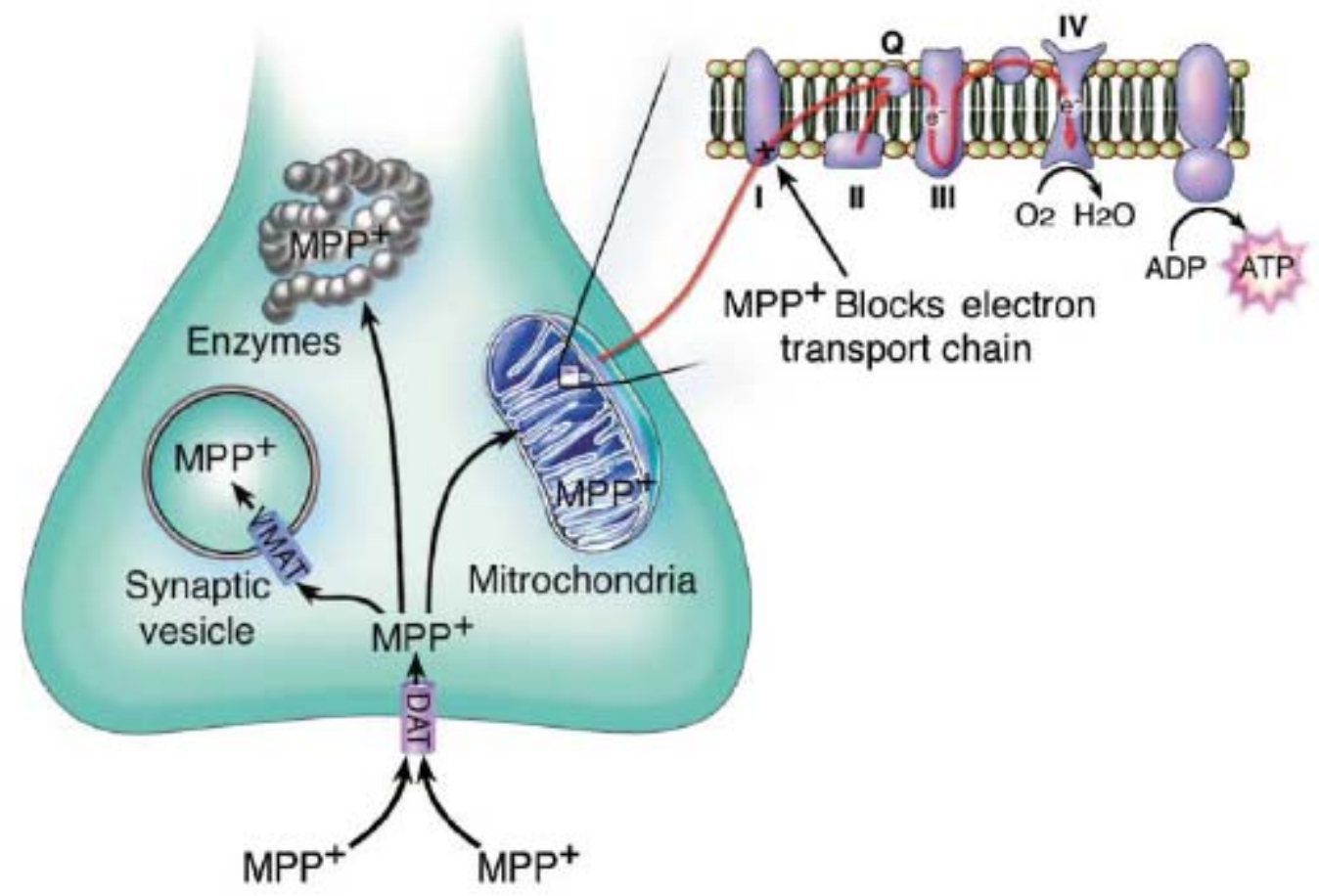

Abb. 4 Schematische Darstellung des intrazellulären Signalweges von MPP ${ }^{+}$

In dopaminergen Neuronen kann $\mathrm{MPP}^{+}$drei Wegen folgen: (1) Aufnahme in die Mitochondrien mit Inhibition des Multienzymkomplex I der Atmungskette. Diese Störung erhöht die Produktion von ROS und vermindert die Synthese von ATP; (2) Interaktion mit Enzymen des Zytosols; (3) Aufnahme in synaptische Vesikel über den VMAT, protektiv. [entnommen aus Dauer und Przedborski (2003), S.898]

\subsubsection{Speziesunterschiede in der Empfindlichkeit gegenüber MPTP}

Das MPTP-Modell wird meist mit Affen oder Mäusen durchgeführt, wobei Affen die neurologischen Defizite des IPS wie Bradykinese, Rigor und posturale Instabilität 
sehr gut widerspiegeln (Bloem et al. 1990; Burns et al. 1983). Ethische Bedenken und die begrenzte Verfügbarkeit limitieren jedoch den Einsatz.

Durch eine hohe Aktivität der endothelialen MAO-B sind Ratten unempfindlich gegen die systemische Gabe von MPTP. Durch frühzeitige Umwandlung zu MPP ${ }^{+}$in der Peripherie wird die Aufnahme in das Gehirn verhindert (Boyce et al. 1984; Heikkila et al. 1984).

Mäuse reagieren wesentlich sensitiver als Ratten auf die Toxizität von MPTP, wobei die in dieser Arbeit verwendeten C57BL/6-Mäuse die höchste Sensitivität und selektive Toxizität aufweisen und verläßlich einen Verlust dopaminerger Neurone nach MPTP-Applikation zeigen.

\subsection{Das Neurotrophin GDNF}

\subsubsection{GDNF und sein Rezeptor}

GDNF ist eines von vier Mitgliedern einer Familie von Proteinen, genannt „GDNF family ligands“ (GFLs). Zur Gruppe der GFLs gehören GDNF (Lin et al. 1993), Neurturin (NRTN) (Kotzbauer et al. 1996), Artemin (ARTN) (Baloh et al. 1998; Masure et al. 1998) und Persephin (PSPN) (Milbrandt et al. 1998), welche in das Überleben, die Proliferation und Differenzierung verschiedener Neuronenpopulationen involviert sind (Airaksinen und Saarma 2002).

Der GDNF-Rezeptor-Komplex besteht aus zwei Untereinheiten. Eine Komponente ist die 1996 identifizierte Signal-transduzierende Komponente Ret (Rearranged during transfection), die über eine Rezeptor-Tyrosinkinase vermittelt (Airaksinen et al. 1999; Durbec et al. 1996; Trupp et al. 1996). Für die Ligandenspezifität ist eine zweite Rezeptorkomponente verantwortlich, ein Mitglied der GFR-Familie (GDNF family receptor). Dieser Rezeptor ist ein Glykosylphosphatidylinositol (GPI)-verankerter KoRezeptor, wobei GFRa-1 präferentiell GDNF bindet (Jing et al. 1996; Treanor et al. 1996) (Abb. 5).

Der homodimerisierte GDNF-Ligand bindet zunächst an den GFRa-1-Ko-Rezeptor, so dass Ret dimerisiert und tyrosinphosphoryliert wird. Dies führt zu einer Triggerung verschiedener Signalwege (Airaksinen und Saarma 2002; Paratcha und Ledda 2008; Santoro et al. 2004; Sariola und Saarma 2003). Der GFRa-Ko-Rezeptor wird jedoch auch in unterschiedlichen Regionen des Nervensystems exprimiert, ohne dass Ret 
dort nachgewiesen wurde. Dies lässt vermuten, dass auch ein Ret-unabhängiger Signalweg existiert (Airaksinen und Saarma 2002; Sariola und Saarma 2003; Trupp et al. 1999).

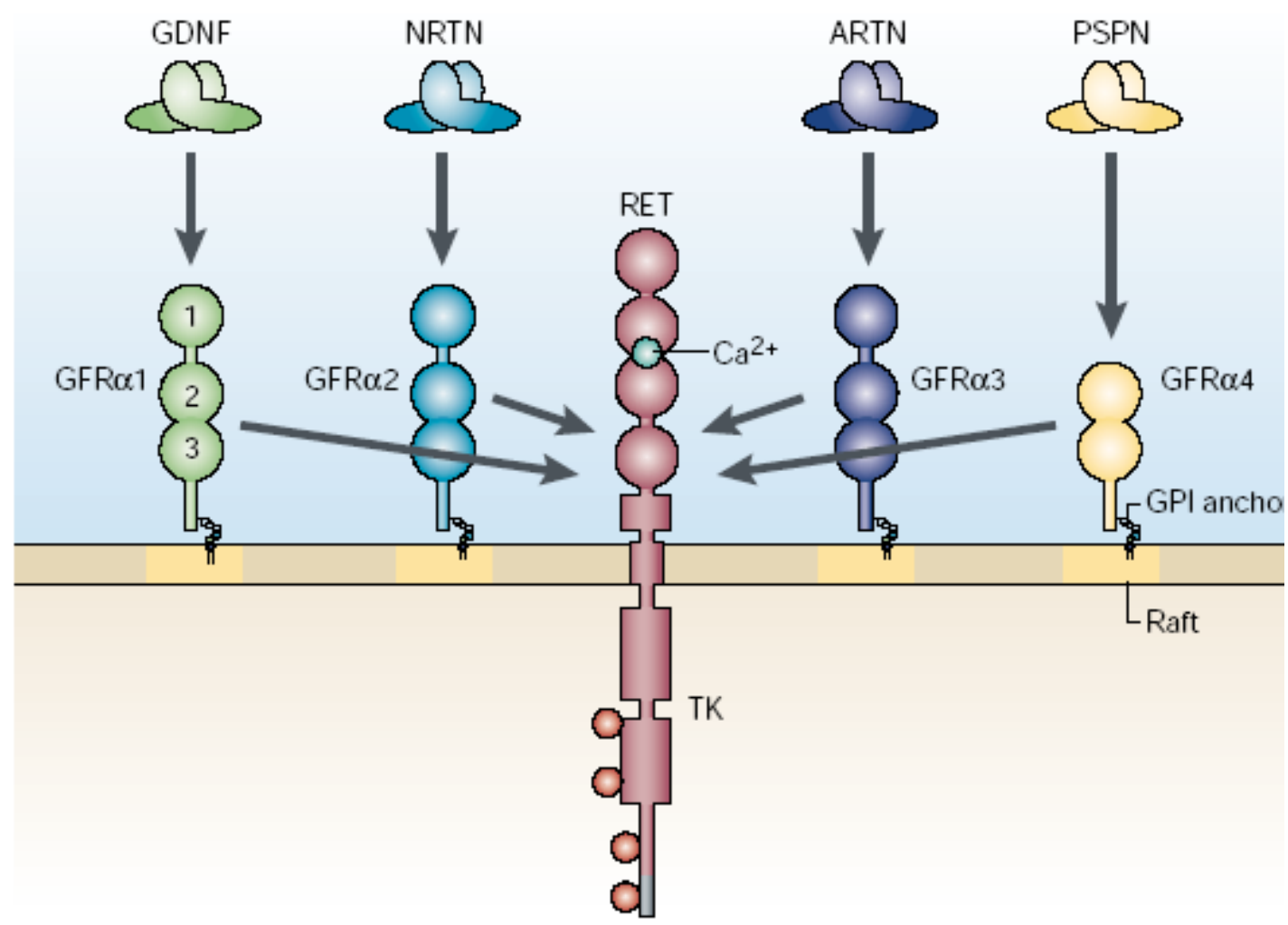

\section{Abb. 5 GFL`s und Rezeptorinteraktionen}

GFLs aktivieren die Ret-Tyrosinkinase über die Bindung an ihren GFR. Pfeile zeigen die bevorzugte Liganden-Rezeptor-Interaktion. [entnommen aus Airaksinen und Saarma (2002), S.384]

\subsubsection{GDNF-vermittelte Effekte}

GDNF wurde im Jahre 1993 erstmals als Wachstumsfaktor für die Differenzierung und das Überleben dopaminerger Mittelhirnneurone identifiziert (Lin et al. 1993). Durch diese Eigenschaft, sowohl in vitro (Krieglstein 2004) als auch in Tiermodellen, wurde GDNF zum Mittelpunkt vieler Untersuchungen im Rahmen einer potentiellen Parkinsontherapie.

Spätere Projekte zeigten einen fördernenden Effekt von GDNF auf das Überleben motorischer Neurone (Henderson et al. 1994) und eine Verminderung der Degeneration von noradrenergen Neuronen im Locus coeruleus nach einer 
Behandlung mit 6-Hydroxydopamin (6-OHDA) (Arenas et al. 1995). Auch wurde GDNF eine unterstützende Rolle sensorischer und autonomer Neurone zugeschrieben (Trupp et al. 1995).

Wiederholte GDNF-Injektionen in die SN von Ratten zeigten einen protektiven Effekt gegenüber Axotomie induzierter Degeneration (Beck et al. 1995). Die Injektion eines GDNF-kodierten Adenovirus im Bereich des Striatums und auch der SN von Ratten bei Behandlung mit 6-OHDA schützte dopaminerge Neurone vor fortschreitender Degeneration und stellte dopaminerge und motorische Funktionen wieder her (Bilang-Bleuel et al. 1997; Choi-Lundberg et al. 1997). In verschiedenen MPTPModellen zeigten zum einen eine intrazerebrale GDNF-Verabreichung besonders im Striatum (Tomac et al. 1995) und zum anderen die Freisetzung von GDNF nach Injektion eines lentiviralen Vektors (Kordower et al. 2000) protektive und regenerative Effekte gegenüber nigrostriataler Degeneration.

Kontroverse Ergebnisse erzielten hingegen andere Projekte mit einem MPTPMausmodell. Eberhardt et al. zeigten trotz ausreichender Expression von GDNF nach adenoviraler Injektion des Striatums keinen Schutz gegen den Verlust THpositiver Neurone in der SN. Hier konnten lediglich protektive Effekte für die Konzentrationen von Dopamin und seinen Metaboliten im Striatum erzielt werden (Eberhardt et al. 2000). Dieses wurde nicht als protektiver, sondern als restaurativer Effekt gewertet. Dietz et al. entwickelten eine GDNF-Form, die die Blut-HirnSchranke passieren kann. Damit zeigten sie, dass GDNF möglicherweise die nigrostriatalen Projektionen der verbliebenen Neurone nach MPTP-Injektion schützt. Jedoch wurde die Anzahl der überlebten Neurone durch GDNF nicht erhöht und somit keine Neuroprotektion erreicht (Dietz et al. 2006).

Durch verschiedene Untersuchungen zeichnete sich ab, dass der Ort für die Verabreichung von GDNF von großer Bedeutung ist. Hier überwiegt die Meinung, dass die Verabreichung in das Striatum effektiver gegen toxischen Schaden schützt als die Verabreichung in das Mittelhirn (Connor et al. 1999; Kirik et al. 2004; Kirik et al. 2000a; Kirik et al. 2000b). Aufgrund der oben beschriebenen Fähigkeiten von GDNF, dopaminerge Neurone in ihrer Funktion zu erhalten, wurde die Applikation dieses neurotrophen Faktors auch in klinischen Versuchen erprobt. Die intrazerebroventrikuläre Injektion von GDNF erbrachte weder eine signifikante Regeneration von nigrostriatalen Neuronen noch eine Verbesserung der Symptome. 
Hier scheint die intraparenchymale Diffusion in relevante Gehirnareale der limitierende Faktor zu sein (Kordower et al. 1999).

Eine direkte unilaterale oder bilaterale Infusion von GDNF in das Putamen erzielte jeweils eine signifikante Verbesserung der motorischen Ergebnisse gemessen mit der UPDRS, ohne dabei schwerwiegende klinische Nebenwirkungen zu verursachen (Gill et al. 2003; Slevin et al. 2005). Diese Beobachtungen ließen sich in einer doppelt verblindeten Placebo-kontrollierten Studie mit 34 IPS-Patienten nicht reproduzieren (Lang et al. 2006). Eine mögliche Ursache für die verschiedenen Ergebnisse der drei zuletzt beschriebenen Studien scheinen methodische Unterschiede zu sein (Sherer et al. 2006).

Bis vor kurzem konnte weder das Gen für GDNF noch für seine Rezeptorkomponenten Ret und GFRa-1 erfolgreich eliminiert werden, ohne dass die gezüchteten Mäuse kurz nach der Geburt verstarben (Baloh et al. 2000). Defizite des enterischen Nervensystems und der Nierenentwicklung limitierten dieses Vorhaben (Cacalano et al. 1998; Enomoto et al. 1998; Moore et al. 1996; Pichel et al. 1996; Sanchez et al. 1996; Schuchardt et al. 1994).

In zwei kürzlich erschienen Studien wurde speziell das Gen, welches für den RetRezeptor in Mäusen kodiert, mittels Cre-Rekombinase unter Kontrolle des DATPromotors, eliminiert (Jain et al. 2006; Kramer et al. 2007). Die Mäuse zeigten eine normale Entwicklung des nigrostriatalen Systems und führten damit zu dem Ergebnis, dass Ret für die Aufrechterhaltung dopaminerger Neurone in jungen erwachsenen Mäusen bis zu einem Alter von 12 Monaten nicht erforderlich ist (Jain et al. 2006). Hingegen wurde belegt, dass die Eliminierung von Ret ab einem Alter von 12 Monaten zu einem Verlust von dopaminergen Neuronen der SNpc und ihren Afferenzen führt, so dass Ret für die langfristige Aufrechterhaltung des nigrostriatalen Systems verantwortlich gemacht wird (Kramer et al. 2007). 


\subsection{Fragestellung und Zielsetzung der Arbeit}

Dem Faktor GDNF wurden verschiedene und zum Teil widersprüchliche Aufgaben und Effekte zugeschrieben. Diese münden in der Diskussion, ob GDNF sowohl neuroprotektive als auch neurorestaurative Eigenschaften besitzt. Die verschiedenen GDNF-Untersuchungen erwecken die Hoffnung, nicht wie bisher mit einer Therapie nur die Symptome der Erkrankung zu mildern, sondern zudem die fortschreitende Degeneration dopaminerger Neurone zu mindern oder auch die Regeneration der verantwortlichen Strukturen zu unterstützen.

Diese Arbeit untersucht den Einfluss von GDNF auf die Erholung des nigrostriatalen Systems im MPTP-Mausmodell. Für dieses Mausmodell wurden C57BL/6-Mäuse mit einer selektiven Eliminierung des Ret-Rezeptors in dopaminergen Neuronen verwendet. Insbesondere sollte die Fragestellung verfolgt werden, ob die selektive Eliminierung des Ret-Rezeptors in dopaminergen Neuronen die regenerative Kapazität des nigrostriatalen Systems beeinflusst.

Für diese Arbeit wurden Ret-defiziente Tiere (DAT-Ret ${ }^{\mid x / x}$ ) und als Kontrolle die Genotypen Ret ${ }^{\mathrm{l}}$ und DAT-Cre fünf Tage mit MPTP bzw. Natriumchlorid ( $\left.\mathrm{NaCl}\right)$ injiziert. Um die langfristigen Auswirkungen dieser Behandlung zu untersuchen, wurden die Gehirne nach 90 Tagen histologisch aufgearbeitet und ausgewertet.

Die Arbeit wurde in Zusammenarbeit mit Sebastian Kowsky (Medizinischer Doktorand, Abteilung für Neurodegeneration und Neurorestaurationsforschung Göttingen, Leitung Prof. Dr. J. B. Schulz) und Dr. Edgar R. Kramer (Abteilung für molekulare Neurobiologie, Max-Planck Institut für Neurobiologie, Martinsried, Deutschland) durchgeführt. Sebastian Kowsky untersuchte den Einfluss des GDNFRezeptors Ret auf die akute MPTP-Toxizität in der Maus nach 14 Tagen (Kowsky 2010; Kowsky et al. 2007). Dr. Edgar R. Kramer stellte die Mäuse mit dem spezifischen Knock-out für Ret zur Verfügung (Kramer et al. 2007).

Da die hier beschriebenen Experimente parallel mit denen von Sebastian Kowsky durchgeführt wurden, können zur Interpretation die Befunde nach 90 Tagen mit denen nach 14 Tagen verglichen werden. Eine Zunahme dopaminerger Marker zwischen Tag 14 und 90 wird hierbei als Regeneration interpretiert. 


\section{Material und Methoden}

\subsection{Material}

\subsubsection{Chemikalien}

1-Methyl-4-Phenyl-1,2,3,6-

Tetrahydropyridin (MPTP)

2-Methylbutan

3,3`-Diaminobenzidin (DAB)

Ammoniumchlorid

Cedernholzöl

Chloroform

Chrom-III-Kaliumsulfat

Diethylether

Dinatriumhydrogenphosphat

Eisessigsäure

Ethanol

Formaldehyd

Gelatine

Glucose

Glucoseoxidase

Methanol

Natriumacetat

Natriumazid
Sigma-Aldrich, München

Roth, Karlsruhe

Sigma-Aldrich, München

Merck, Darmstadt

Sigma-Aldrich, München

Sigma-Aldrich, München

Sigma-Aldrich, München

Sigma-Aldrich, München

Roth, Karlsruhe

Sigma-Aldrich, München

GeReSo GmbH, Dassel-Lauenberg

Sigma-Aldrich, München

Merck, Darmstadt

Roth, Karlsruhe

Sigma-Aldrich, München

Roth, Karlsruhe

Roth, Karlsruhe

Sigma-Aldrich, München 
Natriumchlorid

Natriumchlorid-Lösung, isoton $0,9 \%$

Natriumdihydrogenphosphat

Natronlauge

n-Butanol

Paraformaldehyd (PFA)

Perchlorsäure 70\%

Sucrose

Thionin-Acetat

Tris

Wasserstoffperoxid $\left(\mathrm{H}_{2} \mathrm{O}_{2}\right) 30 \%$

Xylol
Roth, Karlsruhe

Braun, Melsungen

Merck, Darmstadt

Roth, Karlsruhe

Merck, Darmstadt

Roth, Karlsruhe

Sigma-Aldrich, München

Roth, Karlsruhe

Sigma-Aldrich, München

Roth, Karlsruhe

Merck, Darmstadt

Roth, Karlsruhe

\subsubsection{Antikörper}

Biotinylated Anti-Rabbit IgG, 1:200

Vector Laboratories

Normal Goat Serum (NGS)

PAA Laboratories

Rabbit Anti-Tyrosine Hydroxylase

Chemicon international

Antibody, polyklonal 1:1000

\subsubsection{Puffer und Lösungen}

$0,1 \mathrm{M}$ PBS

10,9 g/l Dinatriumhydrogenphosphat $\left(\mathrm{Na}_{2} \mathrm{HPO}_{4}\right)$

$3,14 \mathrm{~g} / \mathrm{l}$ Natriumdihydrogenphosphat $\left(\mathrm{NaH}_{2} \mathrm{PO}_{4}\right)$

$9 \mathrm{~g}$ Natriumchlorid $(\mathrm{NaCl})$ 


\begin{tabular}{|c|c|}
\hline & 0,1\% Natriumazid \\
\hline & $\mathrm{pH} 7,2-7,4$ \\
\hline $0,1 \mathrm{M}$ TBS & $12,11 \mathrm{~g} / \mathrm{l}$ Tris \\
\hline & $9 \mathrm{~g} / \mathrm{l} \mathrm{NaCl}$ \\
\hline & $\mathrm{pH} 7,2-7,4$ \\
\hline $0,2 \mathrm{M}$ PB & $21,8 \mathrm{~g} / \mathrm{l}$ Dinatriumhydrogenphosphat $\left(\mathrm{Na}_{2} \mathrm{HPO}_{4}\right)$ \\
\hline & $6,28 \mathrm{~g} / \mathrm{l}$ Natriumdihydrogenphosphat $\left(\mathrm{NaH}_{2} \mathrm{PO}_{4}\right)$ \\
\hline & $\mathrm{pH} 7,2-7,4$ \\
\hline Ammoniumchlorid & $40 \mathrm{mg} / 200 \mu \mathrm{l}$ Tris GN \\
\hline Chloroform-Lösung & $480 \mathrm{ml}$ Chloroform \\
\hline & $60 \mathrm{ml} \mathrm{95 \%} \mathrm{Ethanol}$ \\
\hline & $60 \mathrm{ml}$ Diethylether \\
\hline & Reihenfolge einhalten \\
\hline Färbelösung & $455 \mathrm{ml}$ Standardfärbelösung, $45 \mathrm{ml}$ Pufferlösung \\
\hline & Pufferlösung: \\
\hline & $7 \mathrm{~g}$ Natriumacetat \\
\hline & $2 \mathrm{ml}$ Eisessigsäure \\
\hline & $1100 \mathrm{ml}$ destilliertes Wasser \\
\hline & Standardfärbelösung: \\
\hline & $1 \mathrm{~g}$ Thionin \\
\hline & $100 \mathrm{ml}$ kochendes destilliertes Wasser \\
\hline Formalin-Essig-Lösung: & $1 \mathrm{ml}$ Eisessigsäure \\
\hline & $1 \mathrm{ml} 39 \%$ Formaldehyd \\
\hline & $100 \mathrm{ml}$ destilliertes Wasser \\
\hline Glucose & $200 \mathrm{mg} / 800 \mu \mathrm{l}$ Tris GN \\
\hline Glucoseoxidase & $30 \mathrm{mg} / 10 \mathrm{ml}$ Tris GN \\
\hline Tris GN & $12,11 \mathrm{~g} / \mathrm{l}$ Tris \\
\hline & $\mathrm{pH} 7,6$ \\
\hline
\end{tabular}




\subsubsection{Kits}

ABC Kit Elite Standard PK-6000

ABC Kit Standard PK 4000

\subsubsection{Verbrauchsmaterial}

Einbettmedium

Entellan

Eppendorfgefäße 1,5 ml

Immersionsöl

Injektionskanüle Sterican

Injektionsspritze Omnifix

Natriumhypochlorit

Nitril-Handschuhe, Nitra Tex

Objektträger

Pipettenspitzen

Spitzen für Multipipette, Combitips

$12,5 \mathrm{ml}$, Combitips plus $50 \mathrm{ml}$

Wellplatten 12er/ 48er
Vector Laboratories

Vector Laboratories
Jung, Leica Instruments $\mathrm{GmbH}$, Nussloch

Merck, Darmstadt

Eppendorf, Hamburg

Merck, Darmstadt

Braun, Melsungen

Braun, Melsungen

Danklorix, Colgate Palmolive $\mathrm{GmbH}$, Hamburg

Ansell, München

Menzel, Braunschweig

Sarstedt, Nümbrecht

Eppendorf, Hamburg

Corning incorporated, NY, USA

\subsubsection{Geräte}

Feinwaage

Gefriermikrotom, CM 3050s
Sartorius, Göttingen

Leica Microsystems GmbH, Nussloch 
HPLC (High performance

liquid chromatography), P580A

Magnetrührer

Mikroskop, Axioskop 2

Mikroskop, DMI 6000 B

Mutipipette, Ripette

$\mathrm{pH}-$ Meter

Pipette

Schüttler, Rotamax 120

Trockenschrank Haraeus

Ultraschallhomogenisator, Sonoplus

Zentrifuge 1-15k
Gynkotek

Heidolph Instruments, Schwabach

Zeiss, Jena

Leica Microsystems GmbH, Nussloch

Ritter, Schwabmünchen

SCHOTT Instruments, Mainz

Eppendorf, Hamburg

Heidolph Instruments, Schwabach

Thermo Scientific, Karlsruhe

Bandelin, Berlin

Sigma, Osterode

\subsubsection{Programme}

GraphPad Prism 4.0

Image J, Version $1.63 \mathrm{~B}$

Scion Image 4.0.3.2

Stereoinvestigator Software
GraphPad Software, San Diego, USA

Wayne Rasband, USA

Scion Corporation; Frederick, Maryland, USA

MicroBrightField Bioscience, Magdeburg 


\subsection{Tiere und Behandlung}

\subsubsection{Tierzüchtung und Versuchsgruppen}

Die transgenen Tiere für dieses Projekt wurden von Dr. Edgar R. Kramer (Abteilung für Molekulare Neurobiologie, Max-Planck Institut für Neurobiologie, Martinsried, Deutschland) bezogen. Das Gen, welches für den Ret-Rezeptor in dopaminergen Neuronen kodiert, wurde selektiv deletiert. Dafür wurden Mäuse mit einem gefloxten Allel für Ret $\left(\operatorname{Ret}^{\mid \mathrm{l}}\right)$ (Kramer et al. 2006) mit DAT-Cre-Mäusen (Zhuang et al. 2005) gepaart, so dass Mäuse mit einem Ret-Mangel in dopaminergen Neuronen resultierten (DAT-Ret ${ }^{\mid \mathrm{x} / \mathrm{x}}$ ) (Kramer et al. 2007). Die DAT-Cre-Mäuse und Ret ${ }^{\mid \mathrm{x}}$-Mäuse dienten zur Kontrolle.

Die gezüchteten Mäuse waren lebensfähig, fruchtbar und durchgehend männlich. Sie

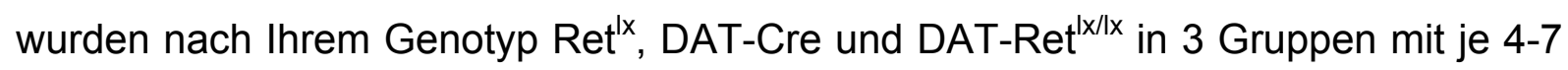
Tieren unterteilt. Ein Teil jeder Gruppe wurde mit MPTP behandelt, der andere Teil erhielt $0,9 \% \mathrm{NaCl}$. Bei Versuchsbeginn waren die Mäuse 12-16 Wochen alt und trugen zur Identifizierung Ohrmarkierungen.

\subsubsection{Tierhaltung}

Vor Experimentbeginn wurden die Tiere einige Tage zur Eingewöhnung und Erholung vom Transport im institutseigenen Tierstall gehalten. Dieser unterlag einem Tag-Nacht-Rhythmus.

4-5 Tiere teilten sich einen Kunststoffkäfig, der mit Käfigstreu ausgelegt war und freien Zugang zu Trinkflaschen und Futter gewährte. Die Betreuung wurde während des gesamten Versuchszeitraums von einem Tierpfleger übernommen, der stets über den aktuellen Stand des Versuchs in Kenntnis gesetzt wurde.

Die Untersuchungen wurden im Rahmen eines vom Regierungspräsidium Braunschweig genehmigten Tierversuchsvorhabens (Aktenzeichen 33.42502/0115.05) durchgeführt und sind im Einklang mit den nationalen und internationalen Leitlinien. 


\subsubsection{MPTP: Vorkehrungen}

Da sowohl der Stoff MPTP als auch $\mathrm{MPP}^{+}$toxisch wirken, sind besondere Schutzmaßnahmen zu beachten. Bei der Injektion selbst und während eines Zeitraums von 3-5 Tagen nach der letzten Injektion sind die Oberflächen im Käfig, die Exkremente, Futter und Trinkflaschen mit MPTP und seinen Metaboliten kontaminiert. Aus Sicherheitsgründen ist es notwendig das „Personal Protective Equipment" (Przedborski et al. 2001) während der Herstellung der MPTP-Lösung und der Injektion, sowie 5 Tage nach der letzten Injektion zu verwenden.

Diese beinhalten einen Anzug, Schuhschutz, Schutzmaske, Schutzbrille sowie doppelschichtige Nitril-Handschuhe unter Latexhandschuhen. Jeder Umgang mit MPTP sollte unter einem Abzug erfolgen. Mit MPTP-kontaminierte Flächen und Spritzen wurden mit Natriumhypochlorit (Danklorix) behandelt, so dass der MPTPKomplex zerstört und damit unschädlich gemacht wurde.

Die jeweiligen Käfige wurden während des gesamten Versuchszeitraums als Käfige mit MPTP-Behandlung gekennzeichnet und das kontaminierte Streu beim Wechseln ebenfalls mit Natriumhypochlorit separat entsorgt.

\subsubsection{MPTP: Injektionslösung}

Verwendet wurde MPTP-Hydrochlorid als Trockenpulver mit einer MPTPKonzentration von $30 \mathrm{mg} / \mathrm{kg}$ Körpergewicht (KG) (freie Base). Somit wurden $100 \mathrm{mg}$ MPTP-Hydrochlorid mit 27,55 ml 0,9\% NaCl verdünnt. Dieses Gemisch wurde an jedem Tag der Injektion unter den oben beschriebenen Schutzmaßnahmen erneut angesetzt.

\subsubsection{Injektionszyklus}

Die Mäuse wurden je nach Gruppenzuordnung mit MPTP oder $\mathrm{NaCl}$ injiziert. Die Injektion wurde gewichtsadaptiert mit $30 \mathrm{mg} / \mathrm{kg}$ KG intraperitoneal (i.p.) im 24Stunden-Rhythmus an 5 aufeinanderfolgenden Tagen durchgeführt. Die Genotypen waren während der Injektion nicht ersichtlich.

Nach dem Wiegen wurde die jeweilige Maus auf das Gitter des Käfigdeckels gesetzt und durch Festhalten mit Daumen und Zeigefinger im Nackenbereich und leichter 
Überstreckung nach dorsal auf den Rücken gedreht, wobei der Schwanz mit den übrigen Fingern fixiert wurde. Diese Methode gewährte zum Schutz der Organe eine ruhige und damit sichere i.p. Injektion des jeweiligen Mediums in den linken unteren Quadranten. Verwendet wurde eine $1 \mathrm{ml}$ Injektionsspritze mit einer Injektionskanüle. Die $\mathrm{NaCl}-$ Injektionen erfolgten stets vor den MPTP-Injektionen, um eine Kontamination zu vermeiden.

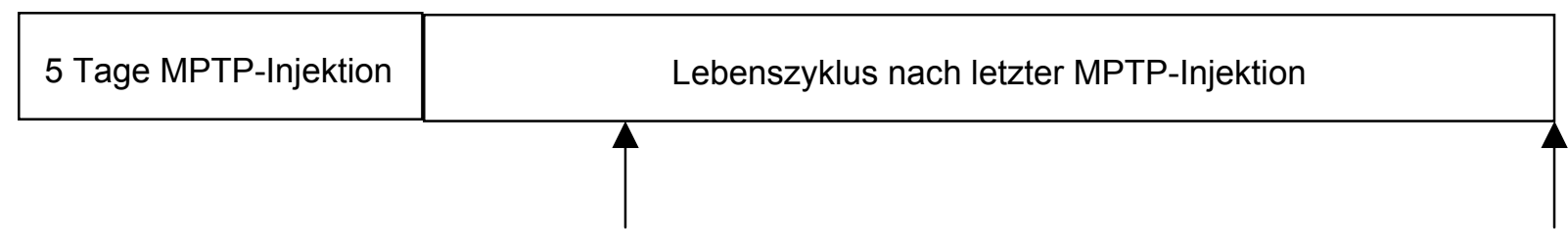

14 Tage*

90 Tage

\section{Abb. 6 Schematische Darstellung zum tierexperimentellen Design}

* Ergebnisse aus der Dissertationsarbeit von Sebastian Kowsky (Kowsky 2010; Kowsky et al. 2007)

\subsection{Gewebeaufarbeitung und Vorbereitung}

Alle Mäuse der jeweiligen Genotypen wurden 90 Tage nach der letzten MPTP- und $\mathrm{NaCl}-$ Injektion durch Dekapitation getötet.

\subsubsection{Gewebenentnahme}

Das jeweilige Gehirn wurde entlang der Sagittallinie an der Schädelkalotte eröffnet und die Öffnung mit einem koronaren Schnitt auf beiden Seiten erweitert. Nachdem die Dura mater gelöst wurde, konnte das Gehirn entnommen werden.

Das linke Striatum wurde schnellst möglich vom übrigen Teil separiert und bis zur Messung der Katecholaminkonzentrationen mittels High performance liquid chromatography (HPLC) bei $-80^{\circ} \mathrm{C}$ aufbewahrt. Das rechte Striatum und der posteriore Anteil mit der im Mittelhirn gelegenen SN desselben Gehirns wurden im Ganzen für 24 Stunden in eine Fixierlösung 4\% Paraformaldehyd (PFA) gegeben und bis zur Überführung in ein weiteres Medium ( $30 \%$ Sucrose) bei $4^{\circ} \mathrm{C}$ auf einem Schüttler gelagert. 


\subsubsection{Gewebefixierung und Kryoprotektion}

\section{4\% PFA-Lösung zur Fixierung}

Zur Herstellung von 4\% PFA-Lösung wurden $4 \mathrm{~g}$ PFA pro $100 \mathrm{ml}$ 0,2 M Phosphatpuffer $\left(\mathrm{PB}=21,8 \mathrm{~g} / \mathrm{l} \mathrm{Na} \mathrm{HPO}_{4}, 6,28 \mathrm{~g} / \mathrm{l} \mathrm{NaH} \mathrm{PO}_{4}, \mathrm{pH} 7,2-7,4\right)$ durch Erhitzen auf $60^{\circ} \mathrm{C}$ für $20-30$ Minuten gelöst. 1-2 Tropfen $4 \mathrm{~N}$ Natronlauge unter Rühren ließ die Lösung aufklaren. Über Nacht abgedeckt, kühlte das Gemisch ab und wurde am nächsten Tag auf einen $\mathrm{pH}-$ Wert von 7,4 eingestellt.

\section{0\% Sucrose-Lösung zur Kryoprotektion}

$30 \mathrm{~g}$ Sucrose wurden mit 0,1 M PB auf $100 \mathrm{ml}$ aufgefüllt.

Das rechte Striatum und der posteriore Anteil eines jeden Gehirns wurden im Ganzen für 24 Stunden in $50 \mathrm{ml} 4 \%$ PFA bei $4^{\circ} \mathrm{C}$ auf einem Schüttler aufbewahrt. Anschließend wurden die Gehirnanteile für weitere 48 Stunden in $50 \mathrm{ml} 30 \%$ Sucrose bei $4^{\circ} \mathrm{C}$ auf einem Schüttler kryoprotektiert. Nach der Kryoprotektion mit Sucrose wurden die Gehirne in 2-Methylbutan, welches mit Trockeneis auf $-40^{\circ} \mathrm{C}$ herunter gekühlt wurde, für 30 Sekunden gefroren. Anschließend wurden die Gehirne bei $-80^{\circ} \mathrm{C}$ bis zur weiteren Behandlung aufbewahrt.

\subsubsection{Gefrierschnitte}

Von den fixierten und kryoprotektierten Gehirnanteilen, die das rechte Striatum und den posterioren Anteil mit der SNpc enthielten, wurden mit einem Gefriermikrotom 30 $\mu \mathrm{m}$ dicke Schnitte angefertigt.

Für die spätere Auswertung und für die Seitendifferenzierung unter dem Mikroskop wurde mit einer Injektionskanüle die linke Großhirnrinde markiert. Die Schnitte wurden von kaudal nach kranial gewonnen und somit koronare Mittelhirnschnitte und striatale Schnitte angefertigt. Zur genauen Orientierung wurde hierzu ein Atlas über die Neuroanatomie der Maus hinzugezogen (Paxinos und Franklin 2004). Die Schnitte wurden in einem Aufnahmemedium (Phosphat gepufferte Salzlösung, PBS= $10,9 \mathrm{~g} / / \mathrm{Na}_{2} \mathrm{HPO}_{4}, 3,14 \mathrm{~g} / \mathrm{l} \mathrm{NaH}{ }_{2} \mathrm{PO}_{4}, 9 \mathrm{~g} \mathrm{NaCl}, 0,1 \%$ Natriumazid, $\mathrm{pH}$ 7,2-7,4) in 48er-Wellplatten bei $4^{\circ} \mathrm{C}$ bis zur Färbung gelagert. 


\subsubsection{Gelatinisierte Objektträger}

Gelatiniserte Objektträger garantieren eine bessere und damit sicherere Haftung der TH-gefärbten Gehirnschnitte. Um diese herzustellen wurden $5 \mathrm{~g}$ Gelatine in $500 \mathrm{ml}$ zweifach destilliertem Wasser unter ständigem Rühren gelöst und auf $80^{\circ} \mathrm{C}$ erhitzt. Nach Abkühlung auf $40^{\circ} \mathrm{C}$ wurde die Lösung um 0,5 g Chrom-III-Kaliumsulfat ergänzt und sterifiltriert. Die unbehandelten Objektträger wurden 30 Sekunden in die fertige Gelatinelösung getaucht, anschließend 20 Minuten getrocknet und für 15 Minuten in 1\% PFA-Lösung fixiert. Im Anschluss wurden die gelatinisierten Objektträger bei $63^{\circ} \mathrm{C}$ im Trockenschrank staubfrei getrocknet.

Diese Objektträger wurden für das Aufziehen der TH-gefärbten SNpc-Schnitte und striatalen Schnitte verwendet, um im Anschluss die SNpc-Schnitte einer NisslFärbung zu unterziehen und die striatalen Schnitte mit guter Haftung entwässern zu können.

\section{$2.4 \quad$ Immunohistochemie und Auswertung}

\subsubsection{Immunohistochemische TH-Färbung zur Quantifizierung dopaminerger Neurone im Mittelhirn}

Um die dopaminergen Neurone der SNpc anzufärben und die Auswirkung von MPTP auf diese Sturkturen zu untersuchen, wurden zur Quantifizierung zehn $30 \mu \mathrm{m}$ dicke, koronare Schnitte der SNpc eines jeden Gehirns in Serie im Abstand von $120 \mu \mathrm{m}$ verwendet. Als Färbegefäße dienten 12er-Wellplatten.

Das Prinzip dieser Färbemethode beruht auf der Anfärbung TH-aktiver Neurone in der SNpc mittels 3,3`Diaminobenzidin (DAB) in einer "free floating“-Technik. Der primäre Antikörper reagiert dabei mit der neuronengebundenen TH in der SNpc. Der sekundäre Antikörper richtet sich als biotinmarkierter Antikörper gegen den primären Antikörper. Anschließend wurde ein Avidin-Biotin-gekoppelter Enzymkomplex hinzugegeben. Avidin zeigt eine außerordentlich hohe Affinität zu Biotin. Im letzten Schritt wurden die Schnitte mit dem Enzymsubstrat DAB inkubiert und somit die THaktiven Neurone sichtbar gemacht. Bei diesem Schritt diente die Peroxidase der Oxidation des vorher farblosen Enzymsubstrats zu einem farbigen Endprodukt. Restliches DAB wurde mittels Natriumhypochlorit inaktiviert. 0,1 M Trisphosphat- 
puffer (TBS= 12,11 g/l Tris, $9 \mathrm{~g} / \mathrm{l} \mathrm{NaCl}, \mathrm{pH}$ 7,2-7,4) diente zwischen den verschiedenen Schritten als Waschmedium (Tab. 1).

\begin{tabular}{|c|c|c|}
\hline Art des Vorgangs & Inkubationszeit & Zusammensetzung der Lösung \\
\hline Waschen & $3 \times 5 \min$ & $0,1 \mathrm{M}$ TBS \\
\hline Peroxidaseblockung & $5 \mathrm{~min}$ & $\begin{array}{l}10 \% \text { Methanol und } 3 \% \mathrm{H}_{2} \mathrm{O}_{2} \text { in } \\
0,1 \mathrm{M} \text { TBS }\end{array}$ \\
\hline Waschen & $3 \times 5 \min$ & $0,1 \mathrm{M}$ TBS \\
\hline Präinkubation & $60 \min$ & $\begin{array}{l}5 \% \text { Normal Goat Serum (NGS) in } \\
0,1 \text { M TBS }\end{array}$ \\
\hline Prim. Antikörper & 48 Stunden & $\begin{array}{l}\text { Rabbit Anti-Tyrosine Hydroxylase } \\
\text { (1:1000, polyklonal), } 2 \% \text { NGS in } \\
0,1 \mathrm{M} \text { TBS bei } 4^{\circ} \mathrm{C}\end{array}$ \\
\hline Waschen & $3 \times 5 \min$ & $0,1 \mathrm{M}$ TBS \\
\hline Sek. Antikörper & $60 \min$ & $\begin{array}{l}\text { Biotinylated Anti-Rabbit lgG } \\
(1: 200), 2 \% \text { NGS in } 0,1 \mathrm{M} \text { TBS }\end{array}$ \\
\hline Waschen & $3 \times 5 \min$ & $0,1 \mathrm{M}$ TBS \\
\hline Enzymkomplex & $60 \min$ & $\begin{array}{l}\text { ABC Kit Standard (PK-4000) in 0,1 } \\
\text { M TBS } \\
2 \text { Tropfen A+ } 2 \text { Tropfen B pro } 10 \\
\text { ml }\end{array}$ \\
\hline Waschen & $3 \times 5 \min$ & $0,1 \mathrm{M}$ TBS \\
\hline DAB-Färbung & $15 \min$ & $\begin{array}{l}\text { in } 50 \mathrm{ml} \text { Tris } \mathrm{GN} \text { : } 25 \mathrm{mg} \mathrm{DAB}, \\
100 \quad \mu \mathrm{l} \quad \mathrm{NH}_{4} \mathrm{Cl}, \quad 150 \quad \mu \mathrm{l} \\
\text { Glucoseoxidase, } 400 \mu \mathrm{ll} \text { Glucose, } \\
\mathrm{pH} 7,6\end{array}$ \\
\hline Waschen & $3 \times 5 \min$ & $0,1 \mathrm{M}$ TBS \\
\hline
\end{tabular}

Tab. 1 Tyrosinhydroxylasefärbung dopaminerger Neurone 
Nach dem letzten Waschgang wurden die zehn Schnitte eines jeden Gehirns in ihrer Reihenfolge von kaudal nach kranial auf gelatinisierte Objektträger gezogen, mit ihrer Kennnummer versehen und luftgetrocknet. Hierbei diente die Markierung in der linken Gehirnhälfte als Orientierung. Anschließend wurde die Nissl-Färbung durchgeführt.

\subsubsection{Nissl-Färbung der Mittelhirnschnitte}

Die Nissl-Färbung dient der Anfärbung von Nisslschollen in Nervenzellen, die aus rauhem endoplasmatischen Retikulum bestehen.

Um auszuschließen, dass ein Abfall von TH-positiven Neuronen in der SNpc auf eine transiente zelluläre Atrophie mit Herunterregulation der TH-Expression zurückzuführen ist, wurden diese Nisslschollen zusätzlich selektiv in einer „freefloating“-Technik angefärbt. Eine Degeneration von TH-positiven Neuronen kann als Zelltod gesehen werden, wenn auch die Nissl-positiven Zellen abnehmen. Die Färbemethode beruht auf einer Überfärbung eines in Alkohol gefärbten Schnittes mit einem Farbstoff (Thionin) und dem nachfolgenden Auswaschen des Farbstoffüberschusses. Die Fasern lassen sich bei diesem Vorgang schneller entfärben als die Zellbestandteile, so dass diese intensiv gegenüber dem farblosen Hintergrund gefärbt sind.

Die verschiedenen Lösungen wurden zuvor wie folgt angesetzt:

Chloroform-Lösung: $\quad 480 \mathrm{ml}$ Chloroform, $60 \mathrm{ml} 95 \%$ Ethanol, $60 \mathrm{ml}$ Diethylether Reihenfolge einhalten

Färbelösung: $455 \mathrm{ml}$ Standardfärbelösung, $45 \mathrm{ml}$ Pufferlösung

$\begin{array}{ll}\text { Pufferlösung: } & 7 \mathrm{~g} \text { Natriumacetat } \\ & 2 \mathrm{ml} \text { Eisessigsäure } \\ & 1100 \mathrm{ml} \text { destilliertes Wasser } \\ \text { Standardfärbelösung: } & 1 \mathrm{~g} \text { Thionin } \\ & 100 \mathrm{ml} \text { kochendes destilliertes } \\ & \text { Wasser }\end{array}$


Formalin-Essig-Lösung: $1 \mathrm{ml}$ Eisessigsäure, $1 \mathrm{ml}$ 39\% Formaldehyd, $100 \mathrm{ml}$ destilliertes Wasser

Um Nissl-Zellen anzufärben, wurden die Objektträger mit den jeweiligen THgefärbten Gehirnschnitten nacheinander in die folgenden Reagenzien getaucht (Tab. 2).

\begin{tabular}{|l|l|}
\hline Reagenz & Inkubationszeit \\
\hline $95 \%$ Ethanol & $20 \mathrm{~min}$ \\
\hline Chloroform-Lösung & $10 \mathrm{~min}$ \\
\hline $95 \%$ Ethanol & $2 \mathrm{~min}$ \\
\hline $100 \%$ Ethanol & $2 \mathrm{~min}$ \\
\hline Xylol & $5 \mathrm{~min}$ \\
\hline $100 \%$ Ethanol & $5 \mathrm{~min}$ \\
\hline $95 \%$ Ethanol & $2 \mathrm{~min}$ \\
\hline $95 \%$ Ethanol & $2 \mathrm{~min}$ \\
\hline Destilliertes Wasser & $2 \mathrm{~min}$ \\
\hline Färbelösung & $7 \mathrm{~min}$ \\
\hline Destilliertes Wasser & $2 \mathrm{~min}$ \\
\hline Destilliertes Wasser & $2 \mathrm{~min}$ \\
\hline Destilliertes Wasser & $2 \mathrm{~min}$ \\
\hline Formalin-Essig-Lösung & $8 \mathrm{~s}$ \\
\hline Destilliertes Wasser & $2 \mathrm{~min}$ \\
\hline Destilliertes Wasser & $2 \mathrm{~min}$ \\
\hline Destilliertes Wasser & $2 \mathrm{~min}$ \\
\hline
\end{tabular}




\begin{tabular}{|l|l|}
\hline $95 \%$ Ethanol & $2 \mathrm{~min}$ \\
\hline $95 \%$ Ethanol & $2 \mathrm{~min}$ \\
\hline $95 \%$ Ethanol & $2 \mathrm{~min}$ \\
\hline $100 \% \mathrm{n}$-Butanol & $10 \mathrm{~min}$ \\
\hline Cedernholzöl & $10 \mathrm{~min}$ \\
\hline Xylol & $10 \mathrm{~min}$ \\
\hline Xylol & $10 \mathrm{~min}$ \\
\hline Eindeckeln mit Entellan & \\
\hline
\end{tabular}

Tab. 2 Nissl-Färbung

\subsubsection{Stereologische Auswertung dopaminerger Neurone in der SNpc}

Für die Auszählung der TH- und Nissl-gefärbten Neurone der SNpc wurden anhand von Serienschnitten stereologische Zählungen durchgeführt (West 1993; West et al. 1991). Hierfür wurde jeder vierte Schnitt mit einem Abstand von $120 \mu \mathrm{m}$ und jeweils nur $20 \%$ der gesamten Fläche ausgewertet. Mittels eines Computerprogramms (Stereoinvestigator Software, MicroBrightField® Bioscience, Magdeburg, Germany) wurden die auszuzählenden Felder randomisiert und nach der Auszählung von der gezählten Stichprobe auf die Gesamtzahl der Neurone im gesamten Volumen hochgerechnet. Die Auswertung der zehn Schnitte erfolgte manuell und der Genotyp einer jeden Maus war nicht zu erkennen. Hierzu wurde ein Mikroskop (Axioskop 2, Zeiss) verwendet. Die Markierung der SNpc eines jeden $30 \mu \mathrm{m}$ dicken Mittelhirnschnittes erfolgte unter niedriger Vergrößerung (10x Objektiv) und unter Vewendung eines Maushirnatlasses (Paxinos und Franklin 2004). Das Programm legt die auszuzählenden Felder von 50 × $50 \mu \mathrm{m}$ in einem zufällig platzierten Raster von $100 \times 125 \mu \mathrm{m}$ fest. Anschließend wurden die TH-positiven und Nissl-positiven Neurone mit einem 63x Objektiv und Immersionsöl ausgezählt. Nicht gezählt wurden Zellen, die die rote Grenze des Zählrahmens überschritten. 
2.4.4 Immunhistochemische TH-Färbung des Striatums zur Messung der optischen Dichte

Die angefertigten Schnitte des rechten Striatums mit dem Kryostat wurden ebenfalls mit einer TH-Färbung gefärbt, die zur Quantifizierung von Axonterminalen dient. Der sekundäre Antikörper bindet in diesem Fall an die Dopamintransporter gebundende TH. Hierfür wurden koronare Schnitte eines jeden Gehirns mit einer Dicke von $30 \mu \mathrm{m}$ verwendet, deren Abstand $320 \mu \mathrm{m}$ betrug.

Die Färbung des Striatums ähnelt der Färbung der dopaminergen Neurone der SNpc. Ein Unterschied bestand lediglich in der Wahl des ABC-Kits und der Inkubationsdauer der DAB-Färbung. Hier wurde der ABC-Kit Elite Standard (PK6100) verwendet. Der Grund hiefür liegt in einer größeren Empfindlichkeit dieses $A B C-K i t s$ und einer geringeren Anfärbung des Hintergrunds. Die Inkubation der Striata im DAB-Gemisch betrug 20 Minuten statt 15 Minuten (Tab. 3).

Die striatalen Schnitte wurden nach der Färbung ebenfalls auf gelatinisierte Objektträger gezogen und anschließend entwässert (Tab. 4).

\begin{tabular}{|l|l|l|}
\hline Art des Vorgangs & Inkubationszeit & Zusammensetzung der Lösung \\
\hline Waschen & $3 \times 5 \mathrm{~min}$ & $0,1 \mathrm{M}$ TBS \\
\hline Peroxidaseblockung & $5 \mathrm{~min}$ & $\begin{array}{l}10 \% \text { Methanol und } 3 \% \mathrm{H}_{2} \mathrm{O}_{2} \text { in } \\
0,1 \mathrm{M} \text { TBS }\end{array}$ \\
\hline Waschen & $3 \times 5 \mathrm{~min}$ & $0,1 \mathrm{M}$ TBS \\
\hline Präinkubation & $60 \mathrm{~min}$ & $5 \% \mathrm{NGS}$ in 0,1 M TBS \\
\hline Prim. Antikörper & 48 Stunden & $\begin{array}{l}\text { Rabbit Anti-Tyrosine Hydroxylase } \\
(1: 1000, \text { polyklonal), } \% \text { NGS in } \\
0,1 \mathrm{M} \text { TBS bei } 4^{\circ} \mathrm{C}\end{array}$ \\
\hline Waschen & $3 \times 5 \mathrm{~min}$ & $0,1 \mathrm{M}$ TBS \\
\hline Sek. Antikörper & $60 \mathrm{~min}$ & $\begin{array}{l}\text { Biotinylated Anti-Rabbit IgG } \\
(1: 200), 2 \% \text { NGS in } 0,1 \mathrm{TBS}\end{array}$ \\
\hline Waschen & & $0,1 \mathrm{M}$ TBS \\
\hline
\end{tabular}




\begin{tabular}{|c|c|c|}
\hline Enzymkomplex & $60 \min$ & $\begin{array}{l}\text { ABC Kit Elite Standard (PK-6100) } \\
\text { in } 0,1 \mathrm{M} \text { TBS } \\
2 \text { Tropfen A+ } 2 \text { Tropfen B pro } 10 \\
\text { ml }\end{array}$ \\
\hline Waschen & $3 \times 5 \min$ & $0,1 \mathrm{M}$ TBS \\
\hline DAB-Färbung & $20 \min$ & $\begin{array}{l}\text { in } 50 \mathrm{ml} \text { Tris } \mathrm{GN} \text { : } 25 \mathrm{mg} \mathrm{DAB} \text {, } \\
100 \mu \mathrm{l} \quad \mathrm{NH}_{4} \mathrm{Cl}, \quad 150 \quad \mu \mathrm{l} \\
\text { Glucoseoxidase, } 400 \mu \mathrm{l} \text { Glucose, } \\
\mathrm{pH} 7,6\end{array}$ \\
\hline Waschen & $3 \times 5 \mathrm{~min}$ & $0,1 \mathrm{M}$ TBS \\
\hline
\end{tabular}

Tab. 3 TH-Färbung des Striatums

\subsubsection{Entwässerung des rechten Striatums}

Die striatalen Schnitte wurden mit Ethanol aufsteigender Konzentrationen entwässert und anschließend mit Xylol behandelt. Die Eindeckelung erfolgte mit Entellan.

\begin{tabular}{|l|l|}
\hline Reagenz & Zeit \\
\hline Destilliertes Wasser & $5 \mathrm{~min}$ \\
\hline $70 \%$ Ethanol & $10 \mathrm{~min}$ \\
\hline $95 \%$ Ethanol & $10 \mathrm{~min}$ \\
\hline $100 \%$ Ethanol & $10 \mathrm{~min}$ \\
\hline $100 \%$ Ethanol & $10 \mathrm{~min}$ \\
\hline Xylol & $10 \mathrm{~min}$ \\
\hline Xylol & $10 \mathrm{~min}$ \\
\hline Eindeckeln mit Entellan & \\
\hline
\end{tabular}




\subsubsection{Bestimmung der optischen Dichte des Striatums}

Als Maß für die Anzahl und Funktion der TH-positiven Fasern im Striatum wurde die Faserdichte von TH-positiv gefärbten Fasern bestimmt.

Nachdem die zwölf striatalen Schnitte auf die Objektträger gezogen und entwässert wurden, schloss sich eine Trocknungsphase von 12 Stunden bei Raumtemperatur an. Danach wurden die striatalen Schnitte als digitale Bilddateien eingescannt (Durchlicht-Modus, 8-bit) und mit Hilfe des Programms Scion Image 4.0.3.2 Software (Scion Corporation; Frederick, Maryland, USA) ausgewertet. Es wurde die striatale Fläche eines jeden Schnittes markiert. Die gemessenen Werte entsprechen willkürlichen Einheiten arbitrary units $(A U)=$ optische Dichte. Die Markierung eines äquivalenten Kortexareals diente zum Ausgleich von Färbeunterschieden zwischen den einzelnen Schnitten. Der Mittelwert der optischen Dichte für den Kortex wurde vom Mittelwert der optischen Dichte für das Striatum subtrahiert (Burke et al. 1990). Die Auswertung erfolgte manuell und der Genotyp einer jeden Maus war nicht ersichtlich.

\subsubsection{Fluoreszenzfärbung und Quantifizierung des Striatums für die Bestimmung der striatalen Faserdichte}

In Kooperation mit Dr. Edgar R. Kramer (Abteilung für Molekulare Neurobiologie, Max-Planck Institut für Neurobiologie, Martinsried, Deutschland) wurde die Innervation des Striatums mit einem zusätzlichen Verfahren zur Quantifizierung der striatalen Faserdichte analysiert. Dieses Verfahren gewährte eine höhere Auflösung und eine genauere Bestimmung. Die dopaminerge Faserdichte wurde anhand von sechs striatalen Schnitten $(30 \mu \mathrm{m})$ eines jeden Gehirns zwischen Bregma $+1,10$ und $-0,10 \mathrm{~mm}$ bestimmt. Die fluoreszierende TH-Färbung dieser Schnitte erfolgte mit wenigen Änderungen wie zuvor beschrieben (Kramer et al. 2007).

Die in PBS/Azid gelagerten Schnitte wurden auf Objektträger gezogen und 30 Minuten getrocknet. Anschließend wurden die Schnitte für 1 Stunde geblockt (4\% BSA, $0,3 \%$ Triton $X-100$ in TBS) und mit dem primären Antikörper für TH (Maus, DiaSorin, Sillwater, Massachusetts, USA, 1:1000) (2\% BSA, 0,1\% Triton X-100 in TBS) bei $4^{\circ} \mathrm{C}$ über Nacht inkubiert. Die Schnitte wurden 3 mal 10 Minuten in TBS gewaschen und mit dem sekundären biotingekoppelten Antikörper (Vectastain ABC- 
Kit, Peroxidase Maus IgG PK4002, 1:200) für 2 Stunden bei Raumtemperatur inkubiert. Erneut schloss sich eine Wäsche für 3 mal 10 Minuten in TBS an, gefolgt von einer Behandlung mit einem Streptavidin-Cy3 Antikörper (1:500, Sigma) über Nacht. Nach weiteren 3 Waschschritten in TBS für jeweils 10 Minuten wurden die Schnitte in Aequeous Mounting Medium mit Anti-Fading Reagenz (Biomedia, Foster City, California, USA, oder DakoCytomation) eingedeckt. Mit einem FluoreszenzMikroskop in 63x Auflösung (Axioplan, Zeiss, Göttingen, Deutschland) wurden von jedem Schnitt 5 Aufnahmen vom dorsalen Striatum und 5 Aufnahmen vom ventralen Striatum genommen.

Um die Fasern automatisch bestimmen zu können und um das Signal-HintergrundVerhältnis zu erhöhen, wurde für die Bilder zunächst eine Schwelle für ein positives Signal manuell festgelegt. Anschließend konnten die Treffpunkte der Fasern mit einem automatischen Zählraster mittels Metamorph Software (Macro von Molecular Devices, Sunnyvale, California, USA) quantifiziert werden, um zu einer Aussage über die Faserdichte zu gelangen. Diese wurde in Fasern pro $\mathrm{mm}^{2}$ ausgedrückt.

Auch hier wurde die Auswertung manuell vorgenommen und der Genotyp war nicht ersichtlich.

\subsubsection{Messung der nigrostriatalen Faserdichte nahe dem Ursprung rostral der SNpc}

Das Striatum ist der Endpunkt für alle nigrostriatalen Fasern. Als Ergänzung zur Bestimmung der Faserdichte im Striatum wurde die Dichte dieser Fasern nahe des Ursprunges etwa $200 \mu \mathrm{m}$ rostral des ersten SNpc-Neurons gemessen. Dadurch ließ sich die Regeneration der striatalen Fasern 90 Tage nach MPTP-Behandlung genauer beurteilen.

Für diese Methode wurden von einem Gehirn jeweils drei Schnitte mit einer Dicke von $30 \mu \mathrm{m}$ 120-240 $\mu \mathrm{m}$ rostral der SNpc verwendet und die nigrostriatalen Projektionen entsprechend der Färbung des Striatums mit einer TH-Färbung kenntlich gemacht. Diese Schnitte wurden in 20-facher Vergrößerung mit dem Mikroskop (Leica DMI 6000 B) eingescannt (Durchlicht-Modus) und mit dem Programm Image $\mathrm{J}$ ausgewertet (Version $1.63 \mathrm{~B}$; Wayne Rasband, USA). Mit einem Plug-in "Threshold_Colour" (Gabriel Landini, School of Dentistry, University of Birmingham) konnte der ausgewählte Bereich auf die angefärbten Projektionsbahnen 
reduziert und in eine 8-Bit-Graustufe umgewandelt werden. Das Areal der zu messenden Projektionsbahnen wurde zuvor manuell bestimmt und durch eine Partikel-Analyse ausgezählt. Es wurden sowohl die Anzahl der TH-positiven Fasern als auch die von den Fasern abgedeckte gesamte Fläche in $\mathrm{mm}^{2}$ gemessen. Auch hier war der Genotyp nicht ersichtlich.

\subsection{Bestimmung der Katecholaminkonzentrationen im Striatum und Auswertung mittels HPLC}

Um die Veränderung der striatalen Marker unter MPTP-Einfluss zu messen, wurden die Katecholaminkonzentrationen von Dopamin und seinen Metaboliten DOPAC und HVA mittels HPLC (Gynkotek P580A) ermittelt. Die HPLC dient der elektrochemischen Detektion dieser Katecholamine (Eberhardt et al. 2000). Um bei dieser Detektion eine frühzeitige Zersetzung der Katecholamine zu vermeiden, wurde die im folgenden vorgenommene Prozedur bei $4^{\circ} \mathrm{C}$ Umgebungstemperatur durchgeführt.

Die bei $-80^{\circ} \mathrm{C}$ gefrorenen Striata wurden in $1,5 \mathrm{ml}$ Eppendorfgefäße überführt, deren jeweiliges Leergewicht zuvor bestimmt wurde. Das Leergewicht wurde vom Gesamtgewicht subtrahiert und somit das genaue striatale Gewicht ermittelt. Im Verhältnis zu ihrem Gewicht wurden alle Striata in einem Verhältnis von 1:3 mit 0,1 M Perchlorsäure versetzt und bis zur weiteren Behandlung gekühlt.

Anschließend wurde das striatale Gewebe bei $4^{\circ} \mathrm{C}$ für 10 Sekunden mit einem gepulsten Ultraschall homogenisiert. Um ein Absinken der Zellbestandteile zu erreichen, wurde das Homogenisat 30 Minuten ruhen gelassen und erneut für weitere 10 Sekunden mit Ultraschall behandelt. Zwischen den verschiedenen Striatabehandlungen wurde auf eine strikte Reinigung der Ultraschallspitze geachtet, um eine Durchmischung der Homogenisate zu vermeiden.

Nach einer erneuten Ruhephase für 20 Minuten wurden die homogenisierten Eppendorfgefäße zentrifugiert ( $4^{\circ} \mathrm{C}, 13.000 \mathrm{rpm}, 20$ Minuten). $20 \mu \mathrm{l}$ des Überstandes wurde für die anschließenden Katecholaminmessungen in der HPLC abpipettiert. Die ermittelten Katecholaminkonzentrationen wurden in $\mathrm{ng}$ pro $\mathrm{mg}$ Nassgewebe ausgedrückt. 


\section{$2.6 \quad \mathrm{MPP}^{+}$-Messungen}

Um sicher zu gehen, dass keine Unterschiede im Metabolismus von MPTP unter den 3 Genotypen bestanden, die potentiell zu unterschiedlicher Toxizität in den Genotypen beitragen könnten, wurden MPP ${ }^{+}$-Messungen durchgeführt.

Die Toxizität von MPTP ist abhängig von der Umwandlung durch die MAO-B zu $\mathrm{MPP}^{+}$. Die striatale $\mathrm{MPP}^{+}-$Konzentration wurde 90 Minuten nach i.p. Injektion von MPTP (30 mg/kg KG) mittels HPLC gemessen (Kowsky et al. 2007). Diese Daten wurden von Sebastian Kowsky erhoben und dienen in dieser Arbeit dem Nachweis, dass alle 3 Genotypen einen vergleichbaren MPTP-Metabolismus besitzen (Kowsky 2010; Kowsky et al. 2007). Die ermittelten $\mathrm{MPP}^{+}$-Konzentrationen wurden in ng $\mathrm{MPP}^{+}$pro mg Nassgewebe ausgedrückt.

\subsection{Statistik}

Berichtet werden Mittelwerte \pm Standardabweichung. Die statistische Auswertung der erläuterten Daten wurden mit ANOVA ausgeführt, gefolgt von Tukey`s post hoc Test, um die Mittelwerte der Gruppen mit GraphPad Prism 4.0 (GraphPad Software; San Diego, USA) vergleichen zu können. Für die Beurteilung der Katecholaminkonzentrationen wurde 2-way ANOVA mit einem Faktor 1 für die Behandlung ( $\mathrm{NaCl}$ oder MPTP) und dem Faktor 2 für die Gruppe, die über den Genotyp und die Zeit nach der MPTP-Behandlung definiert ist, verwendet. In allen durchgeführten Auswertungen wird die Null-Hypothese, falls nicht anders angegeben, bei einem Wert von 0,05 abgelehnt. Die Bars in den Abbildungen entsprechen dem Mittelwert, die Fehlerbalken entsprechen den Standardabweichungen. 


\section{Ergebnisse}

Um die Relevanz des Ret-Rezeptors für die Regeneration dopaminerger Neurone im MPTP-Mausmodell zu untersuchen, wurde stereologisch die Anzahl TH-positiver Neurone und Nissl-positiver Neurone in der SNpc bestimmt. Einen weiteren Aufschluss über die Bedeutung der GDNF-vermittelten Wirkungen gaben Untersuchungen über die striatale Faserdichte, die Messung der Katecholaminkonzentrationen im Striatum und die Messung nigrostriataler Fasern rostral der SNpc. Die von Sebastian Kowsky zur Verfügung gestellten Daten beziehen sich auf den Zeitpunkt 14 Tage nach MPTP-Injektion (Kowsky 2010; Kowsky et al. 2007).

\subsection{Die Effekte von MPTP auf die Zahl dopaminerger Neurone der SNpc}

\subsubsection{Die Effekte von MPTP auf die TH-positiven Zellen der SNpc}

Die dopaminergen Neurone der SNpc wurden mittels TH-Färbung angefärbt und stereologisch ausgewertet.

Die mikroskopischen Übersichtsaufnahmen (Abb. 7) der SNpc zeigen, dass die drei Genotypen DAT-Ret ${ }^{1 / 1 x}$, Ret $^{1 \mathrm{x}}$ und DAT-Cre sowohl 14 Tage (A-C) als auch 90 Tage (G-I) nach der NaCl-Behandlung keinen Unterschied in der Anzahl TH-positiver SNpc Neurone aufwiesen. Betrachtet man die Aufnahmen der MPTP behandelten Tiere, erkennt man keinen Unterschied in der Verminderung TH-positiver Neurone zwischen den Genotypen DAT-Cre (D und J), $\operatorname{Ret}^{\mid \mathrm{x}}(\mathrm{E}$ und $\mathrm{K})$ und DAT-Ret ${ }^{\mid \mathrm{x} / \mathrm{x}}(\mathrm{F}$ und L) zum Zeitpunkt von 14 Tagen (D-F) und 90 Tagen (J-L). Dieser qualitative Eindruck in den mikroskopischen Übersichtsaufnahmen der SNpc spiegelt sich in der Quantifizierung der Zellen wider. 


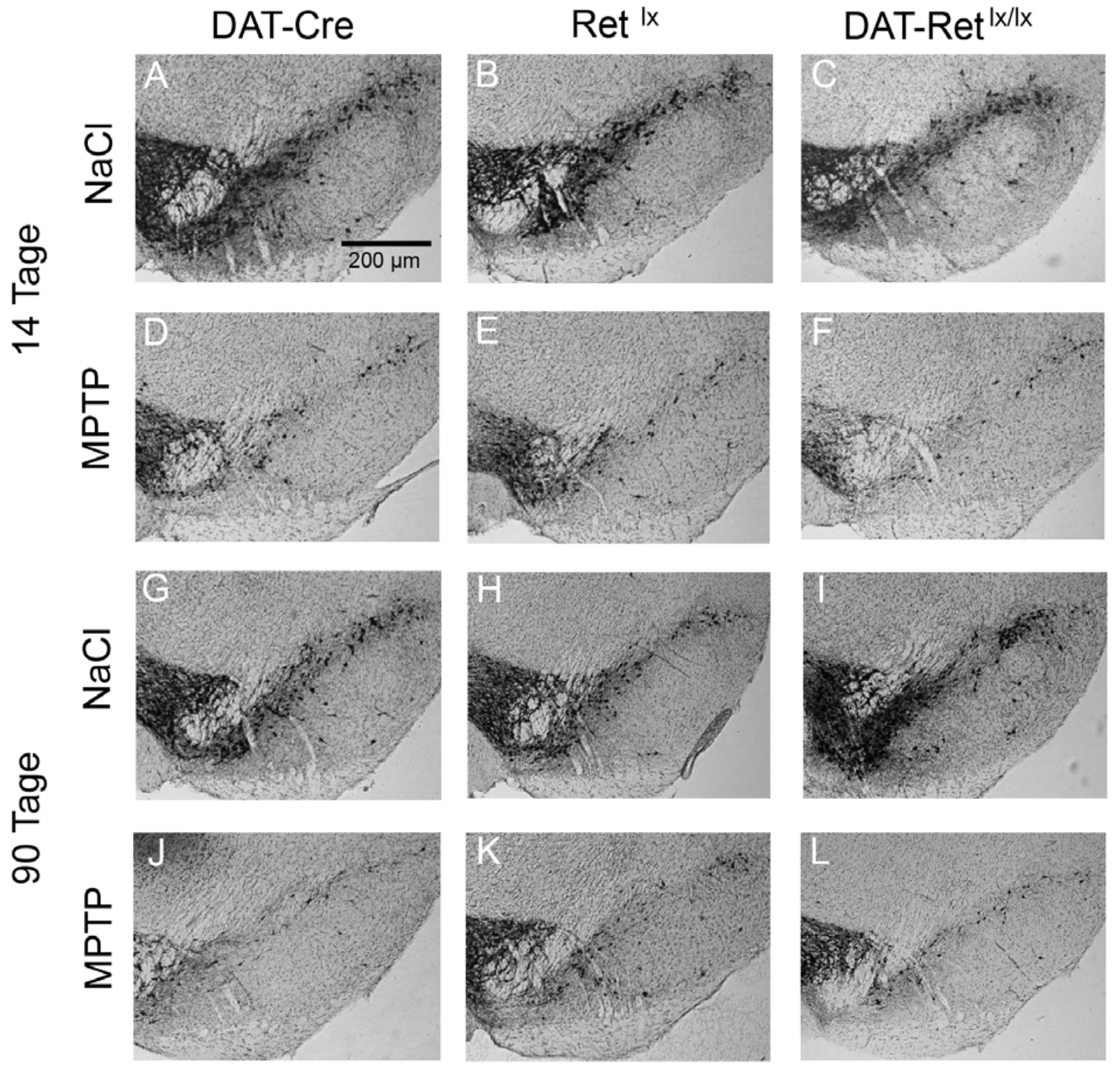

\section{Abb. 7 Mikroskopische Übersichtsaufnahmen der SNpc}

Gezeigt wird der MPTP-induzierte Verlust von TH-positiven Neuronen der SNpc. (A-C und G-I): Bei den $\mathrm{NaCl}$-injizierten Mäusen gab es keinen Unterschied in der Anzahl TH-positiver Neurone der SNpc zwischen den Genotypen DAT-Cre (A und G), $\operatorname{Ret}^{\mid x}(B$ und $H)$ und DAT-Ret ${ }^{|x /| x}(C$ und I) zum Zeitpunkt von 14 Tagen (A-C) und 90 Tagen (G-I). (D-F und J-L): Die MPTP-induzierte Abnahme TH-positiver Neurone der SNpc unterscheidet sich nicht zwischen den Genotypen DAT-Cre (D und J), Ret- ${ }^{1 \mathrm{X}}$ (E und K) und DAT-Ret ${ }^{\mid x / x}(F$ und $L)$ nach 14 Tagen (D-F) und 90 Tagen (J-L). Zudem gab es keinen Unterschied zwischen 14 und 90 Tagen für jeden der drei Genotypen. 
Ein Vergleich der stereologischen Ergebnisse ergab in der Anzahl der TH-positiven Neurone der SNpc keinen signifikanten Unterschied zwischen den drei Genotypen DAT-Ret ${ }^{|x| x}$, Ret ${ }^{\mid x}$ und DAT-Cre zum Zeitpunkt von 14 Tagen nach der $\mathrm{NaCl}-$ Behandlung (Tab. 5). Diese Daten zeigen, dass bei keinem der Genotypen ein primäres Defizit in der Anzahl der dopaminergen Neurone vorlag.

Auch 90 Tage nach der letzten $\mathrm{NaCl}-$ Injektion war zwischen den Genotypen kein Unterschied in der Anzahl TH-positiver Neurone festzustellen (Tab. 5). Eine spontane Degeneration im Alter konnte somit bei allen 3 Genotypen ausgeschlossen werden.

Bei allen 3 Genotypen führte die MPTP-Behandlung sowohl zum Zeitpunkt von 14 Tagen als auch von 90 Tagen zu einer vergleichbaren Verminderung $\mathrm{TH}$-positiver Neurone. Der Verlust der TH-positiven Neurone zeigte die akute toxische Wirkung von MPTP auf dopaminerge Neurone in der SNpc und damit die Funktion des hier verwendeten MPTP-Mausmodells.

14 Tage nach MPTP-Injektion war in der Abnahme TH-positiver Neurone kein Unterschied zwischen den Genotypen festzustellen. Die MPTP-Behandlung zeigte keinen Unterschied in ihrer Toxizität auf die unterschiedlichen Genotypen.

Sowohl die Genotypen DAT-Cre und Ret ${ }^{\mid \mathrm{x}}$ als auch der Genotyp DAT-Ret ${ }^{|\mathrm{x}| \mathrm{x}}$ zeigten innerhalb des Zeitraums 14 Tage und 90 Tage nach MPTP-Injektion keine Zunahme in der Anzahl TH-positiver Neurone (Tab. 5). Diese Daten schlossen eine Neurogenese nach Schädigung des nigrostriatalen Systems durch MPTP aus. Mäuse des verwendeten Alters mit einem Defizit an Ret (DAT-Ret ${ }^{\mid x / x}$ ) zeigen keine höhere Anfälligkeit gegenüber MPTP als die Vergleichsgruppen Ret $^{1 \times}$ und DAT-Cre. Auf der anderen Seite sind auch Prozesse ausgeschlossen, die nach initialer MPTPToxizität zu einer sekundären, progredienten Schädigung dopaminerger Neurone führen. 


\begin{tabular}{|c|c|c|c|c|}
\hline \multirow[b]{2}{*}{ Genotyp und Behandlung } & \multicolumn{2}{|c|}{$\mathrm{TH}^{+}$-Neurone } & \multicolumn{2}{|l|}{ NissI'-Zellen } \\
\hline & 14 Tage & 90 Tage & 14 Tage & 90 Tage \\
\hline \multicolumn{5}{|l|}{ DAT-Ret ${ }^{\mid x / x}$} \\
\hline $\mathrm{NaCl}$ & $8580 \pm 460$ & $9390 \pm 448$ & $11940 \pm 1029$ & $13300 \pm 1157$ \\
\hline MPTP & $4350 \pm 266$ & $4394 \pm 1466$ & $6700 \pm 359$ & $6366 \pm 1241$ \\
\hline \multicolumn{5}{|l|}{$\operatorname{Ret}^{1 \times}$} \\
\hline $\mathrm{NaCl}$ & $9650 \pm 556$ & $8940 \pm 794$ & $13640 \pm 1021$ & $13010 \pm 1374$ \\
\hline MPTP & $4390 \pm 983$ & $5634 \pm 686$ & $7570 \pm 562$ & $8173 \pm 1208$ \\
\hline \multicolumn{5}{|l|}{ DAT-Cre } \\
\hline $\mathrm{NaCl}$ & $9130 \pm 942$ & $9220 \pm 344$ & $12720 \pm 1780$ & $12870 \pm 453$ \\
\hline MPTP & $4256 \pm 370$ & $4334 \pm 242$ & $6563 \pm 732$ & $6813 \pm 580$ \\
\hline
\end{tabular}

Tab. 5 Stereologische Zählung für TH-positive und NissI-positive Zellen in der SNpc

Die Tabelle enthält die Mittelwerte stereologisch gezählter TH-positiver Neurone und Nissl-positiver Zellen der SNpc \pm Standardabweichung. Die Abnahme der TH-positiven und Nissl-positiven Neurone nach MPTP-Behandlung ist signifikant für jeden Genotyp ( $\mathrm{P}<0,001$; ANOVA gefolgt von Tukey`s post hoc Test). Es gibt keine Unterschiede für die Faktoren Genotyp und Zeitpunkt.

\subsubsection{Die Effekte von MPTP auf die Zahl Nissl-positiver Zellen in der SNpc}

Um auszuschließen, dass die Abnahme TH-positiver Neurone auf einer reversiblen Verminderung der TH-Expression beruht, wurden zudem Nissl-Zellen angefärbt.

Die stereologische Auszählung Nissl-positiver Zellen ergab 14 Tage nach $\mathrm{NaCl}$ Injektion keinen Unterschied zwischen den 3 Genotypen (Tab. 5). Es zeigte sich hier ebenfalls, dass die 3 Genotypen kein primäres Defizit aufwiesen.

Die MPTP-Behandlung induzierte eine gleichermaßen signifikante Abnahme der Zellzahlen von Nissl-positiven Neuronen aller drei Genotypen 14 Tage nach MPTPInjektion (Tab. 5). Da die Anzahl der Nissl-positiven Zellen nach der MPTPBehandlung entsprechend den TH-positiven Neuronen signifikant abnahm, ist von einem Zelluntergang der TH-positiven Neurone auszugehen. 
90 Tage nach MPTP-Behandlung war im Vergleich zum Zeitpunkt von 14 Tagen keine Veränderung in der Anzahl Nissl-positiver Zellen festzustellen (Tab. 5). Eine Neurogenese und auch eine sekundäre Degeneration der dopaminergen Neurone konnte ausgeschlossen werden, da sich die Anzahl der Nissl-positiven Zellen bis zum Zeitpunkt von 90 Tagen nicht erholte.

\subsection{Die Effekte von MPTP auf synaptische Marker im Striatum}

3.2.1 Die Effekte von MPTP auf die optische Dichte der striatalen Fasern

Um den Effekt von MPTP auf die projizierenden Bahnen im Striatum zu detektieren, wurden diese ebenfalls mit einer TH-Färbung kenntlich gemacht. Anschließend wurde mit dem Programm Scion Image 4.0.3.2 die Faserdichte eines jeden Striatums als Maß für die Anzahl und Funktion dopaminerger Fasern im Striatum ermittelt (Abb. 8). Die mit $\mathrm{NaCl}$-behandelten Kontrollen wiesen keinen Unterschied in der $\mathrm{TH}$ positiven striatalen Faserdichte zwischen den Genotypen DAT-Cre (A), $\operatorname{Ret}^{1 \mathrm{l}}(\mathrm{B})$ und $\operatorname{DAT} \operatorname{Ret}^{\mid x / x}$ (C) zum Zeitpunkt von 14 Tagen auf. Bei allen 3 Genotypen war kein primäres Defizit nachzuweisen. Auch 90 Tage nach der $\mathrm{NaCl}$-Injektion zeigten die Genotypen keinen Unterschied in der striatalen Faserdichte (G-I).

Die MPTP-induzierte Verminderung der TH-positiven striatalen Fasern unterschied sich nicht zwischen den Genotypen DAT-Cre (D), $\operatorname{Ret}^{1 \mathrm{x}}(\mathrm{E})$ und DAT-Ret ${ }^{\mathrm{I} / \mathrm{x}}(\mathrm{F})$ zum Zeitpunkt von 14 Tagen, übereinstimmend mit der verminderten Anzahl dopaminerger Neurone in der SNpc nach MPTP-Behandlung (Tab. 5). Diese Verminderung der striatalen Fasern zeigte eine signifikante Erholung zum Zeitpunkt von 90 Tagen. Diese Erholung war in den Kontroll-Genotypen DAT-Cre $(\mathrm{J})$ und Ret ${ }^{1 \mathrm{x}}$ (K) zu verzeichnen, blieb jedoch in DAT-Ret ${ }^{|x /| x}$-Mäusen $(L)$ aus. Aus den vorliegenden Ergebnissen ist darauf zu schließen, dass die Regeneration von striatalen dopaminergen Fasern von der physiologischen Aktivierung von Ret in dopaminergen Neuronen abhängig ist. Die Erholung der striatalen Faserdichte könnte durch ein Auswachsen (Sprouting) striataler Fasern hervorgerufen worden sein. Diese Hypothese galt es nachfolgend weiter zu untersuchen. 


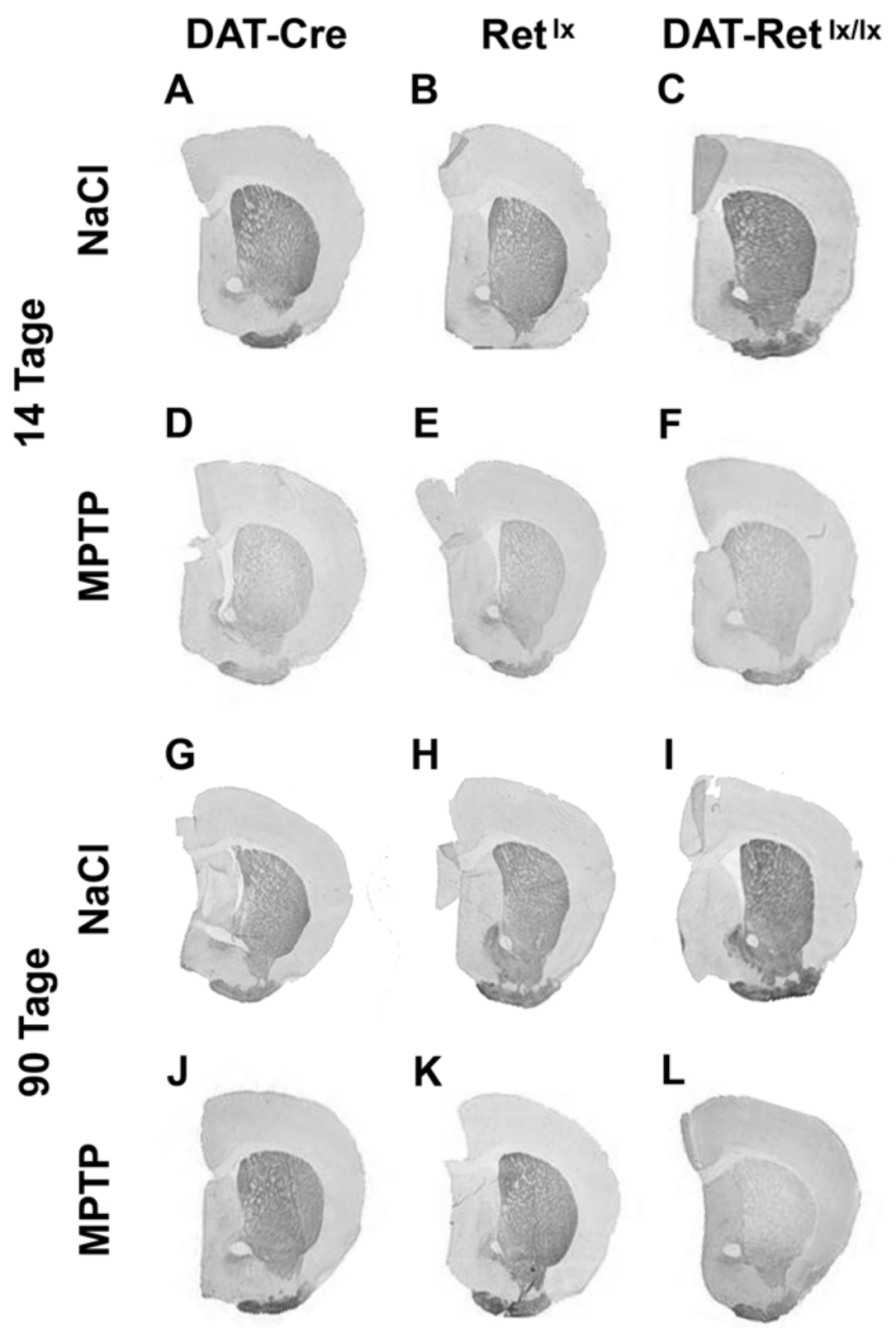

Abb. 8 TH-positive Fasern des Striatums

Färbung TH-positiver Fasern durch DAB. Gezeigt wird der MPTP-induzierte Verlust TH-positiver striataler Fasern. Bei den NaCl-behandelten Mäusen zeigte sich kein Unterschied in der Anzahl striataler TH-positiver Fasern zwischen den Genotypen DAT-Cre (A und G), $\operatorname{Ret}^{1 \mathrm{l}}$ (B und H) und DAT$\operatorname{Ret}^{|x| x}(C$ und I). Die MPTP-induzierte Verminderung TH-positiver striataler Fasern unterschied sich nicht zwischen den Genotypen DAT-Cre (D), $\operatorname{Ret}^{\mid \mathrm{lx}}(\mathrm{E})$ und DAT-Ret ${ }^{\mid \mathrm{x} / \mathrm{x}}(\mathrm{F})$ zum Zeitpunkt von 14 Tagen. Die striatalen Fasern zeigten eine Erholung zwischen 14 und 90 Tagen in DAT-Cre $(\mathrm{J})$ und $\operatorname{Ret}^{\mid x}$-Mäusen (K), jedoch nicht in DAT-Ret ${ }^{|x| x}$-Mäusen (L). 


\subsubsection{Quantifizierung fluoreszenzgefärbter striataler Fasern}

Die zuvor beschriebene Reaktion Ret-defizienter Mäuse auf MPTP spiegelt sich in der Quantifizierung fluoreszenzgefärbter Fasern im ventralen und dorsalen Striatum (Abb. 9) wider (in Kooperation mit Dr. Edgar R. Kramer). Zum Zeitpunkt von 14 Tagen nach MPTP-Injektion war in allen 3 Genotypen eine verminderte Faserdichte in beiden Abschnitten des Striatums zu beobachten. 90 Tage nach MPTP-Injektion war sowohl im ventralen als auch im dorsalen Striatum eine Erholung der DAT-Cre und $\operatorname{Ret}^{\mid \mathrm{x}}$-Mäuse festzustellen. Die reduzierte striatale Faserdichte der DAT-Ret ${ }^{|x /| x}$ Mäuse blieb hingegen unverändert. Diese Ergebnisse unterstützen die Annahme, dass die Anwesenheit von Ret für die Regeneration striataler Fasern erforderlich ist.
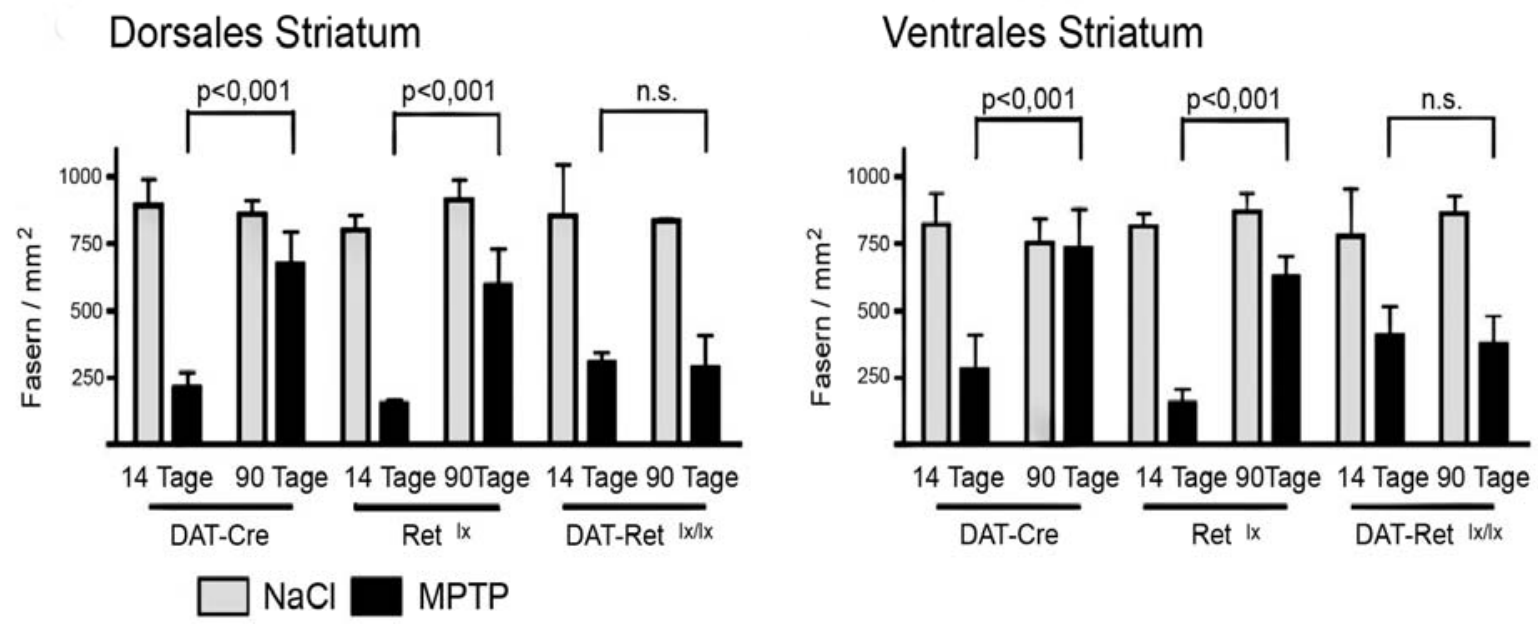

\section{Abb. 9 Striatale Faserdichte im dorsalen und ventralen Striatum}

Färbung TH-positiver Fasern durch Immunofluoreszenz in Kooperation mit Dr. Edgar R. Kramer. Die Balken der Graphen zeigen die Daten für das dorsale und ventrale Striatum. Die Daten sind Mittelwerte \pm Standardabweichung; ANOVA gefolgt von Tukey`s post hoc Test. n.s., nicht signifikant. 
3.2.3 Der Effekt von MPTP auf die striatalen Konzentrationen von Dopamin, DOPAC und HVA

Die Bestimmung striataler Katcholaminkonzentrationen mittels HPLC erlaubte weitere Aussagen über die Wirkung von MPTP auf das Striatum (Abb. 10), da diese ein Maß für die Integrität nigrostriataler Terminalen sind. Die 3 Genotypen zeigten 14 Tage nach $\mathrm{NaCl}-$ Injektion keinen Unterschied in den Konzentrationen für Dopamin und seinen Metaboliten DOPAC und HVA. Nach MPTP-Behandlung waren hingegen zu diesem Zeitpunkt die Konzentrationen der 3 Katecholamine in DAT-Cre-, Ret ${ }^{\text {Ix }}$ und DAT-Ret ${ }^{|x| \mid x}$-Mäusen deutlich erniedrigt, jedoch ohne Unterschiede zwischen den Genotypen. Die striatalen Konzentrationen von Dopamin, DOPAC und HVA der DAT-

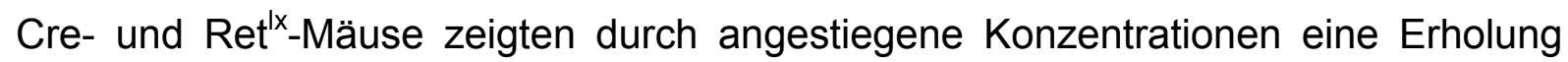
zum Zeitpunkt von 90 Tagen verglichen mit 14 Tagen. Diese Erholung blieb bei den DAT-Ret ${ }^{|x|}$-Mäusen aus. Hier zeigte sich, dass auch die Erholung des striatalen Dopamingehalts von der Anwesenheit von Ret abhängig ist. 


\section{Dopamin}

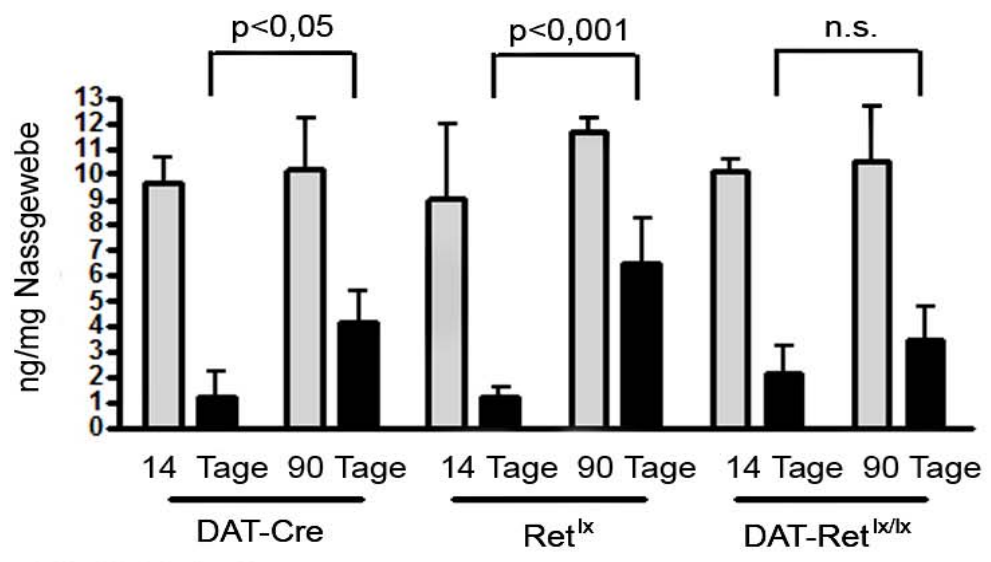

DOPAC

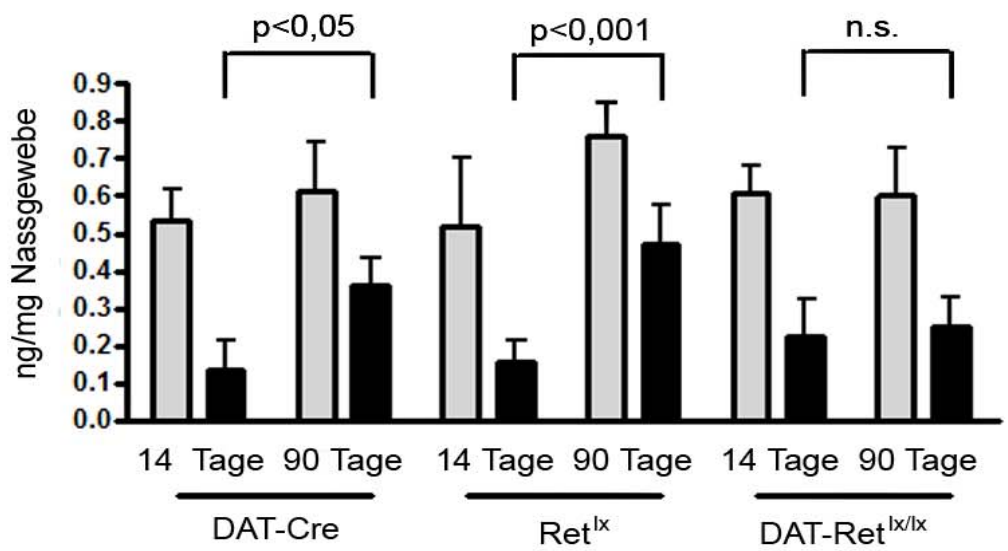

HVA

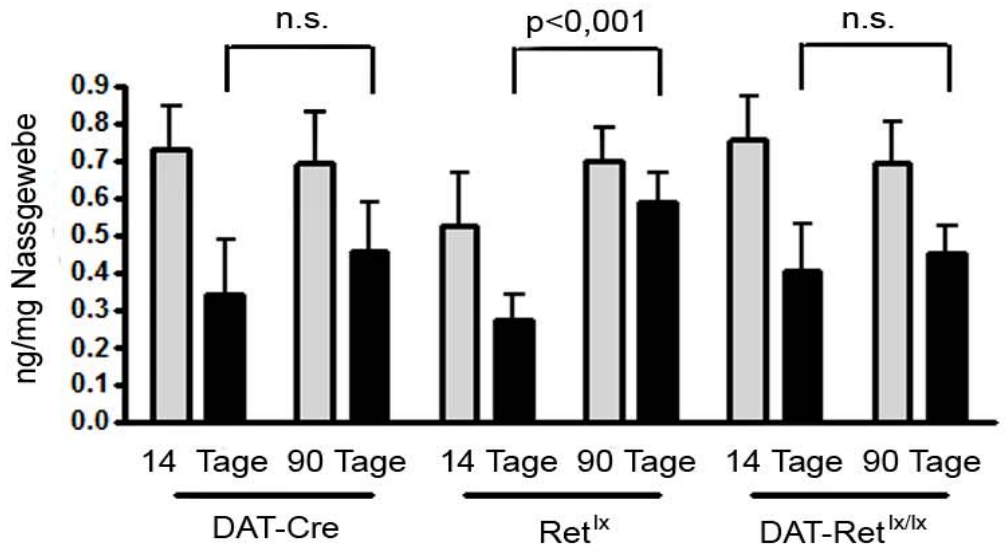

Abb. 10

Striatale Katecholaminkonzentrationen für Dopamin, DOPAC und HVA

MPTP reduziert die striatalen Katecholaminkonzentrationen von Dopamin, DOPAC und HVA. Diese regenerierten sich zwischen 14 und 90 Tagen nach MPTP in DAT-Cre- und Ret ${ }^{\mathrm{lx}}$-Mäusen, jedoch nicht in DAT-Ret ${ }^{|x| \mid x}$-Mäusen. Die Werte sind Mittelwerte \pm Standardabweichung. Für Dopamin, DOPAC und HVA gab es keine signifikanten Unterschiede zwischen den Genotypen 14 Tage nach MPTP-Behandlung. Zum Zeitpunkt von 90 Tagen waren Dopamin, DOPAC und HVA der DAT-Ret ${ }^{\mid x / x}$ Mäuse unterschiedlich zu den Ret ${ }^{1 \mathrm{x}}-$ Mäusen $(P<0,01)$, jedoch nicht zu den DAT-Cre-Mäusen. Twoway ANOVA gefolgt von Tukey`s post hoc Test. 
3.2.4 Die Effekte von MPTP auf die nigrostriatalen Fasern rostral der $\mathrm{SNpc}$

Als Ergänzung zur striatalen Faserdichte wurde die Dichte der nigrostriatalen Fasern nahe des Ursprunges 120-240 $\mu \mathrm{m}$ rostral des ersten SNpc-Neurons gemessen. Dieses Verfahren ließ eine genauere Beurteilung über den Verlust und die Regeneration striataler Fasern zu. Hierbei wurden die Anzahl und die Fläche der nigrostriatalen TH-positiven Fasern quantifiziert (Abb. 11). Für die mit $\mathrm{NaCl}$ behandelten Mäuse ergab sich weder zum Zeitpunkt von 14 Tagen, noch zum Zeitpunkt von 90 Tagen ein Unterschied in der Anzahl der nigrostriatalen Fasern oder in der von nigrostriatalen Fasern abgedeckten Fläche in $\mathrm{mm}^{2}$ zwischen den verschiedenen Genotypen.

Die Anzahl der TH-positiven Fasern und die von den nigrostriatalen Fasern abgedeckte Fläche eines jeden Genotyps erfuhr eine wesentliche Reduktion 14 Tage nach MPTP-Behandlung. Dieser Verlust nigrostriataler Fasern erlangte zum Zeitpunkt von 90 Tagen keine Erholung, weder in DAT-Cre- und Ret ${ }^{1 \mathrm{x}}$-Mäusen noch in DAT-Ret ${ }^{|x| \mid}$-Mäusen.

Daraus ist zu schließen, dass die Erholung der striatalen Fasern nicht auf dem Auswachsen neuer Axone von der SNpc beruht, sondern vielmehr auf der Aussprossung aus axonalen Terminalen erst im Striatum (Sprouting). 


\section{Nigrostriatale Fasern}
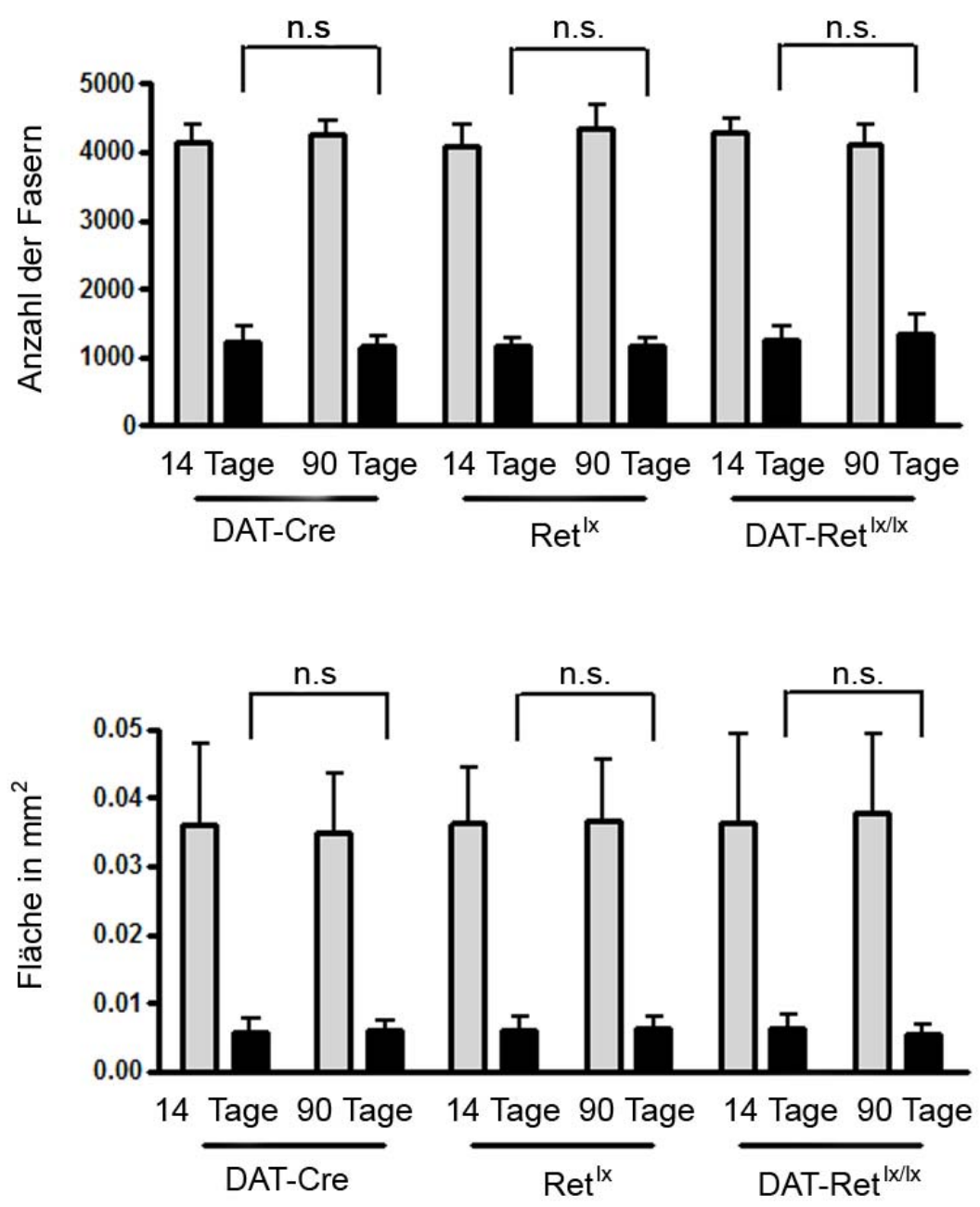

$\mathrm{NaCl}$

MPTP

\section{Abb. 11 Anzahl und Fläche nigrostriataler Fasern rostral der SNpc}

Quantifizierung nigrostriataler Fasern nahe ihres Ursprunges rostral der SNpc. Die Anzahl der THpositiven Fasern und die von den Fasern abgedeckte gesamte Fläche in $\mathrm{mm}^{2}$ wurde 120-240 $\mu \mathrm{m}$ rostral des ersten SNpc-Neurons gemessen. Die Anzahl TH-positiver Fasern und die von den Fasern abgedeckte Fläche zeigten sich 14 Tage nach MPTP-Behandlung erniedrigt und regenerierten sich nach 90 Tagen nicht. Für die Parameter und beide Zeitpunkte gab es keinen Unterschied zwischen den Genotypen. Die Daten zeigen, dass kein Auswachsen neuer Axone sondern ein Sprouting im terminalen Feld des nigrostriatalen Systems besteht. 


\subsection{MPTP-Metabolismus der 3 Genotypen}

Um mögliche Differenzen im Metabolismus von MPTP zu MPP ${ }^{+}$unter den drei Genotypen auszuschließen, werden hier die Ergebnisse von Sebastian Kowsky herangezogen (Kowsky 2010; Kowsky et al. 2007). Die MPP ${ }^{+}-K o n z e n t r a t i o n e n$ wurden mittels HPLC ermittelt und in ng MPP ${ }^{+}$pro mg Nassgewebe ausgedrückt.

Die ermittelten MPP ${ }^{+}-K o n z e n t r a t i o n e n ~ v o n \operatorname{Ret}^{1 x}(n=3 ; 544,6 \pm 53,8)$, DAT-Cre $(n=$ 4; $504 \pm 50.5)$ und DAT-Ret ${ }^{|x| \mid x}(n=3 ; 501 \pm 14.2)$ zeigten keine Unterschiede, so dass Unterschiede im MPTP-Metabolismus nicht die Ursache für die in dieser Arbeit gezeigten unterschiedlichen Ergebnisse der Genotypen darstellten. Mäuse mit einem Mangel an Ret zeigen einen normalen MPTP-Metabolismus. 


\section{Diskussion}

In dieser Arbeit wurde untersucht, wie Mäuse ohne Ret-Rezeptor (DAT-Ret ${ }^{\mid x / x}$ ) auf das Neurotoxin MPTP im chronischen Stadium reagieren. Im Vergleich zu den Kontrollen Ret ${ }^{\mid x}$ und DAT-Cre zeigten DAT-Ret ${ }^{|x /| x}$-Mäuse 90 Tage nach MPTP eine geringere striatale Faserdichte und geringere striatale Katecholaminkonzentrationen von Dopamin, DOPAC und HVA. Dies kann entweder durch eine vermehrte Toxizität von MPTP gegenüber Ret-defizienten Mäusen oder durch deren verminderte Regenerationsfähigkeit erklärt werden. Um zwischen diesen beiden Interpretationen zu unterscheiden, werden Befunde herangezogen, die direkt (14 Tage) nach MPTPGabe erhoben wurden (Kowsky 2010; Kowsky et al. 2007).

\subsection{DAT-Ret ${ }^{\mid \mathrm{x} / \mathrm{x}}$-Mäuse zeigen kein primäres Defizit bzw. keine Entwicklungsstörung}

14 Tage und 90 Tage nach der letzten $\mathrm{NaCl}$-Injektion zeigte sich zwischen den Genotypen kein Unterschied, sowohl in der Anzahl TH-positiver Neurone als auch in der striatalen Faserdichte und in den Konzentrationen der striatalen Marker. Somit konnte ein primäres Defizit der Genotypen und eine spontane Degeneration im Alter ausgeschlossen werden.

In einer Studie von Kramer et al. wurde gezeigt, dass die Eliminierung des RetRezeptors erst ab einem Zeitpunkt von 12 Monaten zu einem dopaminergen Verlust von Neuronen in der SN und einem striatalen dopaminergen Faserverlust führt und mit zunehmendem Alter fortschreitet (Kramer et al. 2007).

Zudem wurde in einer weiteren Studie mit Ret-defizienten Mäusen gezeigt, dass es bis zu einem Alter von 12 Monaten, verglichen mit der Kontrollgruppe, zu keiner Neurodegeneration kam (Jain et al. 2006). Zusammenfassend gesehen beeinflusst eine Eliminierung von Ret die Entwicklung des nigrostriatalen dopaminergen Systems nicht und Ret vermittelte Signale sind für die langfristige Aufrechterhaltung des nigrostriatalen Systems während des Alterns erforderlich (Jain et al. 2006; Kramer et al. 2007). 
Um diese degenerativen Prozesse bei Ret-defizienten Mäusen höheren Alters zu vermeiden, wurden in dieser Arbeit Mäuse mit einem Alter von 12-16 Wochen verwendet.

\subsection{Keine Neurogenese nach MPTP-Gabe}

Die Anzahl dopaminerger Neurone in der SNpc war 90 Tage nach MPTP-Injektion unverändert im Vergleich zu 14 Tagen nach MPTP-Injektion (Tab. 5). Es gibt daher keinen Hinweis auf eine fortschreitende Degeneration dopaminerger Neurone nach MPTP-Gabe in dem hier verwendeten Paradigma. Ebenso fand sich kein Hinweis auf eine Neubildung dopaminerger Neurone nach MPTP-Gabe.

Eine Neurogenese in der SNpc nach initialem Verlust dopaminerger Neuronen wurde häufig diskutiert. Zunächst zeigten Zhao et al. nach MPTP-induzierter Läsion der SNpc von Mäusen einen Anstieg in der Bildung neuer dopaminerger Neurone in der SNpc und zeigten, dass dopaminerge Projektionsneurone in der erwachsenen SNpc kontinuierlich von Stammzellen ausgehend gebildet werden. Auf diesem Wege kann die gesamte Anzahl der dopaminergen Neurone der SNpc im Laufe des Lebens ersetzt werden (Zhao et al. 2003).

Andere Studien, sowohl mit selektiver Schädigung der dopaminergen Neurone von Mäusen durch MPTP (Kay und Blum 2000) als auch von Ratten durch 6-OHDA (Lie et al. 2002), zeigten keine Neurogenese in der SN. Diese unterschiedlichen Ergebnisse können an unterschiedlichen Techniken und experimentellen Paradigmen im Gegensatz zu Zhao et al. (2003) gelegen haben.

Unterschiede in Hinsicht auf die Wahl der Nagetiere, die Art und Weise der Verabreichung des Proliferationsmarkers 5-Bromo-2'-Deoxyuridin und die Wahl des toxischen Metaboliten zur Schädigung der dopaminergen Neurone sind unter anderen Faktoren, welche die Diskrepanzen zwischen den verschiedenen Studien erkären könnten. Die Arbeit von Zhao et al. (2003) wurde durch Frielingsdorf et al. (2004) widerlegt. Es wurde so genau wie möglich den methodischen Vorgängen von Zhao et al. (2003) mit einer Erhöhung der Tierzahlen und einer Ergänzung der Mäuse durch Ratten gefolgt. Nach einer Schädigung des nigrostriatalen Systems, ebenfalls mit 6-OHDA und auch nach Behandlung mit dem Wachstumsfaktor Brainderived neurotrophic factor (BDNF), konnte keine Neuentstehung dopaminerger 
Neurone bei Nagetieren nachgewiesen werden (Frielingsdorf et al. 2004). Ein nachgewiesener Anstieg von dopaminergen Interneuronen im Striatum nach MPTPIntoxikation erfolgte durch eine phänotypische Umwandlung und nicht durch Neurogenese. Zudem konnte dieser Anstieg nur in Primaten und nicht in Nagetieren gezeigt werden (Tande et al. 2006).

In dieser Arbeit zeigt die stereologische Auswertung sowohl TH-positiver als auch Nissl-positiver Zellen zum Zeitpunkt 14 und 90 Tage, dass es nach der Läsion der SNpc durch MPTP zu keiner Neuentstehung dopaminerger Neurone kommt. Demnach stimmt diese Arbeit mit einer grossen Anzahl anderer Arbeiten überein, keinen Hinweis für eine relevante Neurogenese zu sehen.

\subsection{GDNF und der zugehörige Rezeptor Ret vermitteln keine Protektion gegen MPTP}

Ret-defiziente Mäuse zeigten 14 Tage nach MPTP-Gabe einen Verlust dopaminerger Neurone in der SNpc (Tab. 5), eine Abnahme der striatalen Faserdichte (Abb. 8) und eine Erniedrigung der striatalen Konzentrationen von Dopamin, DOPAC und HVA (Abb. 10). Diese Ergebnisse fanden sich in gleichem Ausmaß in den Genotypen für Ret $^{1 \mathrm{x}}$, DAT-Cre und DAT-Ret ${ }^{\mid \mathrm{x} / \mathrm{x}}$ (Kowsky et al. 2007). Da es bei Ret-Defizienz zu keiner vermehrten Toxizität kommt, vermittelt Ret keine Protektion gegen MPTP.

\subsection{Sprouting nach MPTP-Gabe}

14 Tage nach MPTP-Gabe waren die TH-positiven striatalen Fasern und die striatalen Katecholaminkonzentrationen bei den Wildtypen $\operatorname{Ret}^{\mathrm{lx}}$ und DAT-Cre vermindert (Kowsky et al. 2007). 90 Tage nach MPTP zeigten die Wildtypen eine Erholung in der striatalen Faserdichte und einen Anstieg der striatalen Marker Dopamin, DOPAC und HVA (Abb. 8 und 10).

Die erhöhte striatale Faserdichte beruht auf dem Auswachsen von Axonkollateralen aus den überlebenden dopaminergen Axonen. Dies wird als Sprouting bezeichnet.

Im Gegensatz zu dopaminergen Markern im Striatum fand sich keine Erhöhung der Faserdichte oder der von den Fasern abgedeckten Fläche direkt rostral der SNpc 
zwischen 14 und 90 Tagen nach MPTP-Injektion (Abb. 11). Sprouting beruht daher auf dem Auswachsen von Axonkollateralen im Striatum und nicht auf der Ausbildung neuer nigrostriataler Axone.

Sprouting nach MPTP-Gabe wurde vielfach untersucht und beobachtet. Nach MPTPIntoxikation wurde in Affen eine Erholung der motorischen Defizite und eine Anstieg des striatalen Dopaminlevels mit kompensatorischem Sprouting dopaminerger Terminalen gezeigt (Gnanalingham et al. 1995; Iravani et al. 2005; Petzinger et al. 2006). In Mäusen konnte ebenfalls spontanes Sprouting nach MPTP-Gabe nachgewiesen werden (Bezard et al. 2000).

\subsection{Ret-Rezeptor, GDNF und Sprouting}

Während die Wildtypen eine deutliche Erholung striataler Marker von 14 Tagen auf 90 Tagen nach MPTP-Injektion zeigten, blieben sie in den Ret-defizienten Tieren unverändert (Abb. 8 und 10). Der Ret-Rezeptor ist demnach für Sprouting notwendig. Da GDNF ein wichtiger Ligand für den Ret-Rezeptor ist und Effekte von GDNF auf Sprouting in der Literatur mehrfach beschrieben sind, liegt es nahe anzunehmen, dass endogenes GDNF über den Ret-Rezeptor das Auswachsen nigrostriataler Bahnen induziert. Prinzipiell könnte jedoch auch ein anderer endogener RetRezeptor-Ligand für die Induktion von Sprouting verantwortlich sein (Airaksinen und Saarma 2002).

Vielfach wurde gezeigt, dass GDNF Sprouting induzieren kann, der richtige Zeitpunkt der GNDF-Applikation ist weiter fraglich. Für klinische Studien hat die Entscheidung für den Zeitpunkt der GNDF-Applikation jedoch eine große therapeutische Tragweite.

Ratten zeigten nach einer Läsion durch intrastriatale 6-OHDA-Injektion eine Besserung der motorischen Funktionen, als diese 2 Wochen nach Schädigung intrastriatal und intraventriuklär für 4 Wochen mit GDNF-Infusionen behandelt wurden. Dennoch zeigten diese Ratten keine Zeichen von Sprouting und keinen Anstieg der TH-positiven Faserdichte im Striatum (Kirik et al. 2001). Als mögliche Ursache für das fehlende Sprouting gaben Kirik et al. (2001) die späte Gabe von GDNF 14 Tage nach Läsion an, da das volle Ausmaß der Faserdegeneration bereits in der ersten Woche nach toxischer Schädigung mit 6-OHDA stattfinden soll (Rosenblad et al. 2000). Hier wird angenommen, dass bei GDNF-Applikation in das 
Striatum noch ausreichend viele axonale Projektionsbahnen verfügbar sein müssen und GDNF demnach seine Wirkung nur unmittelbar nach einer Läsion zeigt. Durch Gabe des neurotrophen Faktors einen Tag nach Schädigung mit 6-OHDA stimuliert GDNF hingegen axonales Wachstum (Rosenblad et al. 1999).

Entgegen des Arguments von Kirik et al. (2001) zeigten Rosenblad et al. trotz später intrastriataler Applikation von GDNF nach 4 Wochen ein prominentes axonales Sprouting mit einer Verbesserung der motorischen Funktionen bei GDNFbehandelten Tieren (Rosenblad et al. 1998). Eine mögliche Ursache für diese Diskrepanzen kann eine unterschiedliche GDNF-Dosis und die abweichende dosierte Intoxikation mit 6-OHDA gewesen sein.

Die aufgeführten Studien sind vereinbar mit der Annahme, dass die GDNF-Gabe nach einer Schädigung des nigrostriatalen Systems mit 6-OHDA axonales Sprouting induziert, da auch Studien ohne histologischen Nachweis von Sprouting eine Verbesserung des motorischen Verhaltens gezeigt haben.

Auch bei MPTP-geschädigten Affen, die mit GDNF infundiert wurden, konnte sowohl eine Verbesserung der motorischen Defizite als auch ein Anstieg der TH-positiven Fasern im geschädigten Striatum beobachtet werden (Gash et al. 1996; Grondin et al. 2002; Kordower et al. 2000). Eine GDNF-Gabe nach MPTP-Schädigung erzielte auch in Mäusen einen regenerativen Effekt, jedoch nur bei intrastriataler Applikation (Tomac et al. 1995). Exogen zugeführtes GDNF scheint seinen Effekt nur in der Nähe der striatalen Terminalen zu entfalten.

Um neben der regenerativen Wirkung von GDNF auch eine protektive Wirkung zu untersuchen, wurde in einer weiteren Studie von Kirik et al. 6 Stunden vor intrastriataler Schädigung durch 6-OHDA ein Einzelbolus GDNF sowohl intrastriatal, nigral als auch intraventrikulär bei Ratten injiziert. Hiermit konnte bei intrastriataler Verabreichung neben einer Protektion dopaminerger Neurone, eine Protektion der axonalen Terminalen im Striatum und eine bessere motorische Funktion erreicht werden (Kirik et al. 2000a). Der Einzelbolus GDNF induzierte ein ausgedehntes Sprouting TH-positiver Fasern im Globus pallidus und Striatum. Intranigrale Applikation konnte dopaminerge Zellen schützen, jedoch nicht die axonalen Terminalen. Eine bessere motorische Funktion blieb aus und Sprouting blieb nahe der SN lokalisiert. Intraventrikuläre Injektionen zeigten keinen Effekt.

Eine weitere Studie kann möglicherweise durch die Induktion von Sprouting erklärt werden. Kordower et al. (2000) behandelten die Tiere mit MPTP, bevor das durch 
lentiviralen Gentransfer freizusetztende GDNF 1 Woche später in das Striatum und die SN injiziert wurde. Danach zeigten die Tiere eine Regeneration dopaminerger Marker und eine Verminderung klinischer Defizite. Hierbei ist anzunehmen, dass es sich um eine GDNF-vermittelte Regeneration im Sinne von Sprouting handeln kann (Kordower et al. 2000).

Viele Studien deuten demnach darauf hin, dass neben dem Applikationszeitpunkt auch der Applikationsort des neurotrophen Faktors GDNF eine große Rolle spielt. Intrastriatale Injektionen bewirken ein Auswachsen axonaler Bahnen im Striatum mit verbesserter motorischer Funktion, während bei intranigraler Applikation lediglich ein Sprouting nahe der SN ohne Verbesserung der motorischen Fähigkeiten erreicht wurde. Auch zeigt sich anhand dieser Studien, dass die Gabe von GDNF vor oder nach toxischer Läsion, der Zeitpunkt der GDNF-Applikation, die Menge und der Zeitraum über den GDNF gegeben wird zum experimentellen Verlauf beitragen.

Die aufgeführten Studien zeigen, dass bei Schädigung des nigrostriatalen Systems sowohl mit 6-OHDA als auch mit MPTP durch Gabe von GDNF axonales Sprouting nachgewiesen werden kann. Demnach sind die Studien mit den hier präsentierten Ergebnissen bezüglich des Sproutings vereinbar.

Über diese Studien hinaus wurde hier gezeigt, dass es der Ret-Rezeptor ist, der die Wirkung von GDNF vermittelt. In dieser Arbeit wurde kein GDNF verabreicht. Die vom Ret-Rezeptor vermittelte Wirkung auf Sprouting ist demnach durch endogenes GDNF ausgelöst worden. Man kann spekulieren, ob es auch in Patienten durch Degeneration dopaminerger Neurone zu einer Ausschüttung von GDNF kommt, bzw. ob ein im Patienten ausbleibendes Sprouting auf fehlender GDNF-Ausschüttung beruht oder auf fehlendem Ret-Rezeptor. Dies ist wichtig, um die Möglichkeiten einer Therapie durch GDNF-Gabe einzuschätzen und gegebenenfalls zu optimieren.

\subsection{Die Wahl des Parkinsonmodells}

Die hier präsentierten Ergebnisse sind gültig für das MPTP-Mausmodell, können aber in anderen Parkinsonmodellen abweichen. Die Unterschiede zwischen den Modellen sind ein wichtiger Grund, weshalb sich die Ergebnisse in der Literatur widersprechen. Die Wahl des Toxins, die zugeführte Dosis, der 
Verabreichungsrhythmus und -zeitraum sowie die Wahl der Spezies mit unterschiedlichem genetischem Hintergrund beeinflussen die Ergebnisse und führen zu Diskrepanzen zwischen Studien. Ein Beispiel ist der Vergleich des MPTP-Modells mit dem 6-OHDA-Modell. 6-OHDA erzielt im Gegensatz zu MPTP seine Wirkung primär durch die Erzeugung von ROS. Sowohl MPTP als auch 6-OHDA werden durch den DAT in die dopaminergen Neurone aufgenommen und schädigen diese selektiv. Beide Toxine wirken jedoch über unterschiedliche Mechanismen, so dass erzielte protektive oder regenerative Effekte in einem Modell nicht automatisch auf das andere Modell anwendbar und damit reproduzierbar sind. Durch die Übereinstimmung des Modells und des methodischen Aufbaus der hier diskutierten Arbeit zum Zeitpunkt von 90 Tagen und der Arbeit von Sebastian Kowsky zum Zeitpunkt von 14 Tagen (Kowsky 2010; Kowsky et al. 2007), können durch einen zuverlässigen Vergleich einige Diskrepanzen in der wissenschaftlichen Ansicht von GDNF im MPTP-Mausmodell geklärt werden und zuverlässigere Aussagen getroffen werden.

\subsection{Tierexperimentelle Parkinsonmodelle - Parkinsonerkrankung}

Der Vergleich von Studien mit unterschiedlichen Parkinsonmodellen zeigt, dass Parkinsonmodelle nicht zu einheitlichen Ergebnissen führen. Auch wenn diese Ergebnisse zuverlässigere Übereinstimmungen zeigten, wäre unklar, ob sich dieses Ergebnis in Menschen realisieren ließe. Trotz der vielen Bemühungen das IPS in Tieren so realistisch wie möglich darzustellen, ist der Schritt vom Modell zur Anwendung am Patienten ein großer und ungewisser Schritt. Zunächst sind Mensch und Tier eine andere Spezies. Die Neurodegeneration im IPS entwickelt sich über Jahrzehnte mit mitochondrialer Dysfunktion, Inflammation, oxidativem Stress und Ausbildung von Proteinaggregaten. Hingegen zeigt sich die Neurodegeneration in Tiermodellen bereits nach Tagen mit Zelltod und oxidativem Stress wie z.B. im MPTP-Mausmodell. Ein an IPS erkrankter Patient ist in der Regel bei Erstdiagnose zwischen 50 und 60 Jahre alt. Die verwendeten Tiere sind jedoch sehr jung. Auch zeigen die bisher etablierten Parkinsonmodelle nicht alle pathologischen Kennzeichen des IPS. Das MPTP-Modell und das 6-OHDA-Modell zeigen zwar oxidativen Stress und Zelltod in der SNpc, allerdings in der Regel keine Proteinaggregate. Bei Überexpression von im Menschen Parkinson verursachenden 
Proteinen zeigen sich dagegen in der Regel Proteinaggregate, jedoch meist kein Zelltod.

Trotz dieser gravierenden Unterschiede sind bisher durch die tierexperimentelle Forschung viele Fragen klarer geworden. Um die klinische Forschung dieser Erkrankung voranzutreiben, wäre ein zeitechtes Modell des IPS zu langsam. Auch wäre die Anwendung beim Menschen ohne vorherige Tierexperimente ein großes ethisches Problem. Zudem ist die Sicherheit in der Durchführung am Patienten größer, wenn zuvor unter anderem die Applikationsmöglichkeiten, die Diffusion von GDNF in gehirnrelevante Areale und das Verletzungsrisiko getestet wurden.

Besonders die Frage nach der Verbesserung für den Patienten durch axonales Sprouting als auch die Tatsache, dass das Hervorrufen von Kardinalsymptomen des IPS durch MPTP lediglich ein unvollständiges Modell darstellt, zeigt, dass neben Tiermodellen auch klinische Studien von großer Bedeutung sind. Diese klinischen Studien sollten für die Erzielung von signifikanten Ergebnissen einen einheitlichen methodischen und zeitlichen Ablauf beinhalten. Die bisher durchgeführten klinischen Studien variierten in diesem Ablauf und erzielten somit unterschiedliche und schwer vergleichbare Ergebnisse.

\subsection{Klinische Studien mit GDNF}

In dieser Arbeit wurde die endogene und damit physiologische Wirkung von GDNF untersucht und steht damit im Gegensatz zu Studien mit exogener Wirkung von GDNF.

Ein 65 Jahre alter IPS-Patient erhielt monatlich eine intrazerebroventrikuläre Injektion von GDNF. Sein Zustand verschlechterte sich mit vielen Nebenwirkungen bei fortführender GDNF-Therapie. Es gab keinen signifikanten Nachweis für die Regeneration nigrostriataler Neurone oder die intraparenchymale Diffusion von GDNF in relevante Gehirnanteile (Kordower et al. 1999; Nutt et al. 2003).

Die Verteilung von GDNF in das Gehirngewebe aus dem Blut oder aus der Zerebrospinalflüssigkeit ist aufgrund der schlechten Passage durch die Blut-HirnSchranke begrenzt (Pardridge 2002). Studien in Nagetieren und Primaten haben jedoch gezeigt, dass die direkte Infusion in das Putamen vielversprechend ist. In 
folgenden Studien wurde daher die Applikation mit speziellen Kathetern direkt in das Putamen gewählt.

Gill et al. (2003) führten rekombinantes humanes GDNF in variierenden Dosen über einen Katheter bilateral direkt in das Putamen von 5 IPS-Patienten. Es zeigte sich eine Verbesserung der motorischen Untersuchungen des UPDRS von 39\% sowie eine Verbesserung der Aktivitäten des täglichen Lebens von 61\%. Medikamenteninduzierte Dyskinesien konnten um 64\% reduziert werden. In einer PETUntersuchung zeigte sich eine signifikante Erhöhung des Dopamingehaltes im Putamen um $28 \%$. Die UPDRS-Werte verbesserten sich in der Nachuntersuchung weiterhin (Gill et al. 2003; Patel et al. 2005). In einer weiteren klinischen Studie von Slevin et al. (2005) erfolgte eine unilaterale Infusion von GDNF bei 10 IPS-Patienten über einen größeren Katheter mit mehreren Anschlüssen als bei Gill et al. (2003). Die Infusionen wurden in steigender Dosis bis 6 Monate verabreicht, gefolgt von einer 1-monatigen Auswaschungsphase. Die Patienten zeigten zum Zeitpunkt von 6 Monaten und in der Auswaschungsphase eine beidseitige Verbesserung der motorischen Untersuchungen des UPDRS mit 30\% und 30\% zeigten eine Verbesserung der Dyskinesien (Slevin et al. 2005).

Eine randomisierte Doppelblindstudie von Lang et al. mit bilateraler Katheter-Infusion von rekombinantem humanem GDNF oder Placebo in das Putamen bei 34 IPSPatienten ergab keine signifikante Verbesserung in den motorischen Anteilen des UPDRS der GDNF-infundierten Patienten gegenüber dem Placebo (Lang et al. 2006).

Es gibt viele Fragen, die geklärt werden müssen, bevor eine Therapie mit GDNF für Patienten mit IPS in der Zukunft einen effektiven und sicheren Nutzen hat.

Jede dieser hier aufgeführten Studien benutzte unterschiedliche GDNFInfusionssysteme und eine unterschiedliche Dosis sowie Applikationsrhythmen von GDNF. Auch innerhalb einer Studie variierte die Dosis unter den Patienten (Gill et al. 2003). Weder der Applikationsort mit uni- und bilateral war übereinstimmend noch die Länge der Studien oder die Nachbeobachtungszeit.

Ein weiterer großer Unterschied war die Verwendung eines Placebos bei Lang et al. (2006). Zuvor durchgeführte Studien zeigten, dass IPS-Patienten besonders sensibel für Placebo-Effekte sind (Goetz et al. 2003), welches eine Differenzierung der klinischen Verbesserung (UPDRS) schwierig macht. Zudem entwickelten 10\% der Patienten der Doppelblindstudie neutralisierende Antikörper gegen GDNF 
(Tatarewicz et al. 2007). Einen ähnliche Entwicklung zeigte sich bei Lang et al. (2006) und Slevin et al. (2005). Welche Wirkung diese Antikörper haben ist unklar. Die Antikörper können keinen beeinträchtigenden Effekt haben, die Pharmakokinetik von zugeführtem GDNF beeinflussen oder auch endogenes GDNF neutralisieren (Sherer et al. 2006).

Es stellt sich die Frage, woran die Umsetzung des Sproutingkonzepts und die Verbesserung der Motorik in klinischen Modellen scheitern. Wie zuvor beschrieben zeigen Tiermodelle und Parkinsonpatienten viele Unterschiede, so dass hier eine Ursache für das Scheitern der Umsetzung von Tier auf Patient liegen kann. Zudem ist es unklar, welche Dosis ein Parkinsonpatient benötigen würde, um eine Diffusion in die relevanten Gehirnareale zu erreichen und damit einen Effekt der GDNFApplikation zu verspüren.

Auch ist es schwierig bei der Erprobung von GDNF-Infusionen bei Patienten das Sprouting zu messen, da das Striatum und damit die Faserdichte nicht immunhistologisch untersucht werden können.

Somit ist es unklar, ob es in den untersuchten Patienten zu einem Sprouting gekommen ist und sich dieses jedoch nicht klinisch gezeigt hat. Es stellt sich die Frage, ob die verbesserte motorische Funktion in einigen Studien überhaupt eine Folge von stattgefundenem Sprouting ist. Eine mögliche Ursache für fehlendes Sprouting könnte nach der Erhöhung des GDNF-Spiegels auch eine Herunterregulation des Ret-Rezeptors sein. Eine andere Ursache wäre, dass in IPSPatienten durch die alleinige Gabe von GDNF kein Sprouting auszulösen ist. In diesem Fall wäre das Hochregulieren des Ret-Rezeptors eine Therapiestrategie, um die Funktion von GDNF zu vermitteln.

\subsection{GDNF als zukünftiger Therapieansatz}

In der aktuellen Therapie des IPS existieren bislang lediglich symptomatische Ansätze. Ein großer Erfolg basiert unter anderem auf der Strategie, erniedrigte Dopaminkonzentrationen mit L-DOPA wieder anzuheben. Diese Therapie ist initial höchst wirksam, im Langzeitverlauf jedoch mit motorischen Fluktuationen, Dyskinesien und L-DOPA-induzierten Psychosen verbunden (Lang und Lozano 1998a). 
Für die Entwicklung einer kausalen Therapie des IPS sind zwei verschiedene Ansätze von Bedeutung: Zum einen wird der Ansatz verfolgt, die Degeneration von Neuronen zu hemmen und das Fortschreiten des IPS somit aufzuhalten. Zum anderen wird dem Ansatz nachgegangen, die Regeneration von Neuronen oder striataler Projektionen zu fördern und damit ein fortgeschrittenes Krankheitsstadium zu verbessern.

Die Hemmung der Degeneration dopaminerger Neurone und somit eine Protektion durch den Ret-Rezeptor konnte mit der vorliegenden Arbeit nicht gezeigt werden. Somit unterstützt diese Arbeit die mit demselben MPTP-Paradigma durchgeführte Studie von Eberhardt et al. (Eberhardt et al. 2000). Zudem wurden in dieser Arbeit eine Regeneration von Neuronen und eine Neurogenese ausgeschlossen, was den Ansatz von Frielingsdorf et al. unterstützt (Frielingsdorf et al. 2004).

Hingegen konnte ein neuroregenerativer Effekt von GDNF durch axonales Sprouting nachgewiesen werden. Dies gibt Hoffnung, in Patienten durch Aussprossung der striatalen Projektionen neben einer symptomatischen auch eine kausale Verbesserung eines Krankheitsstadiums des IPS zu erreichen. Hier stellt sich jedoch die Frage, inwiefern das Aussprossen von striatalen Projektionsbahnen bei einer fortbestehenden Degeneration von Neuronen eine langfristige oder relevante Verbesserung für den Patienten darstellen würde. Kann dieser Mechanismus irgendwann erschöpft sein und stellen sich dann nach einer Zeitverzögerung dieselben einschränkenden Symptome der Erkrankung ein?

Axonregeneration kann hingegen in anderen Erkrankungen wie traumatischen Läsionen, inflammatorischen Erkrankungen oder ischämischen Insulten nachhaltig zur Therapie beitragen, wenn die ursprünglichen Nervenzellen intakt sind. 


\section{$5 \quad$ Zusammenfassung}

Das idiopathische Parkinsonsyndrom (IPS) ist charakterisiert durch den fortschreitenden Verlust dopaminerger Neurone in der Substantia nigra pars compacta (SNpc). Die gegenwärtigen Therapien für diese Erkrankung mildern die Symptome; die Degeneration der Neurone aufzuhalten oder die Regeneration betroffener Strukturen zu fördern, ist bislang ohne Erfolg geblieben.

Die Aktivierung des Ret- (Rearranged during transfection) Rezeptors durch den Glial cell line-derived neurotrophic factor (GDNF) wurde als wichtiger Differenzierungsund Überlebensfaktor für dopaminerge Neurone des Mittelhirns in vorklinischen Experimenten identifiziert. Diese positiven Ergebnisse führten zu klinischen Versuchen mit GDNF, welche in widersprüchlichen Resultaten endeten.

Um die Wirkung von physiologischem GDNF über den Ret-Signalweg für das IPS weiter zu untersuchen, wurden Mäuse mit einer selektiven Ret-Defizienz in dopaminergen Neuronen verwendet.

Die Toxizität von 1-Methyl-4-Phenyl-1,2,3,6-Tetrahydropyridin (MPTP) ist das beste charakterisierte Tiermodell des IPS. Daher wurden Ret-defiziente Mäuse und Kontrollen an 5 aufeinanderfolgenden Tagen gewichtsadaptiert mit $30 \mathrm{mg} / \mathrm{kg} \mathrm{KG}$ MPTP oder 0,9\% Natriumchlorid ( $\mathrm{NaCl}$ ) injiziert. Um den langfristigen Einfluss des GDNF-vermittelten Signalweges über den Ret-Rezeptor im MPTP-Mausmodell auf die Regeneration des nigrostriatalen Systems zu untersuchen, wurden die Gehirne nach 90 Tagen histologisch aufgearbeitet und ausgewertet. Diese Ergebnisse wurden mit den akuten Veränderungen 14 Tage nach MPTP-Gabe beleuchtet.

Die Auswertung enthielt die stereologische Bestimmung der Anzahl Tyrosinhydroxylase-positiver Neurone und Nissl-positiver Zellen in der SNpc, die Messung der Katecholaminkonzentrationen im Striatum, sowie die Ermittlung der striatalen Faserdichte und der nigrostriatalen Fasern rostral der SNpc.

Die Zellzahlen in der SNpc aller mit $\mathrm{NaCl}$ behandelten Tiere zum Zeitpunkt von 14 und 90 Tagen zeigten, dass Ret-defiziente Mäuse kein primäres Defizit und keine spontane Degeneration aufwiesen. Die MPTP-Gabe führte bei allen drei Genotypen zum Zeitpunkt von 14 Tagen zu einer Verminderung der dopaminergen Neurone und der striatalen Projektionen. Dieses impliziert, dass physiologisches GDNF über den 
Ret-Rezeptor keine Protektion dopaminerger Neurone oder der axonalen Terminalen bewirkt. Eine Neurogenese zum Zeitpunkt von 90 Tagen ließ sich bei keinem der drei Genotypen nachweisen. Die Kontrolltiere zeigten ein Sprouting, das Auswachsen von terminalen Axonkollateralen im Striatum zwischen 14 und 90 Tagen nach MPTPGabe, welches bei Ret-defizienten Mäusen ausblieb. Auch die striatalen Katecholaminkonzentrationen erholten sich nur bei den Kontrollen. Dadurch konnte gezeigt werden, dass der Ret-Rezeptor für die Wirkung von GDNF auf Sprouting verantwortlich ist und dass endogenes GDNF ausreicht, um axonales Sprouting zu induzieren.

Sowohl die selektive Eliminierung des Ret-Rezeptors als auch der Vergleich des akuten Effekts mit dem Langzeiteffekt von MPTP in einem einheitlichen Paradigma wurden bisher in der tierexperimentellen Forschung nicht untersucht und werden hier präsentiert.

Die Schlussfolgerung der präsentierten Arbeit ist, dass der durch endogenes GDNF ausgelöste Ret-Signalweg keinen Einfluss auf das Überleben dopaminerger Neurone im MPTP-Mausmodell hat, jedoch die Regeneration dopaminerger axonaler Terminalen im Striatum fördert. Da durch diese Arbeit der Ret-Rezeptor als verantwortliches Signalmolekül für GDNF identifiziert und somit die Wirkung dieser Signalkaskade näher untersucht wurde, können zukünftig weitere Untersuchungen hier anschließen, um eine Therapie für das IPS zu erarbeiten. 


\section{Literatur}

Adams JD, Jr., Klaidman LK, Leung AC (1993): MPP+ and MPDP+ induced oxygen radical formation with mitochondrial enzymes. Free Radic Biol Med $\underline{15}$, 181186

Airaksinen MS, Saarma M (2002): The GDNF family: signalling, biological functions and therapeutic value. Nat Rev Neurosci $\underline{3}, 383-394$

Airaksinen MS, Titievsky A, Saarma M (1999): GDNF family neurotrophic factor signaling: four masters, one servant? Mol Cell Neurosci $\underline{13}$, 313-325

Alexander GE, Crutcher MD (1990): Functional architecture of basal ganglia circuits: neural substrates of parallel processing. Trends Neurosci $\underline{13}, 266-271$

Arenas E, Trupp M, Akerud P, Ibanez CF (1995): GDNF prevents degeneration and promotes the phenotype of brain noradrenergic neurons in vivo. Neuron $\underline{15}$, 1465-1473

Baloh RH, Gorodinsky A, Golden JP, Tansey MG, Keck CL, Popescu NC, Johnson EM, Jr., Milbrandt J (1998): GFRalpha3 is an orphan member of the GDNF/neurturin/persephin receptor family. Proc Natl Acad Sci U S A $\underline{95}$, 5801-5806

Baloh RH, Enomoto H, Johnson EM, Jr., Milbrandt J (2000): The GDNF family ligands and receptors - implications for neural development. Curr Opin Neurobiol $\underline{10}, 103-110$

Beal MF (2001): Experimental models of Parkinson's disease. Nat Rev Neurosci $\underline{2}$, 325-334

Beck KD, Valverde J, Alexi T, Poulsen K, Moffat B, Vandlen RA, Rosenthal A, Hefti F (1995): Mesencephalic dopaminergic neurons protected by GDNF from axotomy-induced degeneration in the adult brain. Nature $\underline{373}, 339-341$

Benamer TS, Patterson J, Grosset DG, Booij J, de Bruin K, van Royen E, Speelman JD, Horstink MH, Sips HJ, Dierckx RA, et al. (2000): Accurate differentiation of parkinsonism and essential tremor using visual assessment of [123l]-FP-CIT SPECT imaging: the [123I]-FP-CIT study group. Mov Disord 15 , 503-510

Benedetti MD, Bower JH, Maraganore DM, McDonnell SK, Peterson BJ, Ahlskog JE, Schaid DJ, Rocca WA (2000): Smoking, alcohol, and coffee consumption 
preceding Parkinson's disease: a case-control study. Neurology $\underline{55}, 1350-$ 1358

Bernheimer H, Hornykiewicz O (1965): [Decreased homovanillic acid concentration in the brain in parkinsonian subjects as an expression of a disorder of central dopamine metabolism]. Herabgesetzte Konzentration der Homovanillinsaure im Gehirn von parkinsonkranken Menschen als Ausdruck der Storung des zentralen Dopaminstoffwechsels. Klin Wochenschr 43, 711-715

Bernheimer H, Birkmayer W, Hornykiewicz O, Jellinger K, Seitelberger F (1973): Brain dopamine and the syndromes of Parkinson and Huntington. Clinical, morphological and neurochemical correlations. J Neurol Sci $\underline{20}$, 415-455

Bezard E, Gross CE, Fournier MC, Dovero S, Bloch B, Jaber M (1999): Absence of MPTP-induced neuronal death in mice lacking the dopamine transporter. Exp Neurol $\underline{155}, 268-273$

Bezard E, Dovero S, Imbert C, Boraud T, Gross CE (2000): Spontaneous long-term compensatory dopaminergic sprouting in MPTP-treated mice. Synapse $\underline{38}$, 363-368

Bilang-Bleuel A, Revah F, Colin P, Locquet I, Robert JJ, Mallet J, Horellou P (1997): Intrastriatal injection of an adenoviral vector expressing glial-cell-line-derived neurotrophic factor prevents dopaminergic neuron degeneration and behavioral impairment in a rat model of Parkinson disease. Proc Natl Acad Sci U S A $\underline{94}, 8818-8823$

Bloem BR, Irwin I, Buruma OJ, Haan J, Roos RA, Tetrud JW, Langston JW (1990): The MPTP model: versatile contributions to the treatment of idiopathic Parkinson's disease. J Neurol Sci $\underline{97}$, 273-293

Bormann $J$ (1989): Memantine is a potent blocker of N-methyl-D-aspartate (NMDA) receptor channels. Eur J Pharmacol $\underline{166}, 591-592$

Bower JH, Maraganore DM, McDonnell SK, Rocca WA (1999): Incidence and distribution of parkinsonism in Olmsted County, Minnesota, 1976-1990. Neurology $\underline{52}, 1214-1220$

Boyce S, Kelly E, Reavill C, Jenner P, Marsden CD (1984): Repeated administration of N-methyl-4-phenyl 1,2,5,6-tetrahydropyridine to rats is not toxic to striatal dopamine neurones. Biochem Pharmacol $\underline{33}, 1747-1752$

Braak H, Del Tredici K, Rub U, de Vos RA, Jansen Steur EN, Braak E (2003): Staging of brain pathology related to sporadic Parkinson's disease. Neurobiol Aging 24, 197-211 
Brannan T, Martinez-Tica J, Yahr MD (1992): Catechol-O-methyltransferase inhibition increases striatal L-dopa and dopamine: an in vivo study in rats. Neurology $\underline{42}$, 683-685

Brown RG, Marsden CD (1988): 'Subcortical dementia': the neuropsychological evidence. Neuroscience $\underline{25}, 363-387$

Brucke T, Djamshidian S, Bencsits G, Pirker W, Asenbaum S, Podreka I (2000): SPECT and PET imaging of the dopaminergic system in Parkinson's disease. J Neurol 247 Suppl 4, IV/2-7

Burke RE, Cadet JL, Kent JD, Karanas AL, Jackson-Lewis V (1990): An assessment of the validity of densitometric measures of striatal tyrosine hydroxylasepositive fibers: relationship to apomorphine-induced rotations in 6hydroxydopamine lesioned rats. J Neurosci Methods $\underline{35}, 63-73$

Burns RS, Chiueh CC, Markey SP, Ebert MH, Jacobowitz DM, Kopin IJ (1983): A primate model of parkinsonism: selective destruction of dopaminergic neurons in the pars compacta of the substantia nigra by N-methyl-4-phenyl-1,2,3,6tetrahydropyridine. Proc Natl Acad Sci U S A $\underline{80}$, 4546-4550

Cacalano G, Farinas I, Wang LC, Hagler K, Forgie A, Moore M, Armanini M, Phillips H, Ryan AM, Reichardt LF, et al. (1998): GFRalpha1 is an essential receptor component for GDNF in the developing nervous system and kidney. Neuron $\underline{21}, 53-62$

Calne DB, Plotkin C, Williams AC, Nutt JG, Neophytides A, Teychenne PF: Longterm treatment of parkinsonism with bromocriptine. Lancet 1978, 1, 735-738

Chan P, DeLanney LE, Irwin I, Langston JW, Di Monte D (1991): Rapid ATP loss caused by 1-methyl-4-phenyl-1,2,3,6-tetrahydropyridine in mouse brain. $J$ Neurochem $\underline{57}, 348-351$

Chiba K, Trevor A, Castagnoli N, Jr. (1984): Metabolism of the neurotoxic tertiary amine, MPTP, by brain monoamine oxidase. Biochem Biophys Res Commun $\underline{120}, 574-578$

Chiba K, Peterson LA, Castagnoli KP, Trevor AJ, Castagnoli N, Jr. (1985): Studies on the molecular mechanism of bioactivation of the selective nigrostriatal toxin 1-methyl-4-phenyl-1,2,3,6-tetrahydropyridine. Drug Metab Dispos 13, 342-347

Choi-Lundberg DL, Lin Q, Chang YN, Chiang YL, Hay CM, Mohajeri H, Davidson BL, Bohn MC (1997): Dopaminergic neurons protected from degeneration by GDNF gene therapy. Science $\underline{275}, 838-841$ 
Cohen G (1984): Oxy-radical toxicity in catecholamine neurons. Neurotoxicology $\underline{5}$, 77-82

Connor B, Kozlowski DA, Schallert T, Tillerson JL, Davidson BL, Bohn MC (1999): Differential effects of glial cell line-derived neurotrophic factor (GDNF) in the striatum and substantia nigra of the aged Parkinsonian rat. Gene Ther $\underline{6}$, 1936-1951

Cotzias GC, Papavasiliou PS, Gellene R (1969): Modification of Parkinsonism-chronic treatment with L-dopa. N Engl J Med 280, 337-345

Coyle JT, Puttfarcken P (1993): Oxidative stress, glutamate, and neurodegenerative disorders. Science 262, 689-695

Cummings JL (1999): Understanding Parkinson disease. JAMA 281, 376-378

Dauer W, Przedborski S (2003): Parkinson's disease: mechanisms and models. Neuron $\underline{39}$, 889-909

Dawson T, Mandir A, Lee M (2002): Animal models of PD: pieces of the same puzzle? Neuron $\underline{35}, 219-222$

de Rijk MC, Launer LJ, Berger K, Breteler MM, Dartigues JF, Baldereschi M, Fratiglioni L, Lobo A, Martinez-Lage J, Trenkwalder C, et al. (2000): Prevalence of Parkinson's disease in Europe: A collaborative study of population-based cohorts. Neurologic Diseases in the Elderly Research Group. Neurology $\underline{54}$, S21-23

Deuschl G, Raethjen J, Baron R, Lindemann M, Wilms H, Krack P (2000): The pathophysiology of parkinsonian tremor: a review. J Neurol 247 Suppl 5, V3348

Diener HC, Putzki N: Leitlinien für die Diagnostik und Therapie in der Neurologie. 4. überarb. Auflage; Georg Thieme Verlag, Stuttgart 2008

Dietz GP, Valbuena PC, Dietz B, Meuer K, Mueller P, Weishaupt JH, Bahr M (2006): Application of a blood-brain-barrier-penetrating form of GDNF in a mouse model for Parkinson's disease. Brain Res 1082, 61-66

Durbec P, Marcos-Gutierrez CV, Kilkenny C, Grigoriou M, Wartiowaara K, Suvanto P, Smith D, Ponder B, Costantini F, Saarma M, et al. (1996): GDNF signalling through the Ret receptor tyrosine kinase. Nature $\underline{381}, 789-793$

Eberhardt O, Coelln RV, Kugler S, Lindenau J, Rathke-Hartlieb S, Gerhardt E, Haid S, Isenmann S, Gravel C, Srinivasan A, et al. (2000): Protection by synergistic effects of adenovirus-mediated X-chromosome-linked inhibitor of apoptosis 
and glial cell line-derived neurotrophic factor gene transfer in the 1-methyl-4phenyl-1,2,3,6-tetrahydropyridine model of Parkinson's disease. J Neurosci $\underline{20}, 9126-9134$

Enomoto H, Araki T, Jackman A, Heuckeroth RO, Snider WD, Johnson EM, Jr., Milbrandt J (1998): GFR alpha1-deficient mice have deficits in the enteric nervous system and kidneys. Neuron $\underline{21}, 317-324$

Fabre E, Monserrat J, Herrero A, Barja G, Leret ML (1999): Effect of MPTP on brain mitochondrial $\mathrm{H} 2 \mathrm{O} 2$ and ATP production and on dopamine and DOPAC in the striatum. J Physiol Biochem $\underline{55}$, 325-331

Fahn S, Oakes D, Shoulson I, Kieburtz K, Rudolph A, Lang A, Olanow CW, Tanner C, Marek K (2004): Levodopa and the progression of Parkinson's disease. $N$ Engl J Med 351, 2498-2508

Fearnley JM, Lees AJ (1991): Ageing and Parkinson's disease: substantia nigra regional selectivity. Brain 114 ( Pt 5), 2283-2301

Frielingsdorf H, Schwarz K, Brundin P, Mohapel P (2004): No evidence for new dopaminergic neurons in the adult mammalian substantia nigra. Proc Natl Acad Sci U S A 101, 10177-10182

Gash DM, Zhang Z, Ovadia A, Cass WA, Yi A, Simmerman L, Russell D, Martin D, Lapchak PA, Collins F, et al. (1996): Functional recovery in parkinsonian monkeys treated with GDNF. Nature $\underline{380}, 252-255$

Gasser T (2005): Genetics of Parkinson's disease. Curr Opin Neurol 18, 363-369

Gasser T, Schwarz J, Arnold G, Trenkwalder C, Oertel WH (1992): Apomorphine test for dopaminergic responsiveness in patients with previously untreated Parkinson's disease. Arch Neurol $\underline{49}$, 1131-1134

Gerlach M, Riederer P, Vogt H (1996): Effect of adding selegeline to levodopa in early, mild Parkinson's disease. "On treatment" rather than intention to treat analysis should have been used. BMJ $\underline{312}$, 704; author reply 704-705

Gibb WR, Lees AJ (1988): The relevance of the Lewy body to the pathogenesis of idiopathic Parkinson's disease. J Neurol Neurosurg Psychiatry $\underline{51}$, 745-752

Gibb WR, Lees AJ (1991): Anatomy, pigmentation, ventral and dorsal subpopulations of the substantia nigra, and differential cell death in Parkinson's disease. $J$ Neurol Neurosurg Psychiatry $\underline{54}$, 388-396 
Gill SS, Patel NK, Hotton GR, O'Sullivan K, McCarter R, Bunnage M, Brooks DJ, Svendsen CN, Heywood P (2003): Direct brain infusion of glial cell linederived neurotrophic factor in Parkinson disease. Nat Med $\underline{9}$, 589-595

Gnanalingham KK, Milkowski NA, Smith LA, Hunter AJ, Jenner P, Marsden CD (1995): Short- and long-term changes in striatal and extrastriatal dopamine uptake sites in the MPTP-treated common marmoset. Eur J Pharmacol $\underline{277}$, 235-241

Goetz CG, Janko K, Blasucci L, Jaglin JA (2003): Impact of placebo assignment in clinical trials of Parkinson's disease. Mov Disord $\underline{18}, 1146-1149$

Gorell JM, Johnson CC, Rybicki BA, Peterson EL, Richardson RJ (1998): The risk of Parkinson's disease with exposure to pesticides, farming, well water, and rural living. Neurology $\underline{50}, 1346-1350$

Grondin R, Zhang Z, Yi A, Cass WA, Maswood N, Andersen AH, Elsberry DD, Klein MC, Gerhardt GA, Gash DM (2002): Chronic, controlled GDNF infusion promotes structural and functional recovery in advanced parkinsonian monkeys. Brain 125, 2191-2201

Hasegawa E, Takeshige K, Oishi T, Murai Y, Minakami S (1990): 1-Methyl-4phenylpyridinium (MPP+) induces NADH-dependent superoxide formation and enhances NADH-dependent lipid peroxidation in bovine heart submitochondrial particles. Biochem Biophys Res Commun 170, 1049-1055

Hasegawa E, Kang D, Sakamoto K, Mitsumoto A, Nagano T, Minakami S, Takeshige K (1997): A dual effect of 1-methyl-4-phenylpyridinium (MPP+)-analogs on the respiratory chain of bovine heart mitochondria. Arch Biochem Biophys $\underline{337}$, 69-74

Heikkila RE, Manzino L, Cabbat FS, Duvoisin RC (1984): Protection against the dopaminergic neurotoxicity of 1-methyl-4-phenyl-1,2,5,6-tetrahydropyridine by monoamine oxidase inhibitors. Nature $\underline{311}, 467-469$

Heikkila RE, Sieber BA, Manzino L, Sonsalla PK (1989): Some features of the nigrostriatal dopaminergic neurotoxin 1-methyl-4-phenyl-1,2,3,6tetrahydropyridine (MPTP) in the mouse. Mol Chem Neuropathol $\underline{10}, 171-183$

Heinonen EH, Rinne UK (1989): Selegiline in the treatment of Parkinson's disease. Acta Neurol Scand Suppl 126, 103-111

Henderson CE, Phillips HS, Pollock RA, Davies AM, Lemeulle C, Armanini M, Simmons L, Moffet B, Vandlen RA, Simpson LC, et al. (1994): GDNF: a potent survival factor for motoneurons present in peripheral nerve and muscle. Science 266, 1062-1064 
Herkenham M, Little MD, Bankiewicz K, Yang SC, Markey SP, Johannessen JN (1991): Selective retention of MPP+ within the monoaminergic systems of the primate brain following MPTP administration: an in vivo autoradiographic study. Neuroscience $\underline{40}, 133-158$

Hernan MA, Takkouche B, Caamano-Isorna F, Gestal-Otero JJ (2002): A metaanalysis of coffee drinking, cigarette smoking, and the risk of Parkinson's disease. Ann Neurol $\underline{52}, 276-284$

Hirsch EC, Hunot S, Damier P, Faucheux B (1998): Glial cells and inflammation in Parkinson's disease: a role in neurodegeneration? Ann Neurol 44 , S115-120

Hughes AJ, Daniel SE, Blankson S, Lees AJ (1993): A clinicopathologic study of 100 cases of Parkinson's disease. Arch Neurol $\underline{50}$, 140-148

Iravani MM, Syed E, Jackson MJ, Johnston LC, Smith LA, Jenner P (2005): A modified MPTP treatment regime produces reproducible partial nigrostriatal lesions in common marmosets. Eur J Neurosci 21, 841-854

Jackson-Lewis V, Przedborski S (2007): Protocol for the MPTP mouse model of Parkinson's disease. Nat Protoc 2, $141-151$

Jain S, Golden JP, Wozniak D, Pehek E, Johnson EM, Jr., Milbrandt J (2006): RET is dispensable for maintenance of midbrain dopaminergic neurons in adult mice. J Neurosci $\underline{26}, 11230-11238$

Javitch JA, D'Amato RJ, Strittmatter SM, Snyder SH (1985): Parkinsonism-inducing neurotoxin, N-methyl-4-phenyl-1,2,3,6 -tetrahydropyridine: uptake of the metabolite $\mathrm{N}$-methyl-4-phenylpyridine by dopamine neurons explains selective toxicity. Proc Natl Acad Sci U S A 82, 2173-2177

Jenner P, Olanow CW (1996): Oxidative stress and the pathogenesis of Parkinson's disease. Neurology $\underline{47}$, S161-170

Jing S, Wen D, Yu Y, Holst PL, Luo Y, Fang M, Tamir R, Antonio L, Hu Z, Cupples R, et al. (1996): GDNF-induced activation of the ret protein tyrosine kinase is mediated by GDNFR-alpha, a novel receptor for GDNF. Cell $\underline{85}, 1113-1124$

Joyce JN, Smutzer G, Whitty CJ, Myers A, Bannon MJ (1997): Differential modification of dopamine transporter and tyrosine hydroxylase mRNAs in midbrain of subjects with Parkinson's, Alzheimer's with parkinsonism, and Alzheimer's disease. Mov Disord 12, 885-897

Kay JN, Blum M (2000): Differential response of ventral midbrain and striatal progenitor cells to lesions of the nigrostriatal dopaminergic projection. Dev Neurosci 22, 56-67 
Kebabian JW, Calne DB (1979): Multiple receptors for dopamine. Nature 277, 93-96

Kirik D, Rosenblad C, Bjorklund A (2000a): Preservation of a functional nigrostriatal dopamine pathway by GDNF in the intrastriatal 6-OHDA lesion model depends on the site of administration of the trophic factor. Eur J Neurosci $\underline{12}$, 3871-3882

Kirik D, Rosenblad C, Bjorklund A, Mandel RJ (2000b): Long-term rAAV-mediated gene transfer of GDNF in the rat Parkinson's model: intrastriatal but not intranigral transduction promotes functional regeneration in the lesioned nigrostriatal system. J Neurosci $\underline{20}, 4686-4700$

Kirik D, Georgievska B, Rosenblad C, Bjorklund A (2001): Delayed infusion of GDNF promotes recovery of motor function in the partial lesion model of Parkinson's disease. Eur J Neurosci 13, 1589-1599

Kirik D, Georgievska B, Bjorklund A (2004): Localized striatal delivery of GDNF as a treatment for Parkinson disease. Nat Neurosci $\underline{7}, 105-110$

Klaidman LK, Adams JD, Jr., Leung AC, Kim SS, Cadenas E (1993): Redox cycling of MPP+: evidence for a new mechanism involving hydride transfer with xanthine oxidase, aldehyde dehydrogenase, and lipoamide dehydrogenase. Free Radic Biol Med 15, 169-179

Koller WC (1986): Pharmacologic treatment of parkinsonian tremor. Arch Neurol $\underline{43}$, $126-127$

Kopin IJ, Markey SP (1988): MPTP toxicity: implications for research in Parkinson's disease. Annu Rev Neurosci 11, 81-96

Kordower JH, Palfi S, Chen EY, Ma SY, Sendera T, Cochran EJ, Mufson EJ, Penn R, Goetz CG, Comella CD (1999): Clinicopathological findings following intraventricular glial-derived neurotrophic factor treatment in a patient with Parkinson's disease. Ann Neurol $\underline{46}$, 419-424

Kordower JH, Emborg ME, Bloch J, Ma SY, Chu Y, Leventhal L, McBride J, Chen EY, Palfi S, Roitberg BZ, et al. (2000): Neurodegeneration prevented by lentiviral vector delivery of GDNF in primate models of Parkinson's disease. Science $\underline{290}, 767-773$

Kotzbauer PT, Lampe PA, Heuckeroth RO, Golden JP, Creedon DJ, Johnson EM, Jr., Milbrandt J (1996): Neurturin, a relative of glial-cell-line-derived neurotrophic factor. Nature $\underline{384}, 467-470$ 
Kowsky S: Einfluss des GDNF-Rezeptors RET auf die akute MPTP-Toxizität in der Maus. Med. Diss. Göttingen (in Vorbereitung ${ }^{1}$ ) 2010

Kowsky S, Poppelmeyer C, Kramer ER, Falkenburger BH, Kruse A, Klein R, Schulz JB (2007): RET signaling does not modulate MPTP toxicity but is required for regeneration of dopaminergic axon terminals. Proc Natl Acad Sci U S A 104 , 20049-20054

Kramer ER, Knott L, Su F, Dessaud E, Krull CE, Helmbacher F, Klein R (2006): Cooperation between GDNF/Ret and ephrinA/EphA4 signals for motor-axon pathway selection in the limb. Neuron $\underline{50}, 35-47$

Kramer ER, Aron L, Ramakers GM, Seitz S, Zhuang X, Beyer K, Smidt MP, Klein R (2007): Absence of Ret signaling in mice causes progressive and late degeneration of the nigrostriatal system. PLoS Biol $\underline{5}$, e39

Krieglstein K (2004): Factors promoting survival of mesencephalic dopaminergic neurons. Cell Tissue Res $\underline{318}, 73-80$

Lang AE, Lozano AM (1998a): Parkinson's disease. Second of two parts. N Engl J Med $\underline{339}, 1130-1143$

Lang AE, Lozano AM (1998b): Parkinson's disease. First of two parts. N Engl J Med $\underline{339}, 1044-1053$

Lang AE, Gill S, Patel NK, Lozano A, Nutt JG, Penn R, Brooks DJ, Hotton G, Moro E, Heywood P, et al. (2006): Randomized controlled trial of intraputamenal glial cell line-derived neurotrophic factor infusion in Parkinson disease. Ann Neurol $\underline{59}, 459-466$

Langston JW, Irwin I (1986): MPTP: current concepts and controversies. Clin Neuropharmacol $\underline{9}$, 485-507

Langston JW, Ballard P, Tetrud JW, Irwin I (1983): Chronic Parkinsonism in humans due to a product of meperidine-analog synthesis. Science $\underline{219}, 979-980$

Lee T, Seeman P, Rajput A, Farley IJ, Hornykiewicz O (1978): Receptor basis for dopaminergic supersensitivity in Parkinson's disease. Nature $\underline{273}, 59-61$

Lie DC, Dziewczapolski G, Willhoite AR, Kaspar BK, Shults CW, Gage FH (2002): The adult substantia nigra contains progenitor cells with neurogenic potential. J Neurosci 22, 6639-6649

\footnotetext{
${ }^{1}$ mit freundlicher Genehmigung des Verfassers
} 
Limousin P, Krack P, Pollak P, Benazzouz A, Ardouin C, Hoffmann D, Benabid AL (1998): Electrical stimulation of the subthalamic nucleus in advanced Parkinson's disease. N Engl J Med $\underline{339}$, 1105-1111

Lin LF, Doherty DH, Lile JD, Bektesh S, Collins F (1993): GDNF: a glial cell linederived neurotrophic factor for midbrain dopaminergic neurons. Science $\underline{260}$, $1130-1132$

Liu Y, Peter D, Roghani A, Schuldiner S, Prive GG, Eisenberg D, Brecha N, Edwards $\mathrm{RH}$ (1992): A cDNA that suppresses MPP+ toxicity encodes a vesicular amine transporter. Cell $\underline{70}, 539-551$

Lloyd KG, Davidson L, Hornykiewicz O (1975): The neurochemistry of Parkinson's disease: effect of L-dopa therapy. J Pharmacol Exp Ther 195, 453-464

Maher NE, Currie LJ, Lazzarini AM, Wilk JB, Taylor CA, Saint-Hilaire MH, Feldman RG, Golbe LI, Wooten GF, Myers RH (2002): Segregation analysis of Parkinson disease revealing evidence for a major causative gene. Am J Med Genet 109, 191-197

Markey SP, Johannessen JN, Chiueh CC, Burns RS, Herkenham MA (1984): Intraneuronal generation of a pyridinium metabolite may cause drug-induced parkinsonism. Nature $\underline{311}, 464-467$

Marsden CD (1990): Parkinson's disease. Lancet 335, 948-952

Marsden CD, Obeso JA (1994): The functions of the basal ganglia and the paradox of stereotaxic surgery in Parkinson's disease. Brain 117 ( Pt 4), 877-897

Masure S, Cik M, Pangalos MN, Bonaventure P, Verhasselt P, Lesage AS, Leysen JE, Gordon RD (1998): Molecular cloning, expression and tissue distribution of glial-cell-line-derived neurotrophic factor family receptor alpha-3 (GFRalpha3). Eur J Biochem 251, 622-630

Mayer RA, Kindt MV, Heikkila RE (1986): Prevention of the nigrostriatal toxicity of 1methyl-4-phenyl-1,2,3,6-tetrahydropyridine by inhibitors of 3,4dihydroxyphenylethylamine transport. J Neurochem $\underline{47}, 1073-1079$

Mayeux R, Denaro J, Hemenegildo N, Marder K, Tang MX, Cote LJ, Stern Y (1992): A population-based investigation of Parkinson's disease with and without dementia. Relationship to age and gender. Arch Neurol $\underline{49}$, 492-497

Merello M, Lees AJ, Webster R, Bovingdon M, Gordin A (1994): Effect of entacapone, a peripherally acting catechol-O-methyltransferase inhibitor, on the motor response to acute treatment with levodopa in patients with Parkinson's disease. J Neurol Neurosurg Psychiatry 프, 186-189 
Milbrandt J, de Sauvage FJ, Fahrner TJ, Baloh RH, Leitner ML, Tansey MG, Lampe PA, Heuckeroth RO, Kotzbauer PT, Simburger KS, et al. (1998): Persephin, a novel neurotrophic factor related to GDNF and neurturin. Neuron $\underline{20}, 245-253$

Moore MW, Klein RD, Farinas I, Sauer H, Armanini M, Phillips H, Reichardt LF, Ryan AM, Carver-Moore K, Rosenthal A (1996): Renal and neuronal abnormalities in mice lacking GDNF. Nature $\underline{382}, 76-79$

Mori S, Fujitake J, Kuno S, Sano Y (1988): Immunohistochemical evaluation of the neurotoxic effects of 1-methyl-4-phenyl-1,2,3,6-tetrahydropyridine (MPTP) on dopaminergic nigrostriatal neurons of young adult mice using dopamine and tyrosine hydroxylase antibodies. Neurosci Lett $\underline{90}$, 57-62

Myllyla VV, Kultalahti ER, Haapaniemi H, Leinonen M (2001): Twelve-month safety of entacapone in patients with Parkinson's disease. Eur J Neurol $\underline{8}$, 53-60

Nicklas WJ, Vyas I, Heikkila RE (1985): Inhibition of NADH-linked oxidation in brain mitochondria by 1-methyl-4-phenyl-pyridine, a metabolite of the neurotoxin, 1methyl-4-phenyl-1,2,5,6-tetrahydropyridine. Life Sci $\underline{36}$, 2503-2508

Nicklas WJ, Youngster SK, Kindt MV, Heikkila RE (1987): MPTP, MPP+ and mitochondrial function. Life Sci $\underline{40}, 721-729$

Nutt JG, Burchiel KJ, Comella CL, Jankovic J, Lang AE, Laws ER, Jr., Lozano AM, Penn RD, Simpson RK, Jr., Stacy M, et al. (2003): Randomized, double-blind trial of glial cell line-derived neurotrophic factor (GDNF) in PD. Neurology $\underline{60}$, 69-73

Oertel WH, Wolters E, Sampaio C, Gimenez-Roldan S, Bergamasco B, Dujardin M, Grosset DG, Arnold G, Leenders KL, Hundemer HP, et al. (2006): Pergolide versus levodopa monotherapy in early Parkinson's disease patients: The PELMOPET study. Mov Disord 21, 343-353

Pahwa R (2006): Understanding Parkinson's disease: an update on current diagnostic and treatment strategies. J Am Med Dir Assoc ㅁ, 4-10

Paratcha G, Ledda F (2008): GDNF and GFRalpha: a versatile molecular complex for developing neurons. Trends Neurosci $\underline{31}$, 384-391

Pardridge WM (2002): Neurotrophins, neuroprotection and the blood-brain barrier. Curr Opin Investig Drugs $\underline{3}$, 1753-1757

Patel NK, Bunnage M, Plaha P, Svendsen CN, Heywood P, Gill SS (2005): Intraputamenal infusion of glial cell line-derived neurotrophic factor in PD: a two-year outcome study. Ann Neurol $\underline{57}$, 298-302 
Paxinos G, Franklin KBJ: The Mouse Brain in Stereotaxic Coordinates Second Edition; Elsevier Science, San Diego (USA) 2004

Petzinger GM, Fisher B, Hogg E, Abernathy A, Arevalo P, Nixon K, Jakowec MW (2006): Behavioral motor recovery in the 1-methyl-4-phenyl-1,2,3,6tetrahydropyridine-lesioned squirrel monkey (Saimiri sciureus): changes in striatal dopamine and expression of tyrosine hydroxylase and dopamine transporter proteins. J Neurosci Res $\underline{83}, 332-347$

Pichel JG, Shen L, Sheng HZ, Granholm AC, Drago J, Grinberg A, Lee EJ, Huang SP, Saarma M, Hoffer BJ, et al. (1996): Defects in enteric innervation and kidney development in mice lacking GDNF. Nature $\underline{382}$, 73-76

Pimoule C, Schoemaker H, Javoy-Agid F, Scatton B, Agid Y, Langer SZ (1983): Decrease in $[3 \mathrm{H}]$ cocaine binding to the dopamine transporter in Parkinson's disease. Eur J Pharmacol 95, 145-146

Playfer JR (1997): Parkinson's disease. Postgrad Med J $\underline{73}$, 257-264

Przedborski S, Jackson-Lewis V (1998): Mechanisms of MPTP toxicity. Mov Disord 13 Suppl 1, 35-38

Przedborski S, Vila M (2003): The 1-methyl-4-phenyl-1,2,3,6-tetrahydropyridine mouse model: a tool to explore the pathogenesis of Parkinson's disease. Ann N Y Acad Sci 991, 189-198

Przedborski S, Jackson-Lewis V, Naini AB, Jakowec M, Petzinger G, Miller R, Akram $M$ (2001): The parkinsonian toxin 1-methyl-4-phenyl-1,2,3,6-tetrahydropyridine (MPTP): a technical review of its utility and safety. J Neurochem $\underline{76}$, 12651274

Ramsay RR, Singer TP (1986): Energy-dependent uptake of N-methyl-4phenylpyridinium, the neurotoxic metabolite of 1-methyl-4-phenyl-1,2,3,6tetrahydropyridine, by mitochondria. J Biol Chem 261, 7585-7587

Rascol O, Brooks DJ, Korczyn AD, De Deyn PP, Clarke CE, Lang AE (2000): A fiveyear study of the incidence of dyskinesia in patients with early Parkinson's disease who were treated with ropinirole or levodopa. 056 Study Group. N Engl J Med 342, 1484-1491

Riddle EL, Fleckenstein AE, Hanson GR (2005): Role of monoamine transporters in mediating psychostimulant effects. AAPS J $\underline{7}$, E847-851

Rosenblad C, Martinez-Serrano A, Bjorklund A (1998): Intrastriatal glial cell linederived neurotrophic factor promotes sprouting of spared nigrostriatal 
dopaminergic afferents and induces recovery of function in a rat model of Parkinson's disease. Neuroscience $\underline{82}, 129-137$

Rosenblad C, Kirik D, Devaux B, Moffat B, Phillips HS, Bjorklund A (1999): Protection and regeneration of nigral dopaminergic neurons by neurturin or GDNF in a partial lesion model of Parkinson's disease after administration into the striatum or the lateral ventricle. Eur J Neurosci 11, 1554-1566

Rosenblad C, Kirik D, Bjorklund A (2000): Sequential administration of GDNF into the substantia nigra and striatum promotes dopamine neuron survival and axonal sprouting but not striatal reinnervation or functional recovery in the partial 6OHDA lesion model. Exp Neurol 161, 503-516

Ruottinen HM, Rinne UK (1996): Entacapone prolongs levodopa response in a one month double blind study in parkinsonian patients with levodopa related fluctuations. J Neurol Neurosurg Psychiatry $\underline{60}, 36-40$

Sanchez MP, Silos-Santiago I, Frisen J, He B, Lira SA, Barbacid M (1996): Renal agenesis and the absence of enteric neurons in mice lacking GDNF. Nature 382, 70-73

Santoro M, Melillo RM, Carlomagno F, Vecchio G, Fusco A (2004): Minireview: RET: normal and abnormal functions. Endocrinology $\underline{145}, 5448-5451$

Sariola H, Saarma M (2003): Novel functions and signalling pathways for GDNF. J Cell Sci 116, 3855-3862

Schrag A, Good CD, Miszkiel K, Morris HR, Mathias CJ, Lees AJ, Quinn NP (2000): Differentiation of atypical parkinsonian syndromes with routine MRI. Neurology $\underline{54}, 697-702$

Schuchardt A, D'Agati V, Larsson-Blomberg L, Costantini F, Pachnis V (1994): Defects in the kidney and enteric nervous system of mice lacking the tyrosine kinase receptor Ret. Nature $\underline{367}$, 380-383

Schulz JB (2006): Anti-apoptotic gene therapy in Parkinson's disease. J Neural Transm Suppl 467-476

Schulz JB, Falkenburger BH (2004): Neuronal pathology in Parkinson's disease. Cell Tissue Res $\underline{318}$, 135-147

Schulz JB, Klockgether T, Petersen D, Jauch M, Muller-Schauenburg W, Spieker S, Voigt K, Dichgans J (1994): Multiple system atrophy: natural history, MRI morphology, and dopamine receptor imaging with 123IBZM-SPECT. J Neurol

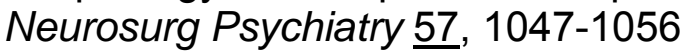


Schulz JB, Skalej M, Wedekind D, Luft AR, Abele M, Voigt K, Dichgans J, Klockgether T (1999): Magnetic resonance imaging-based volumetry differentiates idiopathic Parkinson's syndrome from multiple system atrophy and progressive supranuclear palsy. Ann Neurol 45, 65-74

Schwarz J, Tatsch K, Arnold G, Ott M, Trenkwalder C, Kirsch CM, Oertel WH (1993): 123l-iodobenzamide-SPECT in 83 patients with de novo parkinsonism. Neurology $\underline{43}$, S17-20

Sherer TB, Fiske BK, Svendsen CN, Lang AE, Langston JW (2006): Crossroads in GDNF therapy for Parkinson's disease. Mov Disord 21, 136-141

Sian J, Gerlach M, Youdim MB, Riederer P (1999): Parkinson's disease: a major hypokinetic basal ganglia disorder. J Neural Transm 106, 443-476

Singer TP, Castagnoli N, Jr., Ramsay RR, Trevor AJ (1987): Biochemical events in the development of parkinsonism induced by 1-methyl-4-phenyl-1,2,3,6tetrahydropyridine. J Neurochem $\underline{49}, 1-8$

Singleton AB, Farrer M, Johnson J, Singleton A, Hague S, Kachergus J, Hulihan M, Peuralinna T, Dutra A, Nussbaum R, et al. (2003): alpha-Synuclein locus triplication causes Parkinson's disease. Science $\underline{302}, 841$

Slevin JT, Gerhardt GA, Smith CD, Gash DM, Kryscio R, Young B (2005): Improvement of bilateral motor functions in patients with Parkinson disease through the unilateral intraputaminal infusion of glial cell line-derived neurotrophic factor. J Neurosurg 102, 216-222

Spillantini MG, Schmidt ML, Lee VM, Trojanowski JQ, Jakes R, Goedert M (1997): Alpha-synuclein in Lewy bodies. Nature 388, 839-840

Sriram K, Pai KS, Boyd MR, Ravindranath V (1997): Evidence for generation of oxidative stress in brain by MPTP: in vitro and in vivo studies in mice. Brain Res $\underline{749}, 44-52$

Sveinbjornsdottir S, Hicks AA, Jonsson T, Petursson H, Gugmundsson G, Frigge ML, Kong A, Gulcher JR, Stefansson K (2000): Familial aggregation of Parkinson's disease in Iceland. N Engl J Med $\underline{343}, 1765-1770$

Takahashi N, Miner LL, Sora I, Ujike H, Revay RS, Kostic V, Jackson-Lewis V, Przedborski S, Uhl GR (1997): VMAT2 knockout mice: heterozygotes display reduced amphetamine-conditioned reward, enhanced amphetamine locomotion, and enhanced MPTP toxicity. Proc Natl Acad Sci U S A $\underline{94}$, 99389943 
Tandberg E, Larsen JP, Aarsland D, Cummings JL (1996): The occurrence of depression in Parkinson's disease. A community-based study. Arch Neurol $\underline{53}$, 175-179

Tande D, Hoglinger G, Debeir T, Freundlieb N, Hirsch EC, Francois C (2006): New striatal dopamine neurons in MPTP-treated macaques result from a phenotypic shift and not neurogenesis. Brain $\underline{129}, 1194-1200$

Tanner CM, Aston DA (2000): Epidemiology of Parkinson's disease and akinetic syndromes. Curr Opin Neurol 13, 427-430

Tanner CM, Goldman SM, Aston DA, Ottman R, Ellenberg J, Mayeux R, Langston JW (2002): Smoking and Parkinson's disease in twins. Neurology $\underline{58}, 581-588$

Tatarewicz SM, Wei X, Gupta S, Masterman D, Swanson SJ, Moxness MS (2007): Development of a maturing T-cell-mediated immune response in patients with idiopathic Parkinson's disease receiving $r$-metHuGDNF via continuous intraputaminal infusion. J Clin Immunol 27, 620-627

Teismann P, Schulz JB (2004): Cellular pathology of Parkinson's disease: astrocytes, microglia and inflammation. Cell Tissue Res $\underline{318}, 149-161$

Thomas B, Beal MF (2007): Parkinson's disease. Hum Mol Genet 16 Spec No. 2, R183-194

Tomac A, Lindqvist E, Lin LF, Ogren SO, Young D, Hoffer BJ, Olson L (1995): Protection and repair of the nigrostriatal dopaminergic system by GDNF in vivo. Nature $\underline{373}, 335-339$

Treanor JJ, Goodman L, de Sauvage F, Stone DM, Poulsen KT, Beck CD, Gray C, Armanini MP, Pollock RA, Hefti F, et al. (1996): Characterization of a multicomponent receptor for GDNF. Nature $\underline{382}, 80-83$

Trupp M, Ryden M, Jornvall H, Funakoshi H, Timmusk T, Arenas E, Ibanez CF (1995): Peripheral expression and biological activities of GDNF, a new neurotrophic factor for avian and mammalian peripheral neurons. J Cell Biol $130,137-148$

Trupp M, Arenas E, Fainzilber M, Nilsson AS, Sieber BA, Grigoriou M, Kilkenny C, Salazar-Grueso E, Pachnis V, Arumae U (1996): Functional receptor for GDNF encoded by the c-ret proto-oncogene. Nature $\underline{381}, 785-789$

Trupp M, Scott R, Whittemore SR, Ibanez CF (1999): Ret-dependent and independent mechanisms of glial cell line-derived neurotrophic factor signaling in neuronal cells. J Biol Chem 274, 20885-20894 
Varrone A, Marek KL, Jennings D, Innis RB, Seibyl JP (2001): [(123)l]beta-CIT SPECT imaging demonstrates reduced density of striatal dopamine transporters in Parkinson's disease and multiple system atrophy. Mov Disord $\underline{16}, 1023-1032$

Ward CD, Gibb WR (1990): Research diagnostic criteria for Parkinson's disease. Adv Neurol $\underline{53}, 245-249$

West MJ (1993): New stereological methods for counting neurons. Neurobiol Aging $\underline{14}, 275-285$

West MJ, Slomianka L, Gundersen HJ (1991): Unbiased stereological estimation of the total number of neurons in thesubdivisions of the rat hippocampus using the optical fractionator. Anat Rec 231, 482-497

Wilson JM, Levey AI, Rajput A, Ang L, Guttman M, Shannak K, Niznik HB, Hornykiewicz O, Pifl C, Kish SJ (1996): Differential changes in neurochemical markers of striatal dopamine nerve terminals in idiopathic Parkinson's disease. Neurology $\underline{47}, 718-726$

Wu DC, Teismann P, Tieu K, Vila M, Jackson-Lewis V, Ischiropoulos H, Przedborski $S$ (2003): NADPH oxidase mediates oxidative stress in the 1-methyl-4-phenyl1,2,3,6-tetrahydropyridine model of Parkinson's disease. Proc Natl Acad Sci U $S A \underline{100}, 6145-6150$

Zhao M, Momma S, Delfani K, Carlen M, Cassidy RM, Johansson CB, Brismar H, Shupliakov O, Frisen J, Janson AM (2003): Evidence for neurogenesis in the adult mammalian substantia nigra. Proc Natl Acad Sci U S A $\underline{100}, 7925-7930$

Zhong XH, Haycock JW, Shannak K, Robitaille Y, Fratkin J, Koeppen AH, Hornykiewicz O, Kish SJ (1995): Striatal dihydroxyphenylalanine decarboxylase and tyrosine hydroxylase protein in idiopathic Parkinson's disease and dominantly inherited olivopontocerebellar atrophy. Mov Disord $\underline{10}$, 10-17

Zhuang X, Masson J, Gingrich JA, Rayport S, Hen R (2005): Targeted gene expression in dopamine and serotonin neurons of the mouse brain. $J$ Neurosci Methods $\underline{143}, 27-32$ 


\section{$7 \quad$ Abbildungsverzeichnis}

Abb. 1 Schematische Darstellung der Basalganglien 4

Abb. 2 Schematische Darstellung der Basalganglien bei einem Patienten mit IPS. 5

Abb. 3 Schematische Darstellung des MPTP-Metabolismus ............................ 13

Abb. 4 Schematische Darstellung des intrazellulären Signalweges von $\mathrm{MPP}^{+} \ldots . .14$

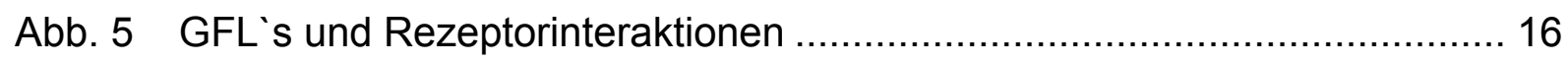

Abb. 6 Schematische Darstellung zum tierexperimentellen Design................... 27

Abb. 7 Mikroskopische Übersichtsaufnahmen der SNpc ............................ 41

Abb. 8 TH-positive Fasern des Striatums ............................................. 45

Abb. 9 Striatale Faserdichte im dorsalen und ventralen Striatum ...................... 46

Abb. 10 Striatale Katecholaminkonzentrationen für Dopamin, DOPAC und HVA.... 48

Abb. 11 Anzahl und Fläche nigrostriataler Fasern rostral der SNpc 50 


\section{Tabellenverzeichnis}

Tab. 1 Tyrosinhydroxylasefärbung dopaminerger Neurone .............................. 30

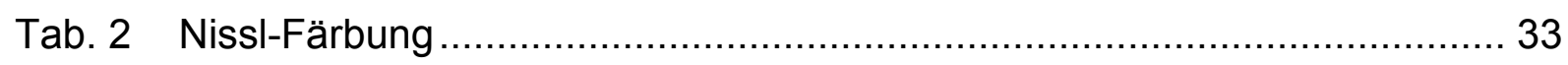

Tab. 3 TH-Färbung des Striatums …........................................................ 35

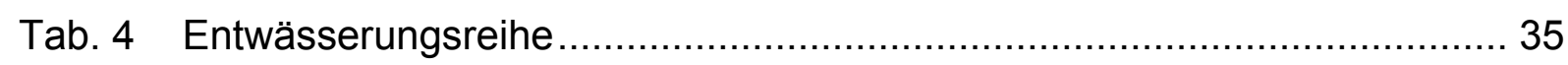

Tab. 5 Stereologische Zählung für TH-positive und Nissl-positive Zellen in der

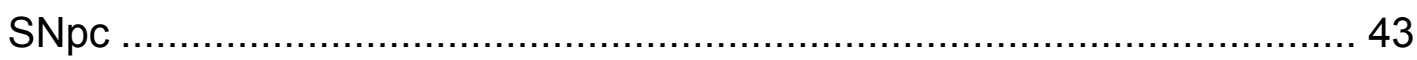




\section{Publikationen}

*Kowsky S, "Poppelmeyer C, *Kramer ER, Falkenburger BH, Kruse A, Klein R, Schulz JB (2007): RET signaling does not modulate MPTP toxicity but is required for regeneration of dopaminergic axon terminals. Proc Natl Acad Sci U S A $104,20049-20054$

* Gleichberechtigte Autoren

Nagel F, Falkenburger BH, Tonges L, Kowsky S, Poppelmeyer C, Schulz JB, Bahr M, Dietz GP (2008): Tat-Hsp70 protects dopaminergic neurons in midbrain cultures and in the substantia nigra in models of Parkinson's disease. $J$ Neurochem $\underline{105}, 853-864$ 


\section{Danksagung}

Bedanken möchte ich mich bei Herrn Prof. Dr. med. Jörg B. Schulz für den Vorschlag meines Dissertationsthemas und damit für die Gelegenheit des selbständigen wissenschaftlichen Arbeitens.

Ebenso möchte ich mich bei Herrn Dr. med. Björn Falkenburger für die gute Betreuung der Dissertation, die freundliche Zusammenarbeit während der Versuchdurchführung und für die vielen Denkanstöße bei der schriftlichen Niederlegung dieser Arbeit bedanken.

Zudem gilt ein großer Dank den Mitarbeitern des Instituts für Neurodegeneration und Neurorestaurationsforschung für das nette Arbeitsklima und die Unterstützung während der Versuche im Labor. Auch danke ich Cathy Ludwig für ihre Hilfe und Organisation.

Für die Bereitstellung der verschiedenen Genotypen und für die Versuchsdurchführung der Fluoreszenzfärbung und Quantifizierung des Striatums bedanke ich mich ganz herzlich bei Herrn Dr. Edgar R. Kramer, Abteilung für molekulare Neurobiologie, Max-Planck Institut für Neurobiologie, Martinsried, Deutschland.

Ein außerordentlicher Dank gilt Sebastian Kowsky für die zuverlässige Zusammenarbeit, die der Grundstein für diese Arbeit war und ganz besonders zum Gelingen des Projektes beigetragen hat. 